Florida International University

FIU Digital Commons

$10-23-2018$

\title{
Fundamental Mechanistic Studies on the Ultrasonic Treatment of Problematic Water Pollutants and Toxins
}

Danni Cui

Florida International University, dcui002@fiu.edu

Follow this and additional works at: https://digitalcommons.fiu.edu/etd

Part of the Analytical Chemistry Commons, Environmental Chemistry Commons, and the Environmental Studies Commons

\section{Recommended Citation}

Cui, Danni, "Fundamental Mechanistic Studies on the Ultrasonic Treatment of Problematic Water Pollutants and Toxins" (2018). FIU Electronic Theses and Dissertations. 3913.

https://digitalcommons.fiu.edu/etd/3913

This work is brought to you for free and open access by the University Graduate School at FIU Digital Commons. It has been accepted for inclusion in FIU Electronic Theses and Dissertations by an authorized administrator of FIU Digital Commons. For more information, please contact dcc@fiu.edu. 


\section{FLORIDA INTERNATIONAL UNIVERSITY}

Miami, Florida

\section{FUNDAMENTAL MECHANISTIC STUDIES ON THE ULTRASONIC TREATMENT OF PROBLEMATIC WATER POLLUTANTS AND TOXINS}

A dissertation submitted in partial fulfillment of the requirements for the degree of DOCTOR OF PHILOSOPHY

in CHEMISTRY

by

Danni Cui 
To: Dean Michael Heithaus

College of Arts, Sciences, and Education

This dissertation, written by Danni Cui, and entitled Fundamental Mechanistic Studies on the Ultrasonic Treatment of Problematic Water Pollutants and Toxins, having been approved in respect to style and intellectual content, is referred to you for judgment.

We have read this dissertation and recommend that it be approved.

Anthony De Caprio

Martin Quirke

Alexander Mebel

Berrin Tansel

Kevin E. O'Shea, Major Professor

Date of Defense: October 23, 2018

The dissertation of Danni Cui is approved.

Dean Michael Heithaus

College of Arts, Sciences, and Education

Andrés G. Gil

Vice President for Research and Economic Development and Dean of the University Graduate School

Florida International University, 2018 
(C) Copyright 2018 by Danni Cui

All rights reserved. 


\section{DEDICATION}

I dedicate this dissertation to my mother, my husband and other family members in China for their love, support and encouragement.

谨以此论文献给我的母亲, 我的丈夫, 以及远在中国的家人, 以感谢他们的爱, 鼓 励和支持。 


\section{ACKNOWLEDGMENTS}

It was such a great experience to work in Dr. Kevin E. O'Shea's research group for the past five years. I sincerely appreciated all the support, help and encouragement provided by Dr. O’Shea. As a mentor, he was very professional, knowledgeable and supportive. I've learned a lot from him, not only about my research, but also about life. I will always admire him and be grateful for his mentorship.

I would also thank my committee members, Dr. Alexander Mebel, Dr. Anthony De Caprio, Dr. Berrin Tansel, and Dr. Martin Quirke. Dr. Mebel generously helped with the details of the computational studies. Dr. De Caprio assisted the LC-MS analyses and provided valuable opinions from forensic perspective. Dr. Tansel, an expert in environmental engineering, offered many valuable suggestions for my research projects. Dr. Quirke provided guidance on the importance and understanding fundamental organic chemistry.

I am grateful to the faculty and staff in the Department of Chemistry and Biochemistry at FIU. Special thanks to Dr. Luis Arroyo-Mora and Dr. Anamary Tarifa with the LC-MS analyses.

I would like to acknowledge Dr. Prashant V. Kamat from University of Notre Dame for his hospitality during my visit to the National Radiation Lab, Dr. Julie Peller from Valparaiso University for her generous help with the steady-state radiolysis study, and Dr. Stephen Mezyk from California State University, Long beach for the training and guidance on the pulse-radiolysis study. 
I'm thankful to my dear husband who has been supportive and encouraging all the time. He always had my back and helped me whenever I needed him. I'm also grateful to my dear mother and other family members in China for their love and emotional support.

Many thanks to all the previous and current group members in Dr. O'Shea's research group.

At last, I would like to acknowledge the University Graduate School and College of Arts and Sciences for the Dissertation Year Fellowship (DYF) the Department of Chemistry and Biochemistry for support through teaching assistantships. 


\title{
ABSTRACT OF THE DISSERTATION
}

\section{FUNDAMENTAL MECHANISTIC STUDIES ON THE ULTRASONIC TREATMENT \\ OF PROBLEMATIC WATER POLLUTANTS AND TOXINS}

\author{
by \\ Danni Cui \\ Florida International University, 2018 \\ Miami, Florida \\ Professor Kevin O'Shea, Major Professor
}

Problematic organic pollutants in industrial and drinking water sources are a leading cause of water scarcity. Among the advanced oxidation processes, sonolytic degradation has received considerable attention because it combines oxidation processes initiated by reactive oxidant species and a pyrolysis processes associated with the high temperatures produced during cavitation.

The degradation of the semi-volatile compound, MCHM, was rapid and followed pseudo-first order kinetics. The Freundlich kinetic model for heterogeneous systems was successfully applied to describe the non-uniform distribution of MCHM at the gas-liquid interface during ultrasonic treatment. Two primary products were confirmed by GC-MS. Computational studies were also applied to assist in a better understanding of the conformational effects and the pyrolytic pathways.

The first-generation antihistamine, diphenhydramine (DPH), was also readily degraded by ultrasound. The heterogeneous process was best fit to a LangmuirHinshelwood kinetic model, which indicated a uniform partitioning at the gas-liquid 
interface. The degradation of DPH was achieved primarily via the addition reaction with hydroxyl radicals to the aromatic rings. Computational studies supported the observed products and the proposed reaction pathways for the pyrolytic and oxidation degradation pathways.

Ultrasound was shown to be a rapid and effective method to remediate cetirizine (CET), a second-generation antihistamine. Addition of different hydroxyl radical scavengers into the solution prior to treatment as the competition studies indicated that CET reacted with hydroxyl radicals at the gas-liquid interface and the bulk solution. When the solution was saturated by $\mathrm{O}_{2}$, CET degraded the most rapidly. Degradation products were confirmed by LC-MS analyses.

Treatment of the emerging problematic perfluorinated alkyl substance, "GenX" with steady state gamma-radiation under various conditions did not lead to significant degradation. However, "GenX" does react with $\mathrm{e}_{\mathrm{aq}}$ " at near diffusion-controlled rate, $\mathrm{k}=$ $5 \times 10^{10} \mathrm{M}^{-1} \cdot \mathrm{s}^{-1}$. Titanium dioxide photocatalysis did not lead to appreciable degradation of "GenX" under a variety of conditions even in the presence of oxalic acid or ethanol as the valence band hole quencher. Sonolysis was a promising method and led to the effective mineralization of "GenX" under argon saturated conditions. A detailed computational study of the pyrolytic degradation pathways was carried out using density function in Gaussian 09 . 


\section{TABLE OF CONTENT}

\section{CHAPTER}

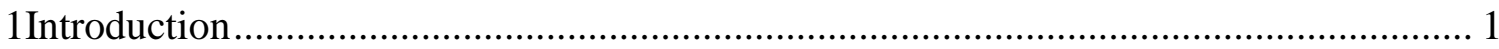

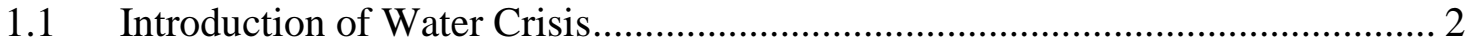

1.2 Background of Advanced Oxidation Processes (AOPs) …………………........ 4

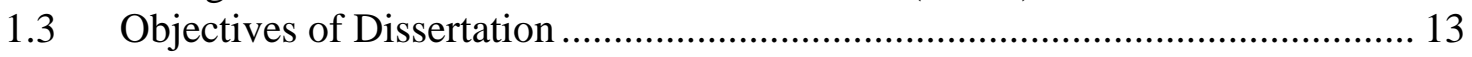

2 Kinetic, product, and computational studies of the ultrasonic induce-degradation of

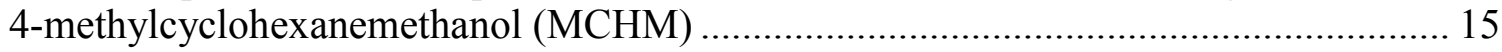

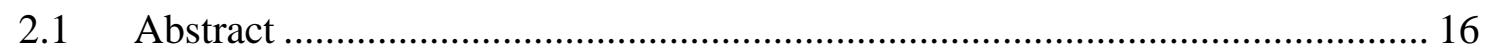

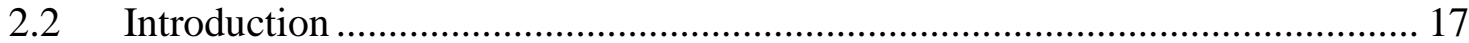

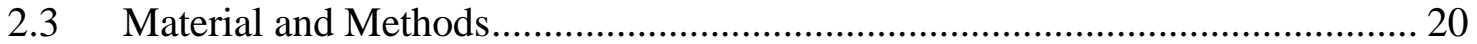

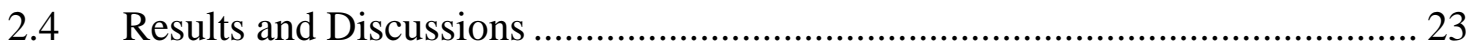

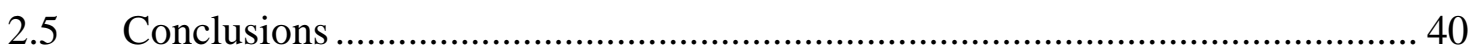

3 Fundamental study of the ultrasonic induced degradation of the popular

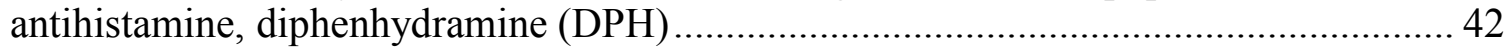

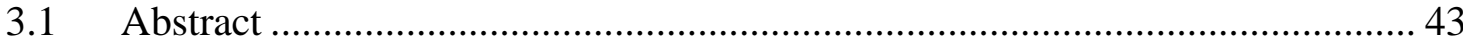

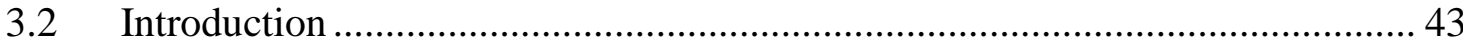

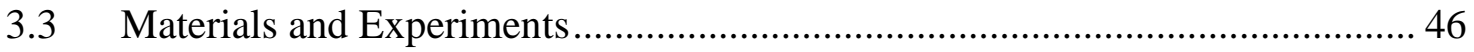

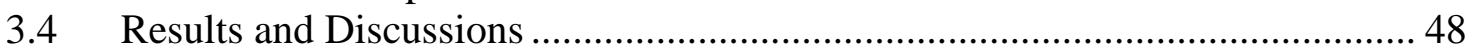

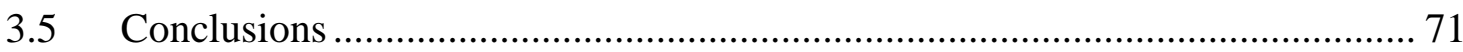

4 Ultrasound-induced remediation of the second-generation antihistamine, Cetirizine ... 73

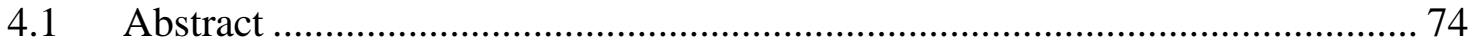

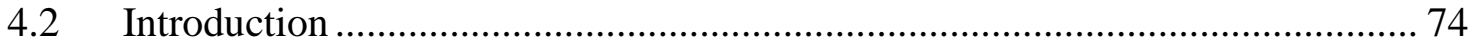

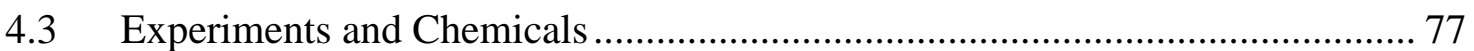

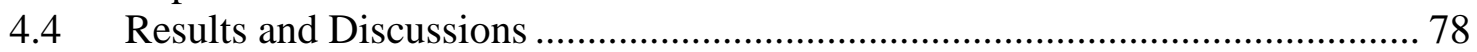

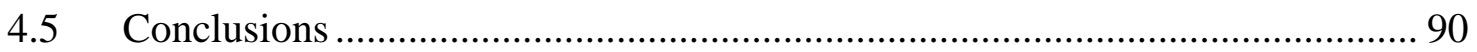

5 An exploration of degradation of "GenX" using different oxidation/reduction

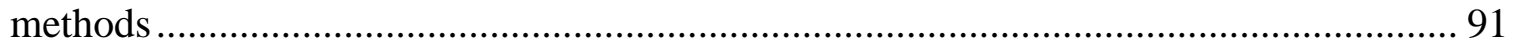

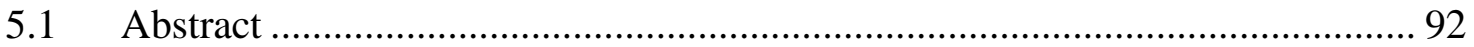

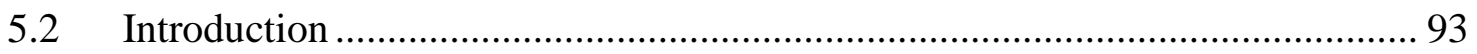

5.3 Experiment Materials and Methods ………................................................... 97

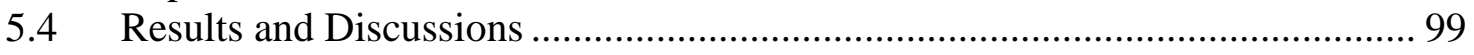

5.5 Conclusions ................................................................................... 114

6 General Conclusions ………………………………........................................ 115

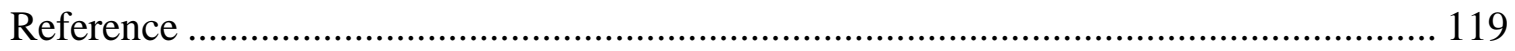

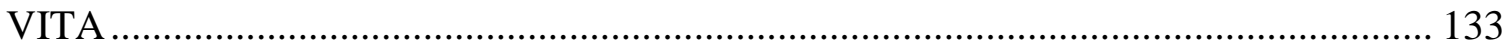




\section{LIST OF TABLES}

TABLE

PAGE

2.1 The ultrasonic degradation of MCHM $(670 \mathrm{kHz})$ half-lives and the pseudo- first order rate constants at different initial concentrations. a) The reproducibilities of trans- and cis-MCHM were $\pm 3 \%$ and $\pm 5 \%$ respectively on the basis of triplicate runs.

2.2 Composition of chair conformers under different temperatures. (According to the equation, $\Delta \mathrm{E}=\Delta \mathrm{H} \approx \Delta \mathrm{G}, \Delta \mathrm{G}=-\mathrm{RT} \operatorname{lnK}$, where $\Delta \mathrm{E}(\mathrm{kcal} / \mathrm{mol})$ is the relative energy, $\mathrm{R}$ (the gas constant) $=0.001987 \mathrm{kcal} /(\mathrm{mol} \cdot \mathrm{K}), \mathrm{T}(\mathrm{K})$ is the phase temperature, (a) bulk solution, (b) interfacial region, (c) hot spot.)

2.3 Homolytic $\mathrm{C}-\mathrm{H}$ bond dissociation energies (model for $\mathrm{HO} \cdot$ abstraction pathway) in the unit of $\mathrm{kcal} / \mathrm{mol}$ of trans- and cis- lower energy conformation.

2.4 The most reactive hydrogens towards $\cdot \mathrm{OH}$ abstraction for different isomers and conformations based on relative homolytic dissociation energies in $\mathrm{kcal} / \mathrm{mol}$.

4.1 Determine rate constant $\mathrm{k}\left(\mathrm{min}^{-1}\right)$ for ultrasonic degradation of CET

4.2 Physical properties of saturation gases (at $1 \mathrm{~atm}, 300 \mathrm{~K}$ ) [152] 86

5.1 The bond cleavage energies of "GenX" and its parent compound. 107 


\section{LIST OF FIGURES}

FIGURE

PAGE

1.1 Mechanisms for hydroxyl radical reaction with target compounds: (a) addition (b) Hydrogen abstraction (c) electron transfer [28] ................................................... 5

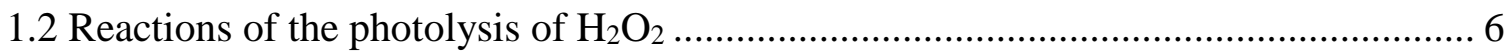

1.3 The graphic summary of the cavitation process [48] ......................................... 11

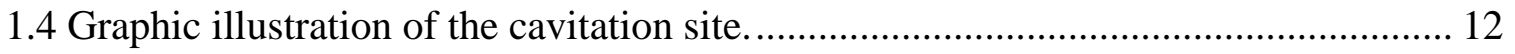

2.1 Structures of trans- and cis- 4-methylcyclohexanemethanol................................ 18

2.2 The GC chromatograph of a 20 ppm MCHM solution. (1) The MS spectra of the cis-isomer; (2) The MS spectra of the trans-isomer................................................ 21

2.3 Calibration of trans- and cis- MCHM isomers of GC-MS.................................. 23

2.4 Degradation of different initial concentrations of trans- and cis- MCHM $(670 \mathrm{kHz}$,

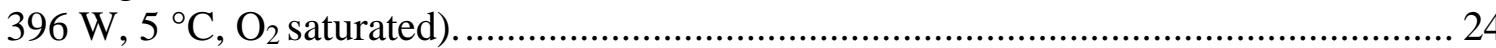

2.5 MCHM molecules partitioning on the gas-liquid interface following (a) LangmuirHinshelwood Model (b) Freundlich Model

2.6 Langmuir-Hinshelwood degradation isotherms of trans- and cis-MCHM in aqueous media under ultrasonic irradiation $\left(670 \mathrm{kHz}, 396 \mathrm{~W}, 5{ }^{\circ} \mathrm{C}, \mathrm{O}_{2}\right.$ saturated $)$................... 29

2.7 Freundlich degradation isotherms of trans- and cis-MCHM in aqueous media under ultrasonic irradiation $\left(670 \mathrm{kHz}, 396 \mathrm{~W}, 5^{\circ} \mathrm{C}, \mathrm{O}_{2}\right.$ saturated $)$.

2.8 The GC chromatograms of the starting MCHM and the reaction products and mass spectra of primary products (3) and (4).

2.9 Degradation products 4-methylcyclohexanone (1) and 4-methylcyclohexenylmethanol (2) from ultrasonic treatment of MCHM $\left(670 \mathrm{kHz}, 396 \mathrm{~W}, 5^{\circ} \mathrm{C}, \mathrm{O}_{2}\right.$ saturated).

2.10 Energetically favored MCHM C-C homolytic bond pyrolytic pathways on the basis of Gaussian 09 computations.

3.1 Ultrasonically mediated degradation of $\mathrm{DPH}$ as a function of treatment time (640 $\mathrm{kHz}, 396 \mathrm{~W}, 5{ }^{\circ} \mathrm{C}, \mathrm{O}_{2}$ saturated).

3.2 Pseudo-first order kinetic plots of ultrasonically mediated degradation of DPH at different initial concentrations $\left(640 \mathrm{kHz}, 396 \mathrm{~W}, 5^{\circ} \mathrm{C}, \mathrm{O}_{2}\right.$ saturated). 
3.3 Langmuir-Hinshelwood plot of DPH (a) and COU (b) degradation in aqueous media under ultrasonic irradiation $\left(640 \mathrm{kHz}, 396 \mathrm{~W}, 5^{\circ} \mathrm{C}\right.$, O2 saturated).

3.4 Degradation of DPH with and without the co-existence of the hydroxy radical scavenger, COU. ( $640 \mathrm{kHz}, 396 \mathrm{~W}, 5{ }^{\circ} \mathrm{C}, \mathrm{O}_{2}$ saturated). Linearity fit is represented by dotted line.

3.5 DPH degradation under different $\mathrm{pH}$ value ............................................................ 56

3.6 DPH chromatograph and mass spectra of untreated solution. ................................... 57

3.7 a) Hydroxylation of DPH yielding mono and di-hydroxylation products.

The $o, m, p$ represent ortho, meta and para substitution; b) The chromatograph of mono-hydroxylation of DPH and (A), (B), (C) are MS spectra of three isomers corresponding to the retention times of 5.665,5.784 and 6.044 min respectively; c). Chromatogram and MS spectra of di-hydroxylation products. (A'), (B'), (C') and (D') are MS spectra of four isomers corresponding to the retention times of 4.902,5.085,

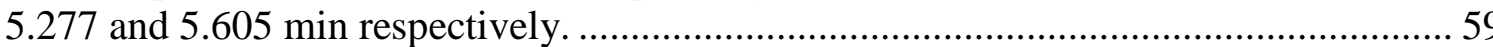

3.8 The degradation pathway and mass spectra of the product with MW $193.1102 \mathrm{~g} / \mathrm{mol}$

3.9 The degradation pathway and mass spectra yielding the product with MW 241.1466.

3.10 The pyrolysis pathway yielding benzophenone (MW 182.0731g/mol).

3.11 DPH molecule hydrogen abstraction energies $\left(\Delta \mathrm{E}\right.$ is given in $\left.\mathrm{kcal} \cdot \mathrm{mol}^{-1}\right) 278 \mathrm{~K}$, $2000 \mathrm{~K}$ and $5000 \mathrm{~K}$.

3.12 Pyrolysis pathway for carbon centered radical intermediates 1,2,3 and 4 formed by $\mathrm{H}$-abstraction. Energies of transition states and products are shown in $\mathrm{kcal} / \mathrm{mol}$....... 68

3.13 Direct pyrolysis pathway under high temperature. Relative energies of various species are shown in $\mathrm{kcal} \cdot \mathrm{mol}^{-1}$............................................................................... 71

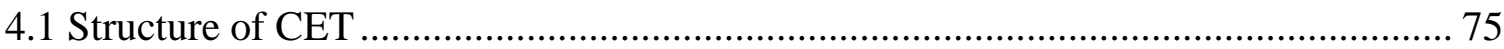

4.2 Degradation plots dependent of initial concentration. Triplicate trials were applied to $65.0 \mu \mathrm{mol} / \mathrm{L}$ solution and the reproducibility was $\pm 4 \%$............................................ 79

4.3 Langmuir-Hinshelwood kinetic plot of ultrasonic degradation of CET...................... 81

4.4 Terephthalate reacts with $\mathrm{HO} \cdot$ and forms 2-hydroxyterepthalate............................... 82

4.5 Coumarin reacts with HO. and forms 7-hydroxycoumarin........................................ 83 
4.6 Calibration curve of 7-OHC was determined as $\mathrm{y}=291 \mathrm{x}+3.27$.

4.7 The production of 7-OHC in $0.1 \mathrm{mmol} / \mathrm{L} \mathrm{COU}$ solution with and without $0.1 \mathrm{mmol} / \mathrm{L}$ CET. Triplicate experiments were conducted and the reproducibility was within $\pm 3 \%$.

4.8 Calibration curve of 2-HTPA

4.9 The production of 2-HTPA in $0.1 \mathrm{mmol} / \mathrm{L}$ TPA blank and in $0.1 \mathrm{mmol} / \mathrm{L}$ TPA and $0.1 \mathrm{mmol} / \mathrm{L}$ CET mixture solution $(0.1 \mathrm{v} 0.1)$. Triplicate experiments were applied and the reproducibility was within $\pm 4 \%$. 85

4.10 Effect of different saturation gases on the degradation of CET............................ 87

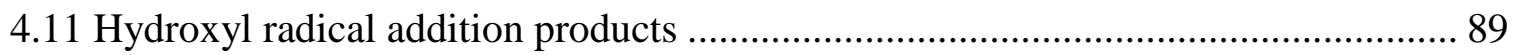

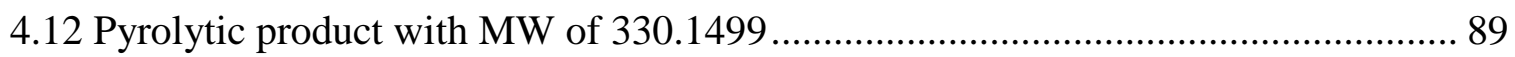

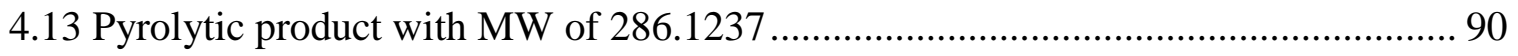

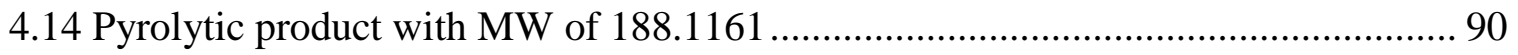

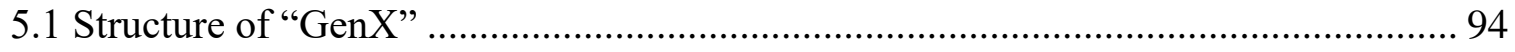

5.2 Determination of bimolecular rate constant for "GenX" and aqueous electrons. (a) Exponential decay of the absorption at $720 \mathrm{~nm}$ in the pulse radiolysis solution of 100 to $500 \mu \mathrm{M}$ "GenX" solution. (b) Bimolecular rate constant determined as $5 \times 10^{10} \mathrm{M}^{-1} \cdot \mathrm{s}^{-1} 99$

5.3 The degradation of $5 \mathrm{ppm} \mathrm{N}_{2}$ saturated "GenX" solution and the production of $\mathrm{F}^{-} .101$

5.4 The degradation of 5 ppm N2O and O2 saturated "GenX" solution. ...................... 101

5.5 The degradation of "GenX" under different $\mathrm{pH}$ and different saturation gases.

5.6 $\mathrm{TiO}_{2}$ photocatalytic degradation of "GenX" with oxalic acid and $10 \%$

ethanol under acidic and alkaline conditions.

5.7 Degradation of "GenX" at different initial concentrations.

5.8 (a) Production of fluoride at different starting concentrations of "GenX" under ultrasound (640 kHz, $396 \mathrm{~W}$, Ar saturated). (b) Mineralization efficiency of "GenX". 106

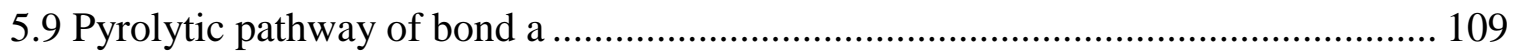

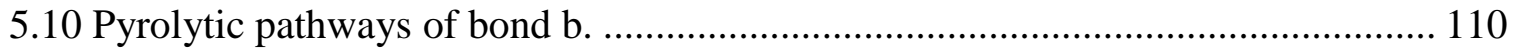

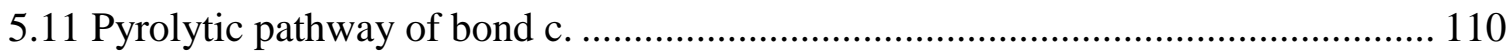




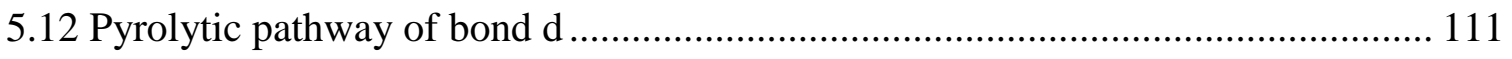

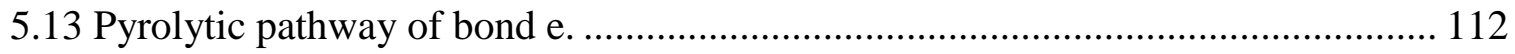

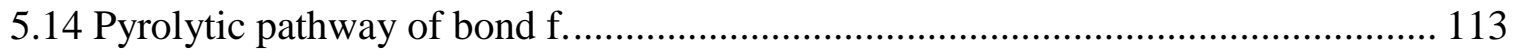

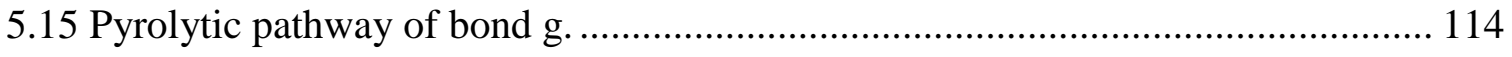




\section{Chapter 1 Introduction}




\subsection{Introduction of Water Crisis}

In the $21^{\text {st }}$ century, people face serious environmental challenges related to water quality and quantity worldwide associated with the pollution from the spread of industrialization and urbanization [1]. Water scarcity has become a major issue in most countries. Industrial, agricultural, and daily usage are the main purposes of accessible freshwater consumption [2]. The increasing global population requires larger amounts of freshwater and an estimated 3 billion people will suffer from the lack of fresh water within 10 years $[3,4]$. In response to the serious global water shortage, governments have made major recent efforts to address the shortages of clean water. The demands for fresh water dramatically out-pace the availability of water, thus water conservation is critical to addressing the global water shortage. Effective water treatment and re-use strategies are an essential part of meeting the urgent need for clean water.

Micro and macro-pollutants present in industrial and drinking water sources are not remediated by current water treatment processes [5]. Macro-pollutants, at the ppm level, are mainly composed of nutrients and natural organic matters [6,7]. Micro-pollutants are typically present at ppb to ppm levels, and often have pronounced toxic effects even at trace concentrations. The sources of micro-pollutants include agricultural inputs [8]; pharmaceutical and personal care products released into aqueous system through sewer effluents [9]; industrial wastewater and chemical spills [10,11].

The classification of PPCPs (pharmaceutical and personal care products) was first introduced by the U.S. Environmental Protection Agency (USEPA) [12,13]. Pharmaceutical and personal care products include a diverse group of regularly consumed 
chemicals, such as prescription and over the counter drugs, fragrances and cosmetics [14]. Pharmaceutical and personal care products are released into water from individual households, sewer effluents and hospital waste discharges. Waste streams contain a mixture of original substrates and metabolic products [15]. In general, standard water treatment processes do not effectively degrade or remove PPCPs. In addition, treated wastewater is often diluted with ground and surface water before discharge, leading to dilution, but not removal, of these biologically active contaminants, which are released into the environment. The discharged water contains residual PPCPs, which require advanced treatment to degrade and detoxify [16].

A large chemical spill of MCHM and PPH was released into the Elk River in West Virginia on January 14, 2014. The main ingredient of this spill was coal-washing solvents, 4-methylcyclohexanemethanol (MCHM) and 1-phenoxy-2-propanol (PPH). The biological activities and environmental impact of these compounds were relatively unknown. Following the spill, West Virginia Poison Center started to receive reports of rashes, nausea, vomiting, diarrhea, and other symptoms. As a result, approximately 300,000 residents from West Virginia were notified not to drink, cook, or bathe with tap water. The main spilled chemical was crude MCHM, however careful analysis of the contaminated water revealed the presence of 1-phenoxy-2-propanol (PPH) as a secondary pollutant. The Center of Disease Control and Prevention (CDC) had suggested a guideline of $1 \mathrm{ppm}$, but announced that MCHM should not be present in drinking water sources.

Legacy perfluoroalkyl substances (PFASs) were widely used in aqueous firefighting foams, non-stick pans, food wrapping coating layers, and other purposes in the 
past few decades [17]. The stability of PFASs makes them highly resistant to a biodegradation process. The bio-accumulativity of PFASs resulted in human health effects.

On the basis of these concerns, perfluorooctanoic acid (PFOA) and similar long-chain PFASs were banned in the US, as well as in some other countries. The emerging PFASs, including short-chain PFASs, and perfluoroether carboxylic acids (PFECA), were used as the replacement of the legacy PFASs [18]. Perfluoro(2-methyl-3-oxahexanoic) acid ("GenX") was introduced in 2009 as a substitute for PFOA [19]. However, "GenX" had recently been detected in the drinking water sources and surface water in many places, such as Ohio and North Carolina[18]. Similar to PFOA, "GenX" is also resistant to biodegradation. The ether functionality increases the water solubility of "GenX," and the short chain length enhances its mobility. Limited information was reported on the "GenX" human health impacts, however, the lab experiments of rats exposed to "GenX" indicated liver damage $[20,21]$.

\subsection{Background of Advanced Oxidation Processes (AOPs)}

Professor William Glaze was the first person to define advanced oxidation processes (AOPs) in 1987 [22] and the definition has rapidly evolved in subsequent decades. Advanced oxidation processes describe water treatment methods that employ primarily hydroxyl radicals (and related species) to degrade and mineralize pollutants to less toxic compounds, ideally $\mathrm{CO}_{2}$, water and mineral acids [23]. Characterized by producing the powerful oxidant, hydroxyl radical, AOPs involve a variety of different initiation processes, including photochemical and photocatalytic methods, chemical processes, sonolysis, $\gamma$-radiolysis among a wide variety of systems [24]. 
The hydroxyl radical with an oxidation potential of $2.8 \mathrm{eV}$ is one of the most reactive oxidant species [25]. When the hydroxyl radical attacks an organic compound, there are three possible pathways: (1) addition (2) hydrogen abstraction (3) electron transfer $[26,27]$. Addition reactions commonly occur with the unsaturated compounds, especially aromatic systems to form unsaturated alcohols (Figure. 1.1 (a)). The hydroxyl radical can also abstract a hydrogen from a $\mathrm{C}-\mathrm{H}$ bond, leading to a carbon-centered radical(Figure.1.1 (b)) [26]. The product of electron transfer reaction could be an ion, an atom or a radical (Figure.1.1 (c)) [26]. In some cases, two hydroxyl radicals react with other to form hydrogen peroxide. The reaction rate of each pathway is the key factor that determines the reaction mechanism. The addition and abstraction pathways generally present faster reaction rates, which means that the electron transfer is less likely to occur [28].

(a)

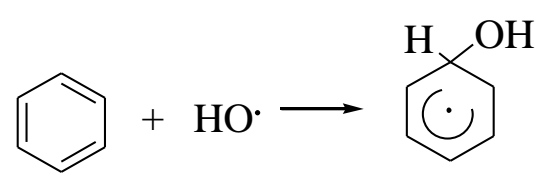

(b) $\mathrm{HO} \cdot+\mathrm{CH}_{3} \mathrm{OH} \rightarrow \mathrm{H}_{2} \mathrm{O}+\cdot \mathrm{CH}_{2} \mathrm{OH}$

(c) $\mathrm{HO} \cdot+\left[\mathrm{Fe}(\mathrm{CN})_{6}\right]^{4-} \rightarrow\left[\mathrm{Fe}(\mathrm{CN})_{6}\right]^{3-}+\mathrm{OH}^{-}$

Figure. 1.1 Mechanisms for hydroxyl radical reaction with target compounds: (a) addition (b) Hydrogen abstraction (c) electron transfer [28].

\subsection{1 $\mathrm{UV} / \mathrm{H}_{2} \mathrm{O}_{2}$ Process}

Photochemical processes decompose pollutants by the HO generated from UV irradiation coupled with oxidants or catalysts. The advantages of photochemical 
technologies are costs, efficiency, and ease-of-use in comparison to chemical processes. The production of hydroxyl radicals is achieved by radiating $\mathrm{H}_{2} \mathrm{O}_{2}$ using UV light (200 to $300 \mathrm{~nm}$ ), which leads to the homolytic cleavage of the O-O bond. Following the initiation step, several reactions take place successively, as illustrated in Figure. 1.2.

$$
\begin{aligned}
& \mathrm{H}_{2} \mathrm{O}_{2}+\mathrm{h} v \rightarrow 2 \mathrm{HO} \cdot \\
& \mathrm{H}_{2} \mathrm{O}_{2}+\mathrm{HO} \cdot \rightarrow \mathrm{H}_{2} \mathrm{O}+\mathrm{HO}_{2} \cdot \\
& \mathrm{H}_{2} \mathrm{O}_{2}+\mathrm{HO}_{2} \cdot \rightarrow \mathrm{HO} \cdot+\mathrm{H}_{2} \mathrm{O}+\mathrm{O}_{2} \\
& \mathrm{HO}+\mathrm{HO}_{2}^{-} \rightarrow \mathrm{HO}_{2} \cdot+\mathrm{OH}^{-} \\
& 2 \mathrm{HO}_{2} \cdot \rightarrow \mathrm{H}_{2} \mathrm{O}_{2}+\mathrm{O}_{2} \\
& \mathrm{HO} \cdot+\mathrm{HO}_{2} \cdot \rightarrow \mathrm{H}_{2} \mathrm{O}+\mathrm{O}_{2} \\
& 2 \mathrm{HO} \cdot \rightarrow \mathrm{H}_{2} \mathrm{O}_{2}
\end{aligned}
$$

Figure. 1.2 Reactions of the photolysis of $\mathrm{H}_{2} \mathrm{O}_{2}$

The production of the free radicals is closely related to the parameters of the UV lamp and the medium. Under alkali condition $(\mathrm{pH}>10)$, the formation of $\mathrm{HO}_{2} \cdot$ from the ionized $\mathrm{H}_{2} \mathrm{O}_{2}$ can greatly increase the reaction rate. The drawback of $\mathrm{UV} / \mathrm{H}_{2} \mathrm{O}_{2}$ method is that a very high concentration of $\mathrm{H}_{2} \mathrm{O}_{2}$ is required because of the low molar absorption coefficient of $\mathrm{H}_{2} \mathrm{O}_{2}$ [23,29]. 


\subsection{2 $\mathrm{TiO}_{2}$ photocatalysis}

Semiconductor materials have been widely applied as a result of their special properties related to the special electronic structure [30]. Titanium dioxide is one of the most stable, well-performed and inexpensive catalysts used in photocatalysis [31]. $\mathrm{TiO}_{2}$ photocatalysis has been applied to remediate different types of compounds, such as pesticides, halocarbons, aromatic compounds and so on, to less toxic compounds even $\mathrm{CO}_{2}$ and $\mathrm{H}_{2} \mathrm{O}$ [32]. The initiation of photocatalysis is to excite the $\mathrm{TiO}_{2}$ by photons with energies higher than the band gap to promote an electron $\mathrm{e}_{\mathrm{CB}}{ }^{-}$from the filled valence band (VB) to the empty conduction band (CB) and leave a positively charged hole, $\mathrm{h}^{+}$(as in Eq.1.1) [33]. The band gap of $\mathrm{TiO}_{2}$ is approximately $3 \mathrm{eV}$, which indicates that the excitation wavelength is in the UV region [34]. The holes at VB have strong oxidation potential and the electrons at $\mathrm{CB}$ are powerful reductants [30]. Redox reactions may occur when suitable scavengers are present to trap either the hole or the electron. The hole reacts with water and forms hydroxyl radicals, as in Eq.1.2. The electron reacts with oxygen and forms an oxidant, superoxide (Eq.1.3) [30].

$$
\begin{aligned}
& \mathrm{TiO}_{2}+\mathrm{h} v \rightarrow \mathrm{h}^{+}+\mathrm{e}_{\mathrm{CB}^{-}} \\
& \mathrm{H}_{2} \mathrm{O}+\mathrm{h}^{+} \rightarrow \mathrm{HO} \cdot+\mathrm{H}^{+} \\
& \mathrm{e}_{\mathrm{CB}}{ }^{-}+\mathrm{O}_{2} \rightarrow \mathrm{O}_{2}{ }^{-}
\end{aligned}
$$

$\mathrm{TiO}_{2}$ can be used in photocatalysis processes either dispersed as a suspension in solution, or made into a thin film on the supporting material [35]. The large surface area of the powdered $\mathrm{TiO}_{2}$ increases the catalyst efficiency which is easy to prepare at the same 
time. The possibility of formation of a dark catalytic sludge that can lead to a decrease of the UV irradiation efficiency is a main drawback when using powdered $\mathrm{TiO}_{2}$. Even though the high stability and activity of the catalyst are required when the $\mathrm{TiO}_{2}$ thin film is applied, the elimination of the removal of the $\mathrm{TiO}_{2}$ particles after the reaction is a great advantage [36].

\subsubsection{Radiolysis}

Gamma-radiolysis has been successfully applied to decompose and disinfect many water pollutants without any addition of reagents or catalysts for decades $[37,38]$. One of the advantages of radiolysis is the fact that as a groundwater treatment method, the presence of solid suspended solids does not affect the degradation efficiency significantly [38]. The radiation of water by gamma ray or high energy electron beam leads to bond cleavage and forms many reactive species and molecular products. The number of produced or decomposed molecules per $100 \mathrm{eV}$ absorbed is termed the G-value [39]. The cross reaction of water radiolysis is shown Eq.1.4, with the G-value at $\mathrm{pH} 7$ given in parentheses [39]. The fraction of the production of $\mathrm{e}_{\mathrm{aq}}{ }^{-}$is proportional to the energy absorbed by the aqueous solution, which also yields the production of primary reactive species. Aqueous electrons, hydroxyl radicals and hydrogen atoms are all generated at high yield.

$$
\begin{gathered}
\mathrm{H}_{2} \mathrm{O} M \rightarrow \mathrm{e}_{\mathrm{aq}}^{-}(2.7)+\cdot \mathrm{H}(0.6)+\mathrm{HO} \cdot(2.8)+\mathrm{H}_{2}(0.45) \\
+\mathrm{H}_{2} \mathrm{O}_{2}(0.7)+\mathrm{H}_{\mathrm{aq}^{+}}{ }^{+}(3.2)+\mathrm{OH}_{\mathrm{aq}}{ }^{-}(0.5) \\
\mathrm{e}_{\mathrm{aq}}{ }^{-}+\mathrm{N}_{2} \mathrm{O}+\mathrm{H}_{2} \mathrm{O} \rightarrow \mathrm{N}_{2}+\mathrm{HO}^{-}+\mathrm{HO} \\
\mathrm{H} \cdot+\mathrm{N}_{2} \mathrm{O} \rightarrow \mathrm{HO} \cdot+\mathrm{N}_{2}
\end{gathered}
$$




$$
\begin{array}{lc}
\mathrm{H} \cdot+\mathrm{O}_{2} \rightarrow \mathrm{HO}^{-} & \text {Eq.1.7 } \\
\mathrm{e}_{\mathrm{aq}}{ }^{-}+\mathrm{O}_{2} \rightarrow \mathrm{O}_{2} \cdot{ }^{-} & \text {Eq.1.8 } \\
\left(\mathrm{CH}_{3}\right)_{2} \mathrm{CHOH}+\mathrm{HO} \cdot \rightarrow\left(\mathrm{CH}_{3}\right)_{2} \mathrm{C} \cdot \mathrm{OH}+\mathrm{H}_{2} \mathrm{O} & \text { Eq.1.9 } \\
\left(\mathrm{CH}_{3}\right)_{2} \mathrm{CHOH}+\mathrm{H} \cdot \rightarrow\left(\mathrm{CH}_{3}\right)_{2} \mathrm{C} \cdot \mathrm{OH}+\mathrm{H}_{2} & \text { Eq.1.10 }
\end{array}
$$

In the presence of $\mathrm{O}_{2}$ or $\mathrm{N}_{2} \mathrm{O}$, the oxidation reaction is promoted by the elimination of the reducing species. Aqueous electrons and hydrogen atom are converted to $\mathrm{O}_{2} \cdot{ }^{-}$(Eq.1.8) and HO-- (Eq.1.7) by reaction with oxygen, or $\mathrm{HO}^{-}$and $\mathrm{HO}$ - by reacting with $\mathrm{N}_{2} \mathrm{O}$ (Eq.1.5 1.6). Similarly, to study the reduction reaction of the aqueous electrons and the pollutants, isopropanol is added to the $\mathrm{N}_{2}$-saturated solution as the scavenger of $\mathrm{HO}$ - and $\mathrm{H}$ - (Eq.1.9 $\sim 1.10$ ).

In recent years, abundant literature have been published on the application of removal of organic pollutants by radiolysis, which is among the most efficient advanced oxidation processes $[40,41]$.

\subsubsection{Sonolysis}

The focus of my dissertation is on the application of ultrasound. Ultrasound is defined as inaudible sound waves with the frequencies above $20 \mathrm{kHz}$, grouped into two categories: (1) high frequencies (2-10 MHz), mostly used in medical imagining or testing (2) low to medium frequencies (20 -1000 kHz), widely applied in industry, cleaning, sonochemistry and other areas [42]. Sonolysis is often used in the remediation processes of water pollutants using low to medium frequency ultrasound. The earliest reports of ultrasound can be traced back to the 1950s with the first application of ultrasound in water 
treatment reported in the 1970s [43]. In the past few decades, ultrasound has matured and attracted significant interest for widespread water treatment because it has advantages over other methods. For example, it does not require chemical additives, it can be fast and effective for a variety of chemical contaminants and mixtures. One of the primary challenges of operating the sonolysis treatment is the cost of converting electrical energy to ultrasonic waves [44].

Ultrasound remediation is caused by the propagation of sound waves through an elastic medium, such as water. The sound wave oscillation goes through compression and rarefaction cycles in the aqueous solution. The rarefaction cycle adds a negative pressure to the liquid and pulls the liquid apart, while the compression cycle adds a positive pressure and pushes the liquid together. Microbubbles are formed from the existing gaseous impurities, known as the "weak spots" [45]. There are two theories describing the formation of microbubbles: (1) there are gas bubbles trapped in the solid particles, (2) the existing gas bubbles are coated with the organic impurities [46]. The graphic summary illustrates the cavitation process clearly, as shown in Figure. 1.3 [46]. Under weak or moderate conditions, the term "stable cavitation" defines the phenomena that the bubble size decreases during the compression cycles and increases during the rarefaction cycles at an equilibrium rate [47]. The rates of the compression and rarefaction cycles are closely related to the properties of the medium, such as the density, viscosity and surface tension. Rectified diffusion is defined by the process that the bubble size goes up substantially during the rarefaction cycle due to the greater amount of the diffusing gas. When the bubble reaches the resonance size, which is determined by the applied frequency, and can no longer absorb any energy, the bubble becomes unstable and explodes. Stable cavitation 
mostly occurs to small bubbles, and transient cavitation describes the process which applies to the large bubbles under the high intensity ultrasound. After several cycles, the bubble size goes up by tens to hundreds of times in a number of cycles then collapses violently during the compression cycle in an extremely short time [50]. In summary, the term "cavitation" describes a three-step process: formation, growth and collapse of the bubbles.

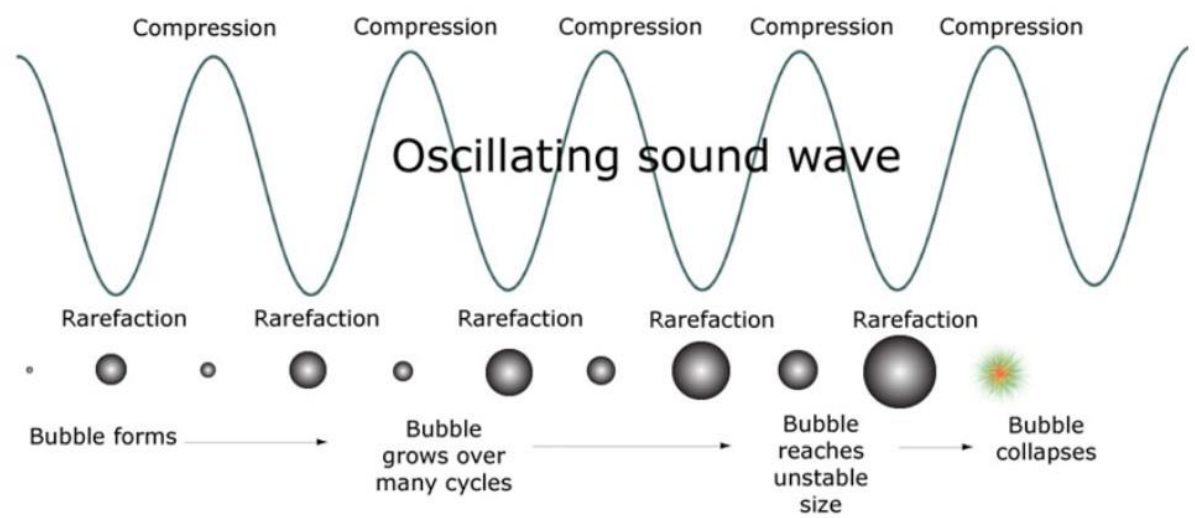

Figure. 1.3 The graphic summary of the cavitation process [48].

Three regions are generated with the collapse of the bubbles: the hot-spot, the gasliquid interface and the bulk solution, shown in Figure. 1.3. The hot-spot presents an extremely high temperature (> $5000 \mathrm{~K})$ and a high pressure (> $500 \mathrm{~atm}$ ) [49]. The gasliquid (g-l) interface with a high temperature (> $2000 \mathrm{~K})$ and a high pressure (> $200 \mathrm{~atm})$ satisfies the condition of supercritical water, thus, this region becomes hydrophobic rather than hydrophilic [50]. The bulk solution remains at near ambient temperature.

The high temperature and high pressure create unique reaction conditions at the cavitation site. At the hot-spot and the g-l interface, the formation of hydroxyl radicals is initiated by the pyrolysis of water molecules, and followed by several secondary reactions 
(Eq.1.11 1.14). Volatile compounds can diffuse to the hot-spot and be destructed under the high temperature as well. The hydroxyl radicals formed at the hot-spot and gas-liquid are released to the bulk solution and react with the compounds. The $\mathrm{g}-\mathrm{l}$ interface is a distinct region, which localizes the hydroxyl radicals to react with the target compound, and also degrades the pollutants through thermal processes. Therefore, the combination of pyrolysis and oxidation of the target makes ultrasound-induced remediation of the pollutants an attractive water treatment method.

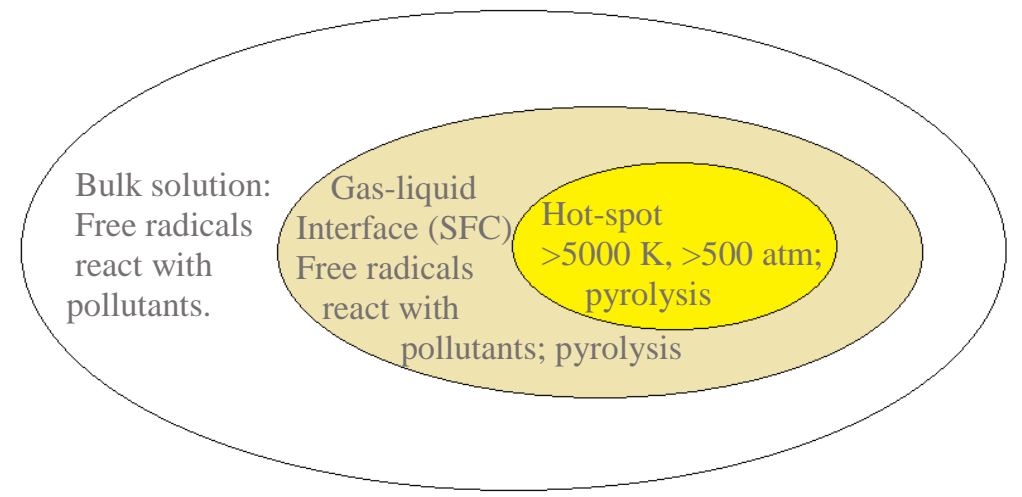

Figure. 1.4 Graphic illustration of the cavitation site.

$$
\begin{aligned}
& \mathrm{H}_{2} \mathrm{O} \rightarrow \mathrm{H} \cdot+\mathrm{HO} \cdot \\
& \mathrm{H}_{2} \mathrm{O} \rightarrow \mathrm{H}_{2}+\mathrm{O} \\
& \mathrm{H}_{2} \mathrm{O}+\mathrm{O} \rightarrow \mathrm{HO} \cdot+\mathrm{HO} \cdot \\
& \mathrm{H} \cdot+\mathrm{H}_{2} \mathrm{O} \rightarrow \mathrm{HO} \cdot+\mathrm{H}_{2}
\end{aligned}
$$

Ultrasound induced degradation has been successfully applied to manage many types of compounds. The properties of the target compounds, such as the octanol-water partition coefficient, Henry's law constant, rate constant with $\mathrm{HO}$, and diffusivity, 
significantly affect the degradation process. The compounds with a high hydrophobicity and a low diffusivity, or the opposite, tend to have additional time to partition to the gasliquid interface [51]. The volatile compounds tend to diffuse to the hot-spot, and are decomposed by the high temperature. For example, methyl tert-butyl ether (MTBE), a volatile and flammable liquid, was added to gasoline to assist combustion as a replacement of lead. Methyl tert-butyl ether was detected in 22 of 42 states and in $5 \%$ of wells from 1993 to 1998 . The conventional methods, such as GAC adsorption, were not able to remove MTBE efficiently as a consequence of the high saturation rate. Advanced oxidation species, especially ultrasound, were proved to be one of the most useful methods to remediate MTBE in water [52].

The massive toxic cyanobacteria blooms have become a serious issue in freshwater or coast area. The fresh microcystins are a group of potent toxins produced by different species cyanobacteria. Ultrasound successfully degraded the structure of microcystins, leading to a decrease of activity and bio-toxicity. The results indicated that ultrasound can detoxify the drinking water problem related to microcystins [53].

\subsection{Objectives of Dissertation}

This dissertation project leads to a better fundamental understanding of ultrasoundinduced degradation of four problematic organic pollutants: 4-methylcyclohexane methanol (MCHM), the main component in the chemical spill in West Virginia,2014; diphenhydramine, an over-the-counter first-generation antihistamine; cetirizine, the second-generation antihistamine; and "GenX", an emerging perfluorinated ether carboxylic acid. The detailed kinetic and product studies will help in the development of 
structure reactivity relationships among different classes of pollutants. These studies will provide in-depth knowledge about ultrasound induced degradation and are critical for advancing water treatment applications and technologies. 
Chapter 2 Kinetic, product, and computational studies of the ultrasonic induced degradation of 4-methylcyclohexanemethanol (MCHM) 


\subsection{Abstract}

A massive spill of 4-methylcyclohexanemethanol (MCHM), a semi-volatile organic compound, contaminated the Elk river and forced the closure of tap water for nearly 300,000 residents. Typical water treatment methods are not effective for MCHM remediation, however, ultrasonic irradiation leads to its rapid pseudo-first order degradation. The degradation processes were effectively modeled employing heterogeneous kinetic models with the reaction surface corresponding to the gas-liquid interface of the cavitation bubble. The Freundlich model which takes into account nonuniform distribution within the reactive zone showed the strongest correlation to the observed degradation kinetic data with $\mathrm{R}^{2}>0.99$. Solute-solute clustering behavior is proposed to explain non-uniform distribution of MCHM. The results indicate the degradation occurs predominantly at the gas-liquid interface as a result of hydroxyl radical reactions and pyrolysis with primary reaction products, (4-methylcyclohexenyl) methanol and 4-methylcyclohexanone. Computational methods using density functional B3YPL/6$311 \mathrm{G}^{* *}$ calculations with Gaussian 09 provided insight into the hydroxyl radical and pyrolytic degradation pathways for the isomeric and conformational forms of MCHM. Our studies demonstrate that heterogeneous kinetic models and computational methods are important tools for the fundamental understanding and effective application of ultrasonically mediated degradation of MCHM which may be extended to a number of semi-volatile compounds. 


\subsection{Introduction}

The world faces serious environmental challenges related to water quality and quantity as a result of pollution from the spread of industrialization and urbanization. The daily demands for clean water dramatically outpace the availability of water, and while water conservation is critical to addressing the global water shortage, effective water treatment and re-use strategies are an essential part of meeting the urgent need for clean water. With the scarcity of fresh water, reuse and purification are critical to address water storages $[1,5]$.

A variety of pollutants present in industrial waters and drinking water sources are not effectively treated by current water treatment processes. The sources of chemical pollutants include agricultural inputs [8]; pharmaceutical and personal care products released into aqueous systems through sewer effluents [9]; industrial wastewater and chemical spills, typically present at ppb to ppm level can have pronounced toxic effects even at trace concentrations $[10,11]$.

A massive spill of the coal washing solvent, crude 4-methylcyclohexanemethanol (MCHM) (Figure. 2.1) [54] contaminated the tap water source for approximately 300,000 residents, and the local poison control center received reports of rashes, nausea, vomiting, diarrhea, and other symptoms from residents using the contaminated drinking water $[55,56]$. 4-methylcyclohexanemethanol, the main ingredient in the spill, was deemed responsible for the reported health problems. As a result the center for disease control and prevention (CDC) set a guideline maximum contamination level (MCL) for MCHM of $1 \mathrm{ppm}$ in the drinking water, but alternative drinking water sources were still recommended even at 
levels below the detection level [57]. 4-methylcyclohexanemethanol is a cyclic hydrocarbon bearing a single primary alcohol as the only functional group. 4methylcyclohexanemethanol is thus resistant to typical biological and environmental transformation processes. The absence of double bonds and chromophores make the compound also resistant to hydrolysis, photochemical transformation, and oxidation treatments such as ozonization [58]. The treatment of MCHM by biodegradation also has limited efficiency and is time consuming even at low initial concentration [59].

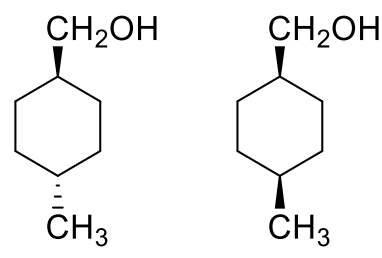

Figure. 2.1 Structures of trans- and cis- 4-methylcyclohexanemethanol.

Advanced oxidation processes (AOPs) have been used to treat an extensive number of pollutants in a variety of water sources. Oxidative species produced during AOPs react with target pollutants leading to oxidative transformation and ultimately mineralization. Unlike most oxidative water treatment methods, ultrasound does not require the addition of oxidants or catalysts [60]. Ultrasonically induced degradation is achieved via a cavitation process upon irradiating with ultrasound at frequencies above $20 \mathrm{kHz}$. The cavitation process leads to the generation of three zones: a hot-spot located at the interior of the bubbles, a gas-liquid interface referred to as the reaction zone for the purposes of this paper, and the bulk solution $[46,47,61]$.

At the interior of the bubble or hot spot, extreme high temperatures (above $5000{ }^{\circ} \mathrm{C}$ ) and pressures (above $500 \mathrm{~atm}$ ) can be reached during the collapse of the bubble general 
[47]. Under such conditions, pyrolysis of $\mathrm{H}_{2} \mathrm{O}$ and $\mathrm{O}_{2}$ leads to the creation of reactive species, such as $\mathrm{HO} \cdot \mathrm{H}^{\cdot}, \mathrm{HO}_{2}$ ', shown in Eq. 2.1-2.4 [47]. The free radicals generated at the hot spot and gas-liquid interfacial regions may diffuse into the bulk solution and react with dissolved substrate.

$$
\begin{aligned}
& \left.\left.\left.\mathrm{H}_{2} \mathrm{O}\right)\right)\right) \rightarrow \mathrm{H} \cdot+\mathrm{HO} \cdot \\
& \mathrm{O}_{2} \rightarrow 2 \mathrm{O} \\
& \mathrm{H} \cdot+\mathrm{O}_{2} \rightarrow \mathrm{HOO} \cdot \\
& \mathrm{O}+\mathrm{H}_{2} \mathrm{O} \rightarrow 2 \mathrm{HO} .
\end{aligned}
$$

The interfacial region has unique properties and is often referred to as a supercritical (SC) fluid because both the high temperature and pressure from the cavitation event are above the critical point of water $[47,62,63]$. In the supercritical fluid state, water behaves as a hydrophobic solvent and thus can be an effective solvent for non-polar chemicals [43]. The local concentration or partitioning of non-polar (hydrophobic) solutes at the interfacial $\mathrm{SC}$ region may be higher than the bulk aqueous solution during ultrasound induced remediation [64]. The ultrasonically induced degradation reactions of target compounds in the bulk solution are generally considered as the result of $\mathrm{HO} \cdot$ generated at the hot-spot and gas-liquid interfacial regions diffusing to bulk solution and reacting with target compounds $[61,65]$.

Reported herein for the first time are detailed fundamental kinetic, product, and partitioning isotherm studies to assess MCHM degradation by ultrasonic irradiation. Computation studies using Gaussian 09 (software package) were used to elucidate degradation pathways. These results demonstrate effective application of heterogeneous 
modeling of ultrasound induced degradation of MCHM, a semi-volatile substrate and effective prediction of the degradation pathways.

\subsection{Material and Methods}

\subsubsection{Materials and Chemicals}

A cis- and trans- mixture of MCHM (Product 1412, Lot. RCGNA-PT, 5g, >98.0\%) was purchased from the Tokyo Chemical Industry (TCI) company. All experiments were conducted using the mixture of cis and trans-MCHM. Individual isomers are not readily available from commercial sources and isomeric separation not practical. The manufacturer did not provide specific composition of the isomeric mixture but Foreman et al. reported the trans isomer was present in less than $50 \%$ [66]. The peak areas and observed retention times from the GC-MS analysis of prepared samples indicated the trans-isomer was $40 \%$ and cis was $60 \%$. The GC chromatograph (Figure. 2.2) shows two clearly resolved peaks with retention times of 9.62 and $9.86 \mathrm{~min}$ assigned to the cis- and trans-isomers respectively. Integration of the two peaks yields a ratio of 40:60 for the trans- and cis- ratio. The MS fragmentation patterns for the isomers were similar. The molecular weight of MCHM was $128.212 \mathrm{~g} / \mathrm{mol}$, and the MS of trans- and cis- isomers share $\mathrm{m} / \mathrm{z}$ ions at 55.1 , 67.0, 81.0, 95.0, 97.0 and 110.0. The $110 \mathrm{~m} / \mathrm{z}$ peak corresponds to $\mathrm{M}-18$, and is assigned to the loss of a water molecule from MCHM. The loss of $\mathrm{H}_{2} \mathrm{O}$ from a primary alcohol was fast and thus the molecular ion was not observed in the spectrum. The observed peaks matched the fragmentation mechanism of primary alcohols.

We confirmed the composition by integration of unique peaks in $\mathrm{H}^{1} \mathrm{NMR}$ spectra. 
All MCHM solutions were prepared with millipore filtered water (18 M $\Omega . c m)$ and volumetric glassware.
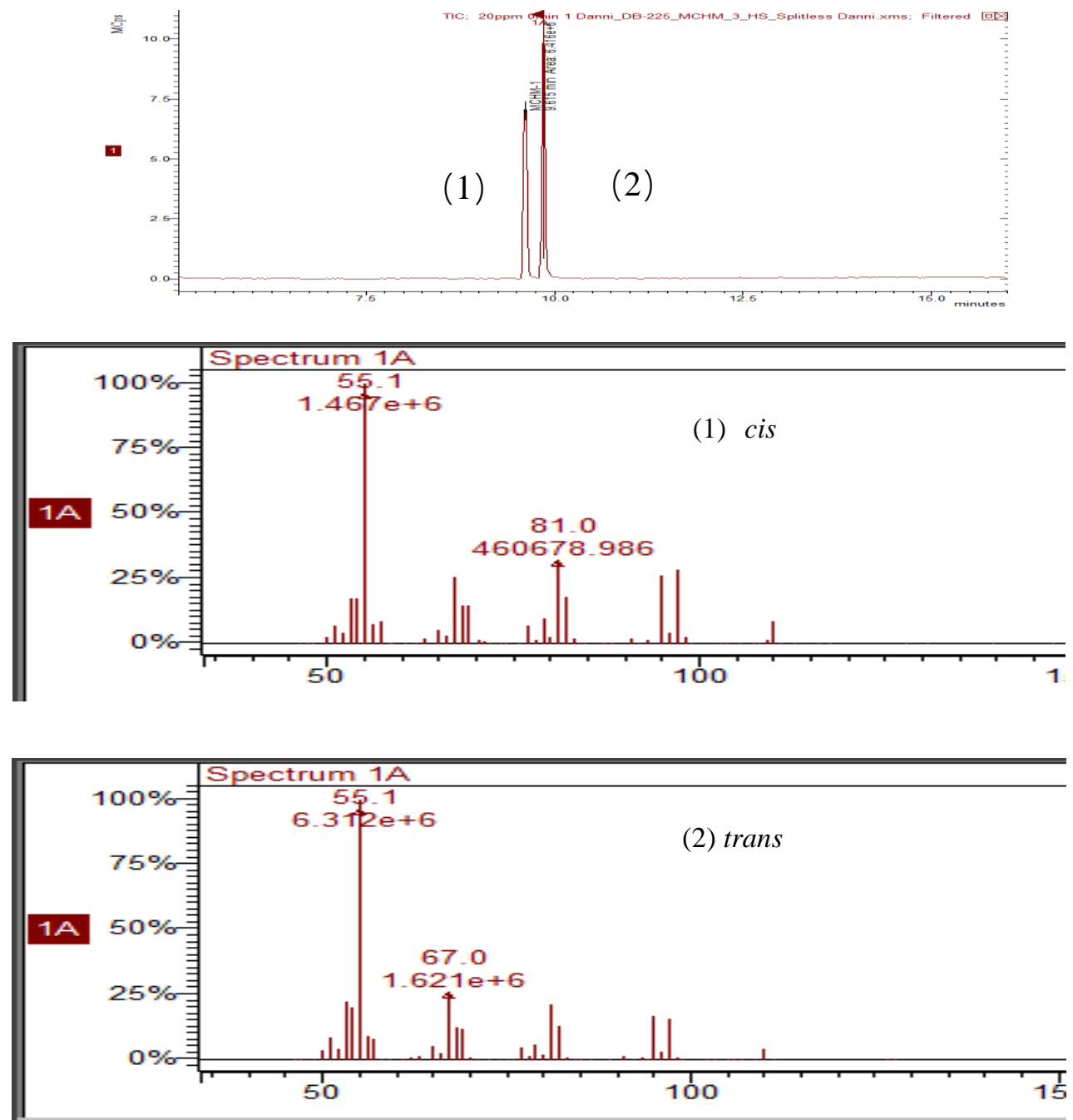

Figure. 2.2 The GC chromatograph of a $20 \mathrm{ppm}$ MCHM solution. (1) The MS spectra of the cis-isomer; (2) The MS spectra of the trans-isomer.

\subsubsection{Analytical Method}

Gas chromatography-mass spectrometry (GC-MS) was chosen to monitor the concentration of MCHM as the quantitative method employing solid phase micro- 
extraction (SPME). Desorption was conducted from a solid micro fiber coated with 100 $\mu \mathrm{m}$ PDMS as the absorbent material. The fiber was pre-heated in the GC for $5 \mathrm{~min}$ to remove any impurities. Extraction of MCHM from the solution was achieved by inserting the clean fiber into the MCHM solution at room temperature for $5 \mathrm{~min}$. After extraction, the fiber was transferred into $\mathrm{GC}$ injection port at $40^{\circ} \mathrm{C}$ for a 5 -min desorption period.

A Bruker Scion $436 \mathrm{GC}$ equipped with a DB-225 $(30 \mathrm{~m} \times 0.25 \mathrm{~mm}, 0.25 \mu \mathrm{m}$ thickness film) column and SQ series mass spectrometer as the detector was employed to monitor MCHM concentration and for product studies. The oven temperature was $40{ }^{\circ} \mathrm{C}$ initially, after $5 \mathrm{~min}$ hold time, the temperature was increased at the rate of $25^{\circ} \mathrm{C} / \mathrm{min}$ to $150{ }^{\circ} \mathrm{C}$ and held for $1 \mathrm{~min}$, then increased to $240{ }^{\circ} \mathrm{C}$ at $25^{\circ} \mathrm{C} / \mathrm{min}$. The carrier gas was helium at the flow rate of $1 \mathrm{~mL} / \mathrm{min}$.

The concentration of MCHM was determined from a carefully constructed calibration curve. Solutions were prepared using volumetric glassware. The MCHM samples used in these studies are a mixture of cis and trans-isomers. Individual calibration plots were developed on the basis of the areas of the well-resolved cis and trans peaks. The calibration curves for the trans-isomer yields a slope of 478667 with $\mathrm{R}^{2}=0.9991$, while the cis-isomer was yield a slope of 343112, with $\mathrm{R}^{2}=0.9944$. Simply multiplying the area from a reactor solution by the slope where $\mathrm{y}$ represented the peak area and $\mathrm{x}$ was the concentration in the unit of $\mu \mathrm{mol} / \mathrm{L}$ (Figure. 2.3). 


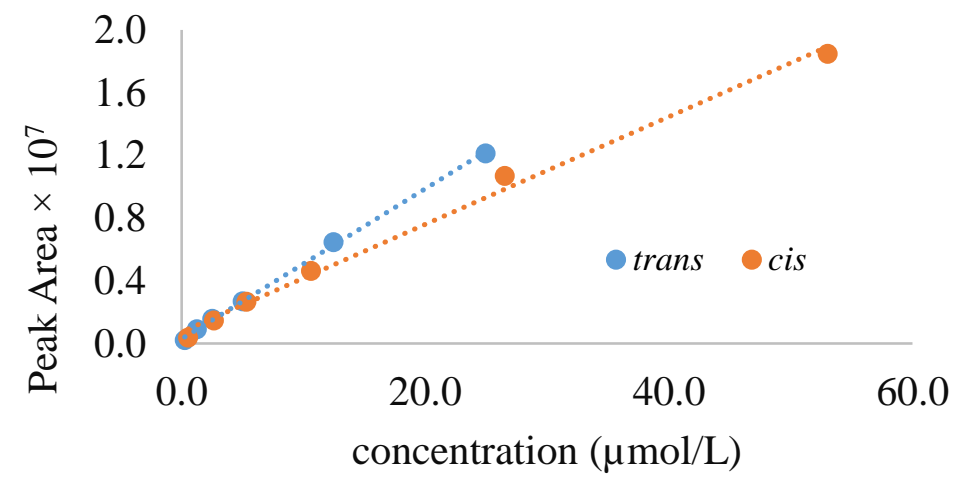

Figure. 2.3 Calibration of trans- and cis- MCHM isomers of GC-MS.

\subsubsection{Ultrasound Reactor}

The ultrasound reactor consisted of an ultrasound generator, a transducer and a 580$\mathrm{mL}$ capacity energy-focusing glass vessel. The ultrasound generator was UES Model 15660, from Ultrasonic Energy System Company of Panama City, Florida. The vessel was placed into a 10 -gallon water bath. The water temperature was maintained at $5-10{ }^{\circ} \mathrm{C}$ using a cooling bath. The aqueous solution containing the target compound was added into the reaction vessel, saturated by gentle bubbling with $\mathrm{O}_{2}$ for $15 \mathrm{~min}$ and applied ultrasound at $396 \mathrm{~W}, 670 \mathrm{kHz}$. Samples were taken at specific treatment intervals to monitor the reaction. Samples were stored in the refrigerator until analyses.

\subsection{Results and Discussions}

\subsubsection{Degradation kinetics and adsorption isotherm study}

The concentration of MCHM (mixture of cis and trans-isomers) was monitored as a function of treatment time over a range of initial concentrations as shown in Figure.2.4. The extent of degradation decreases with the increase in initial MCHM concentrations. 
Within $30 \mathrm{~min}$, greater than $50 \%$ of trans- and cis-isomers were degraded for $\mathrm{C}_{0} \leq 50 \mu \mathrm{M}$. Higher initial concentrations require longer treatment times to reduce the MCHM concentration to less than $50 \%$. The degradation rates and half-lives of the cis and transisomers, summarized in Table 2.1, are similar for similar initial concentrations. The degradation is likely the result of pyrolysis and reactive oxygen species, primarily HO ', which is produced during the cavitation collapse at the gas-liquid interfacial and hot-spot regions.
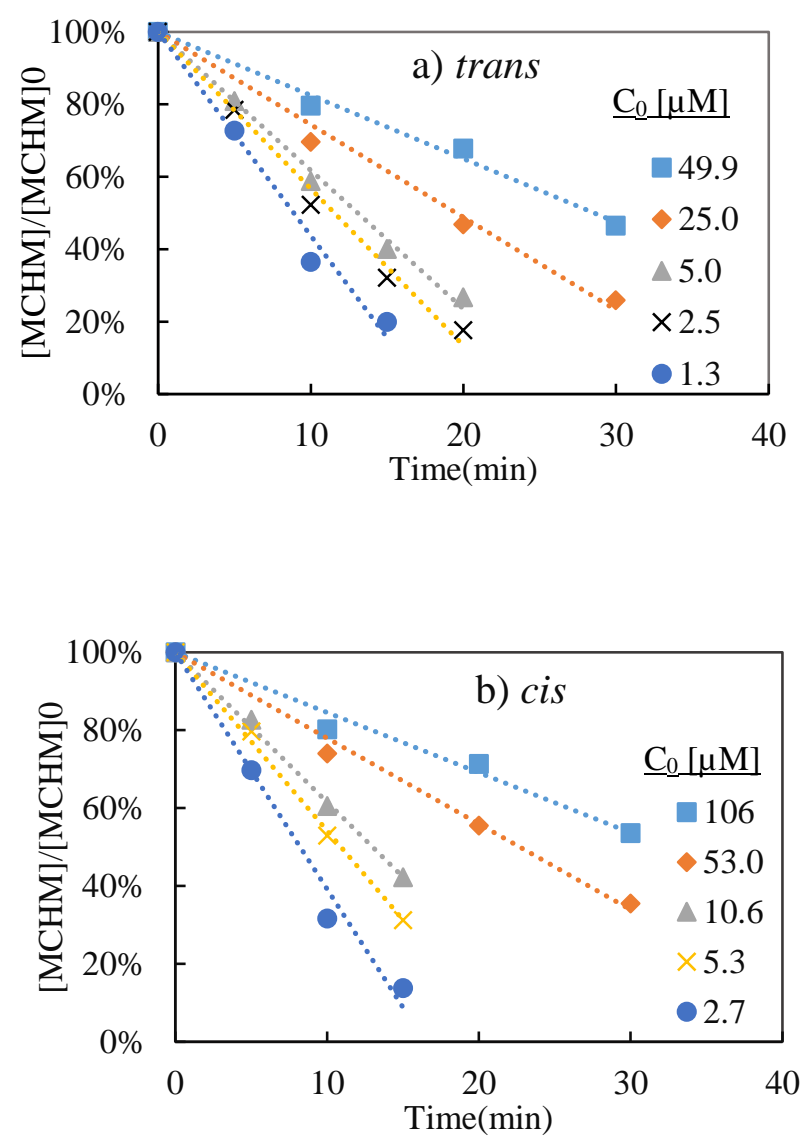

Figure. 2.4 Degradation of different initial concentrations of trans- and cis- MCHM $\left(670 \mathrm{kHz}, 396 \mathrm{~W}, 5{ }^{\circ} \mathrm{C}, \mathrm{O}_{2}\right.$ saturated). 
The degradation of the MCHM isomeric mixture was conducted over a range of initial concentrations from 3.9 to $156.0 \mu \mathrm{mol} / \mathrm{L}$, individually $1.2,2.5,5.0,25.0,49.9$ $\mu \mathrm{mol} / \mathrm{L}$ for trans-MCHM, and 2.7, 5.3, 10.6, 53.0 and $106.1 \mu \mathrm{mol} / \mathrm{L}$ for $c i s-\mathrm{MCHM}$. The concentrations of cis- and trans- MCHM were monitored as a function of treatment time. The ultrasonically induced degradation kinetics of organic compounds at specific concentrations have been reported to exhibit pseudo-first order kinetic behavior (Eq. 2.5). $[67,68]$

Table 2.1 The ultrasonic degradation of MCHM $(670 \mathrm{kHz})$ half-lives and the pseudo-first order rate constants at different initial concentrations. a) The reproducibilities of trans- and cis-MCHM were $\pm 3 \%$ and $\pm 5 \%$ respectively on the basis of triplicate runs.

\begin{tabular}{|c|c|c|c|c|c|}
\hline \multicolumn{3}{|c|}{ trans-MCHM } & \multicolumn{3}{c|}{ cis-MCHM } \\
\hline $\begin{array}{c}\text { Concentration } \\
(\mu \mathrm{M})\end{array}$ & $\begin{array}{c}\mathrm{t}_{1 / 2} \\
(\mathrm{~min})\end{array}$ & $\begin{array}{c}\text { Pseudo-first order } \\
\text { rate constant } \\
\left(\mathrm{min}^{-1}\right)\end{array}$ & $\begin{array}{c}\text { Concentration } \\
(\mu \mathrm{M})\end{array}$ & $\begin{array}{c}\mathrm{t}_{1 / 2} \\
(\mathrm{~min})\end{array}$ & $\begin{array}{c}\text { Pseudo-first order } \\
\text { rate constant } \\
(\mathrm{a}) \\
\left(\mathrm{min}^{-1}\right)\end{array}$ \\
\hline 1.3 & 8.9 & 0.10 & 2.7 & 8.2 & 0.12 \\
\hline 2.5 & 11.6 & 0.08 & 5.3 & 10.9 & 0.08 \\
\hline 5.0 & 13.1 & 0.06 & 10.6 & 13.0 & 0.06 \\
\hline 25.0 & 19.5 & 0.04 & 53.0 & 22.7 & 0.03 \\
\hline 49.9 & 28.6 & 0.02 & 106.0 & 32.5 & 0.02 \\
\hline
\end{tabular}

$-\frac{\mathrm{dC}_{\mathrm{t}}}{\mathrm{dt}}=\mathrm{kc}_{\mathrm{t}} \quad \ln \left(\mathrm{C}_{\mathrm{t}}\right)=\mathrm{kt}+\ln \left(\mathrm{C}_{0}\right) \quad \ln \frac{\left[\mathrm{C}_{\mathrm{t}}\right]}{\left[\mathrm{C}_{0}\right]}=-\mathrm{kt}$

Eq. 2.5

The MCHM degradation profiles were fit to pseudo-first order kinetics by plotting $\ln \frac{\left[\mathrm{C}_{\mathrm{t}}\right]}{\left[\mathrm{C}_{0}\right]}$ as a function of treatment time. Where $\mathrm{C}_{0}$ is the initial concentration and $\mathrm{C}_{\mathrm{t}}$ is the concentration at time t. From the pseudo-first plots, the rate constants were obtained and summarized in Table 2.1. The degradation profiles of cis- and trans-MCHM yield excellent 
linear fits to pseudo-first order kinetic models at each individual concentration, however the rate constants decreased 5 to 6 times with a 50 -fold increase in initial concentration. Such changes in rate constants as a function of concentration are inconsistent with a true pseudo-first order process, which has been observed for a variety of heterogeneous processes $[69,70]$. Such kinetic anomalies have been attributed to mass transfer limitations at interface during cavitation (reaction zone) and saturation effects [71]. The target compound residing at or near the interface can react with reactive oxygen species, primarily 'OH radicals or undergo pyrolysis. Under the uniform conditions employed in the reported experiments the production of hydroxyl radicals and the volume of the reactive surface leading to pyrolytic degradation will be the constant and the limiting factors in the degradation. Thus, as the concentration of the target compound increases the extent of degradation decreased.

To better understand the degradation kinetics, heterogeneous models were applied to simulate the degradation with the liquid-gas interface serving as the reactive surface where the reactions of target compound with reactive radical species can lead to the extensive degradation. At the gas-liquid interface, water exists in a supercritical state (supercritical water has $648 \mathrm{~K}$ and $218 \mathrm{~atm}$ ) [72], and exhibits hydrophobic properties. The supercritical fluid layer (SCF-L) or gas-liquid interface is thus modeled as a reactive surface where partitioning of the target compound and generation of radicals and high temperatures can lead to the extensive degradation [73]. To probe the partitioning of hydrophobic MCHM to the SCF interfacial region from the polar bulk aqueous solution [63], standard kinetic models for heterogeneous processes, Langmuir-Hinshelwood (L-H) and Freundlich isotherms were applied. L-H and Freundlich models have been applied for 
an extensive number of heterogeneous processes including a limited number applied to ultrasonic degradation $[43,74-76]$. The partitioning of MCHM molecules to the gas-liquid interface can be considered an equilibrium adsorption process, where this reactive zone results in degradation because of high temperatures and reactive species namely $\mathrm{HO} \cdot[77]$. Okitsu et al. reported the Langmuir-Hinshelwood isotherm (Eq. 2.6) was effectively applied to the kinetics for the ultrasound induced degradation of several organic pollutants. $[43,77,78]$ The effective modeling of the experimental data by L-H is consistent with the gas-liquid interface (reactive zone) acting as an adsorption layer critical to ultrasound degradation process [79,80]. The L-H kinetic model includes four assumptions: (1) all sites on the adsorption zone are equivalent (2) each site is occupied by one molecule with a uniform monolayer (Figure.2.5 (a)) (3) the molecules have no interactions with adjacent sites (4) the adsorption and desorption process is in an equilibrium [76,81].

$$
\text { Langmuir-Hinshelwood equation } \frac{1}{r_{0}}=\frac{1}{k_{r} K C_{0}}+\frac{1}{k_{r}}
$$

where $\mathrm{r}_{0}\left(\mu \mathrm{M} \cdot \mathrm{min}^{-1}\right)$ is the initial rate, $\mathrm{C}_{0}(\mu \mathrm{M})$ is the initial concentration, $\mathrm{k}_{\mathrm{r}}(\mu \mathrm{M} /$ $\min )$ is the reactivity constant and $\mathrm{K}(1 / \mu \mathrm{M})$ is the equilibrium constant.

(a)

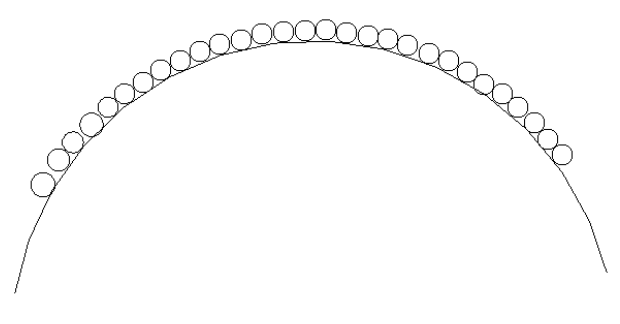

(b)

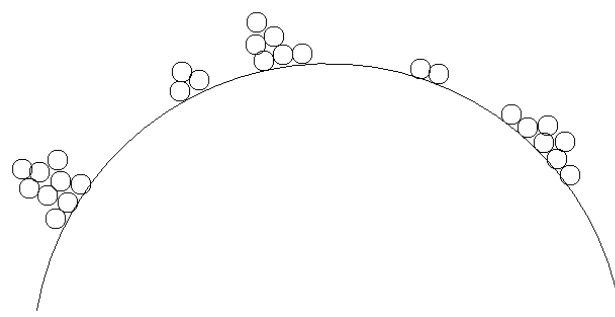

Figure. 2.5 MCHM molecules partitioning on the gas-liquid interface following (a) Langmuir-Hinshelwood Model (b) Freundlich Model 
The degradations of the MCHM mixture were performed over a range of concentrations 1.3 to $49.9 \mu \mathrm{M}$ of trans- isomer and 2.7 to $106.0 \mu \mathrm{M}$ of cis- isomer. The resulting kinetic data were used to construct the $\mathrm{L}-\mathrm{H}$ plot $\left(1 / \mathrm{r}_{0} \mathrm{vs} 1 / \mathrm{c}_{0}\right)$ (Figure. 2.6). The $\mathrm{L}-\mathrm{H}$ parameters, $\mathrm{K}$ and $\mathrm{k}_{\mathrm{r}}$ were determined from the intercept and slope of the L-H plot. The reactivity constants, $\mathrm{k}_{\mathrm{r}}$, were 0.72 for the trans and $1.23 \mu \mathrm{M} \cdot \mathrm{min}^{-1}$ for the cis, while the equilibrium constants $\mathrm{K}$ were 0.08 and $0.05 \mu \mathrm{M}^{-1}$ respectively. The equilibrium constant, $\mathrm{K}$, can be assigned to surface partitioning of MCHM at the interface and $\mathrm{k}_{\mathrm{r}}$ is a coefficient related to the reactivity of the target compound (susceptibility of MCHM to degradation) [82]. The results suggest that the trans-isomer may exhibit greater partitioning to the interface while the cis-isomer exhibits higher reactivity at the gas-liquid interfacial region. Trans-isomers are often less polar as individual molecular bond dipole moments can partially cancel while in the cis-isomers they can be additive. Less polar molecules, those with smaller overall dipole moments can partition to a greater extent to the less-polar SC interface. L-H model assumes uniform partitioning at the reactive zone (liquid-gas interface). Modest deviation from linearity of L-H plot is observed at the highest concentration which may be a result of MCHM saturation at the interface. 

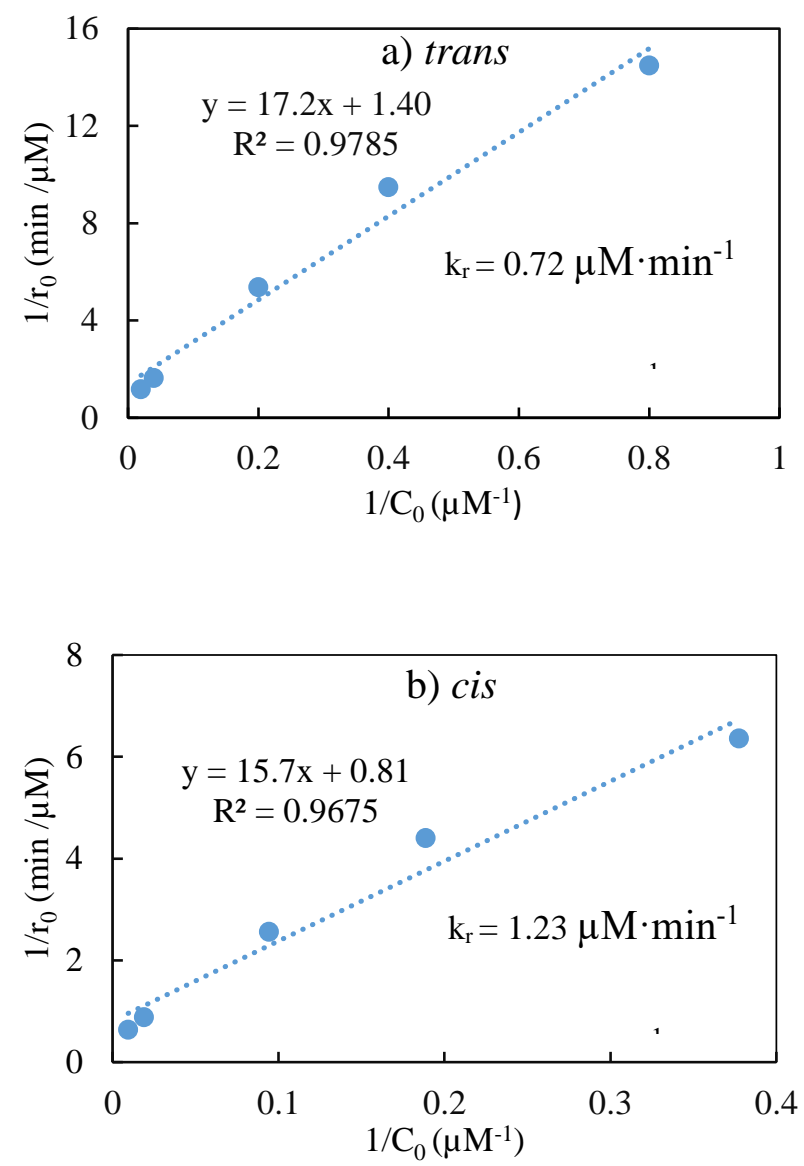

Figure. 2.6 Langmuir-Hinshelwood degradation isotherms of trans- and cisMCHM in aqueous media under ultrasonic irradiation $\left(670 \mathrm{kHz}, 396 \mathrm{~W}, 5^{\circ} \mathrm{C}, \mathrm{O}_{2}\right.$ saturated $)$.

To consider non-uniform partitioning, the Freundlich model (Eq.2.7) was employed over a wide range of concentrations. We applied the Freundlich model to assess the nonuniformity in distribution of MCHM in the reactive zone [83]. The Freundlich isotherm describes the adsorbent/adsorbate ratio $\left(\mathrm{q}_{\mathrm{e}}\right)$ as the function of the concentration at equilibrium, which can also represent the partitioning or disappearance of the adsorbent from the bulk solution. Cavitation bubble size is related to the applied frequency [84], therefore, the interface area and volume should remain relatively constant since the same frequency and experimental conditions were employed for the studies reported herein. The 
amounts of molecules partitioning to the interface change with the initial concentration, and thus the degradation rate $\mathrm{r}_{0}$ replaces $\mathrm{q}_{\mathrm{e}}$.

The Freundlich Isotherm: $\quad \log \mathrm{r}_{0}=\frac{1}{\mathrm{n}} \log \mathrm{C}_{0}+\log \mathrm{K}_{\mathrm{f}} \quad$ Eq. 2.7 where $\mathrm{r}_{0}(\mu \mathrm{M} / \mathrm{min})$ is the initial rate, $\mathrm{n}$ is a factor related to the reactivity, $\mathrm{C}_{0}(\mu \mathrm{M})$ is the initial concentration, and $\mathrm{K}_{\mathrm{f}}(\mu \mathrm{M})$ is the adsorption capacity.

The Freundlich adsorption isotherm (Eq.2.7) for cis- and trans-isomers are illustrated in Figure.2.7 with $\mathrm{R}^{2}>0.99$. The factor $\mathrm{n}$, indicating the adsorption intensity obtained from the plots were 1.42 and 1.56 , and the adsorption capacity $\mathrm{K}_{\mathrm{f}}$ values were 0.058 and 0.083 for cis and trans- isomers respectively [83]. The results show that the cisisomer has lower adsorption or partitioning capacity to the reactive zone than the transisomer. The superior fit of the observed data to the Freundlich model indicates the adsorption or partitioning isotherm possesses non-uniformity in comparison to the L-H model which assume of uniform partitioning (Figure.2.5 (b)). This observation is consistent with the properties of SCF where non-uniform distribution of solutes is reported, specifically referred to as solute-solute or solute-solvent clustering, a phenomenon unique to supercritical conditions [81]. For the case of MCHM at the SC interface it is reasonable to invision the individual MCHM molecules with primarily hydrocarbon character can have stronger Van der Waals interactions with other MCHM molecules than the water molecules composing the solvent thus leading to small clusters of MCHM molecules and higher local densities of MCHM molecules at the SC region. 

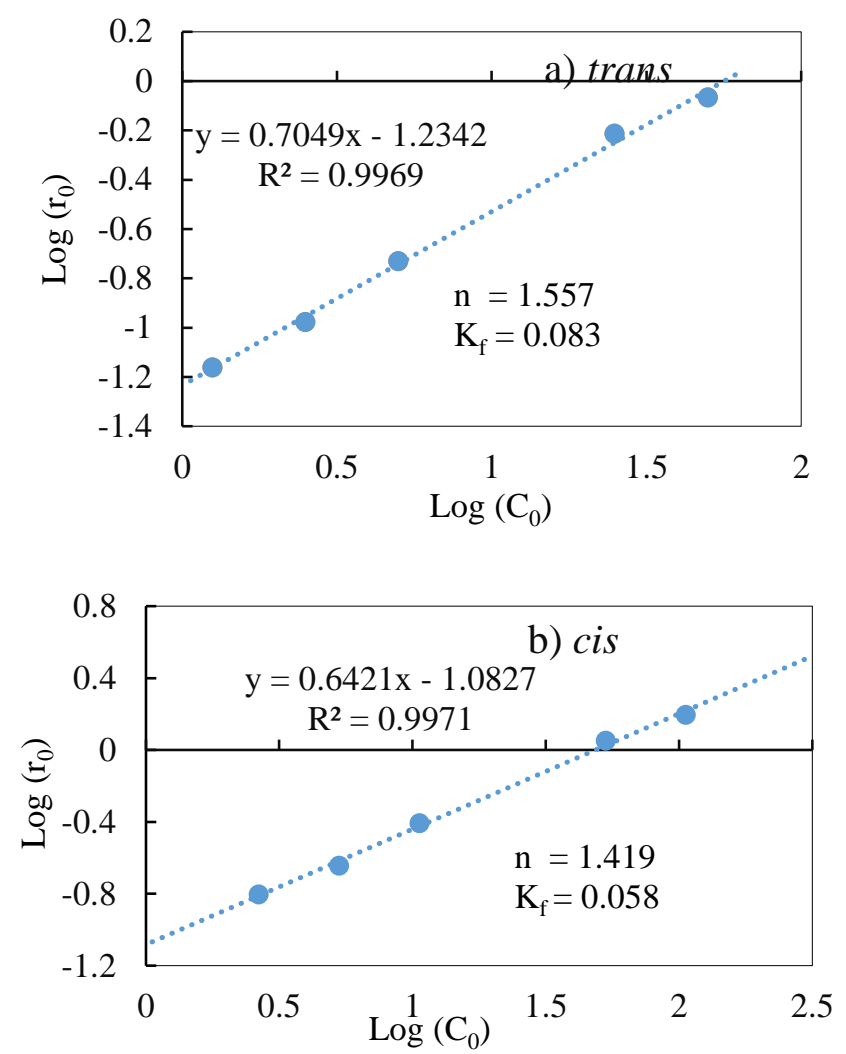

Figure. 2.7 Freundlich degradation isotherms of trans- and cis-MCHM in aqueous media under ultrasonic irradiation $\left(670 \mathrm{kHz}, 396 \mathrm{~W}, 5^{\circ} \mathrm{C}, \mathrm{O}_{2}\right.$ saturated $)$.

\subsubsection{Degradation Product Study}

Although MCHM is readily degraded by ultrasonic treatment, it is also important to conduct product studies to understand better the reaction pathways involved in the degradation. The GC-MS analyses employing SPME techniques were used to conduct product studies for the ultrasonic degradation of MCHM. The cis- and trans- isomers have GC retention times of 9.62 and $9.85 \mathrm{~min}$, respectively. After ultrasound treatment, two predominant GC peaks were observed with retention times of 8.80 and $9.01 \mathrm{~min}$ (Figure.2.8) 

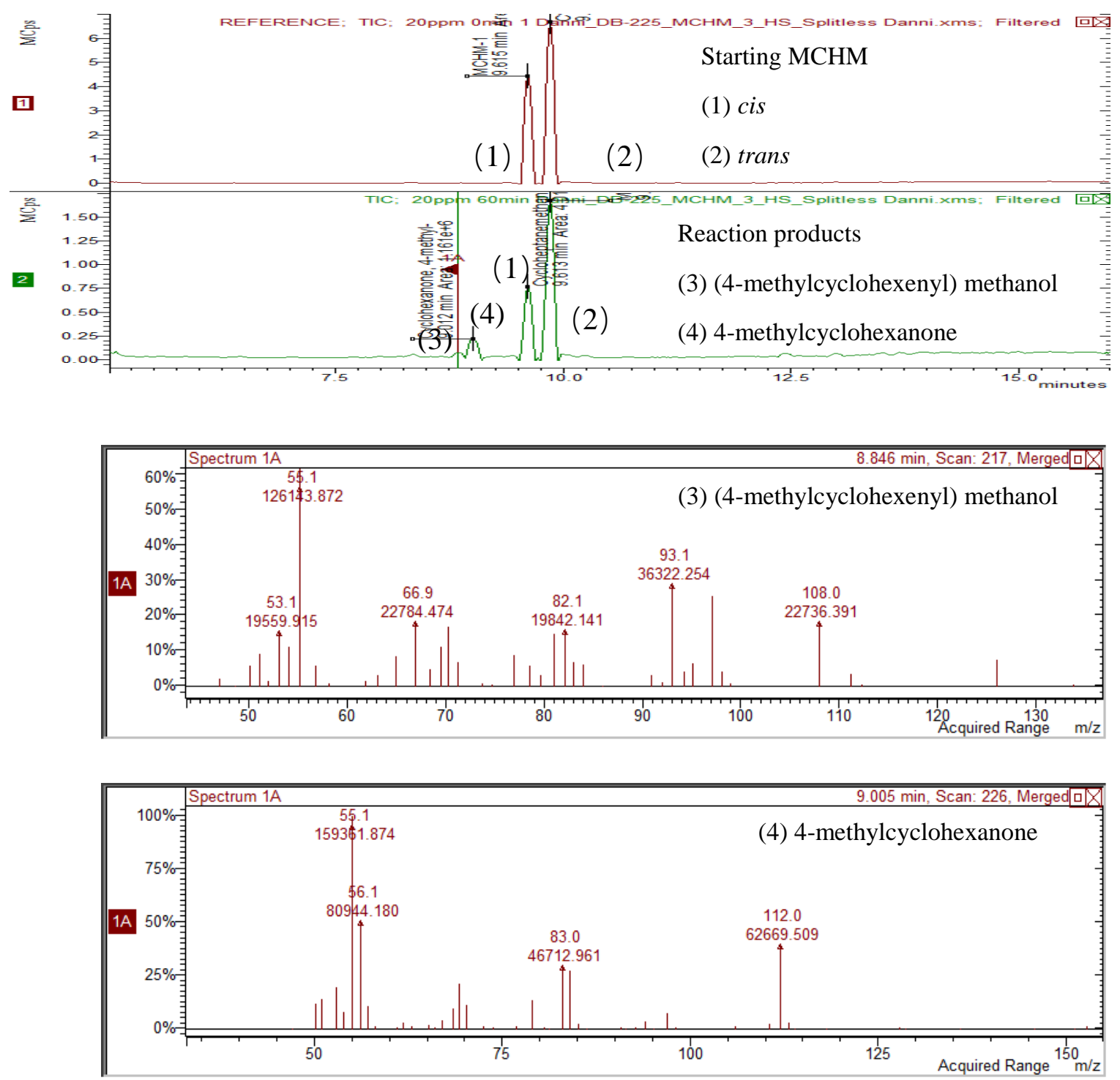

Figure. 2.8 The GC chromatograms of the starting MCHM and the reaction products and mass spectra of primary products (3) and (4).

The chromatographic peak at 8.80 min has parent ion with the mass to charge ratio $(\mathrm{m} / \mathrm{z})$ of 126 which was on the basis of library match and fragmentation pattern has been assigned as 4-methylcyclohexenylmethanol. While 4-methylcyclohexanecarbaldehyde also has $\mathrm{m} / \mathrm{z}=126$, and is a possible product of the oxidation of MCHM, careful analysis and the absence of M-29 and/or M-30 indicates the observed product does not contain an 
aldehyde functional group. The compound with a retention time of 9.01 min yields a $\mathrm{m} / \mathrm{z}$ of 112 which after careful analysis of fragmentation pattern is assigned as 4methylcyclohexanone (Figure. 2.9).

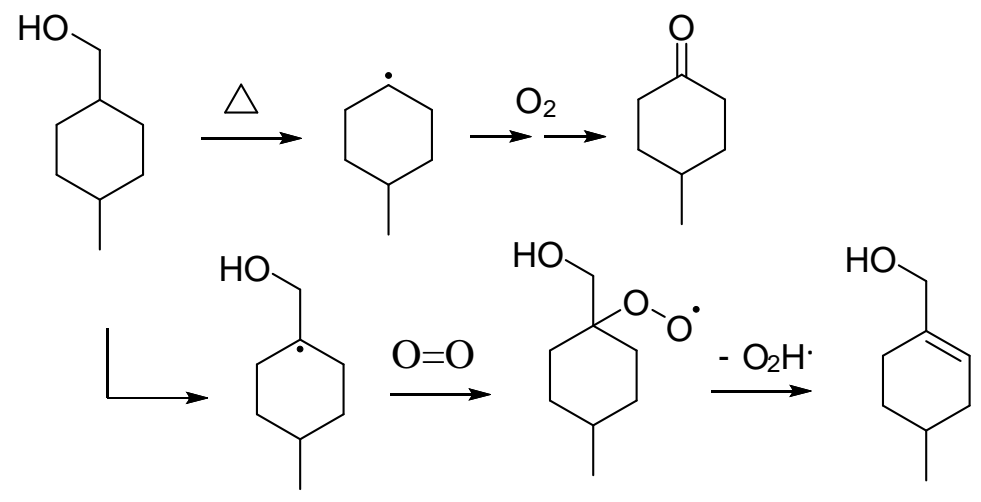

Figure. 2.9 Degradation products 4-methylcyclohexanone (1) and 4-methylcyclohexenylmethanol (2) from ultrasonic treatment of MCHM $\left(670 \mathrm{kHz}, 396 \mathrm{~W}, 5{ }^{\circ} \mathrm{C}, \mathrm{O}_{2}\right.$ saturated).

\subsubsection{Computational Study}

Ultrasonically induced degradation of MCHM can occur by hydroxyl radical mediated oxidation and pyrolysis. Density function theory (DFT) is a powerful tool in predicting geometries and energy barriers $[85,86]$. To assess the individual degradation pathways for MCHM, we have employed computational methods employing the DFTB3LYP method with the $6-311 \mathrm{G}^{* *}$ basis set, using Gaussian 09 program $[87,88]$. The cisand trans-isomers can populate two cyclohexane chair conformations, illustrated in Eqs. 2.8 and 2.9. 


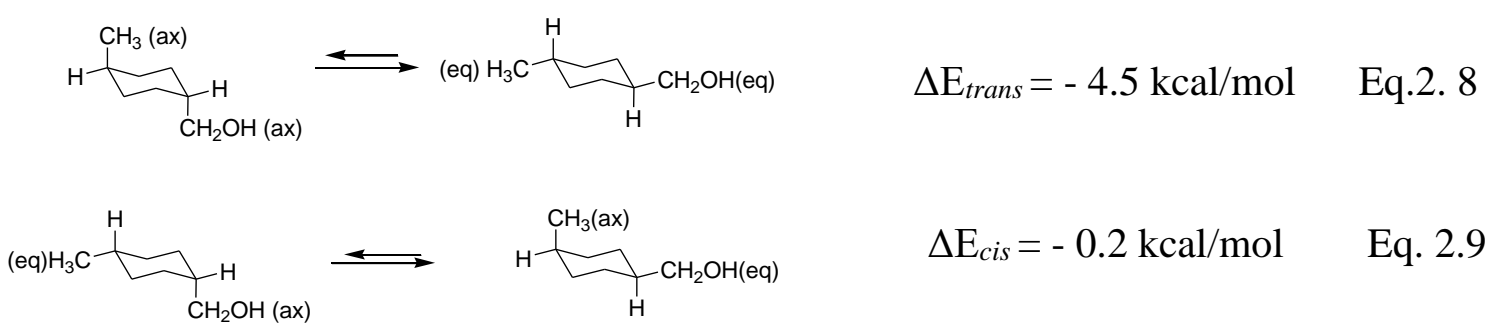

The reactivities of the cyclohexane hydrogens is dependent on residence at axial or equatorial positions. With this in mind, the energies of different chair conformers for the cis- and trans-isomers were calculated. The two stable chair conformers of trans-isomer include one with a significantly higher energy in which both substituents, $\mathrm{CH}_{3}$ and $\mathrm{CH}_{2} \mathrm{OH}$ occupy axial positions. In the lower energy conformation, both substituents occupy equatorial positions. For the cis-isomer, the two stable staggered conformers are similar in energy with each having one axial and one equatorial substituent. The percentage (ratio) of the higher energy conformer was calculated using the enthalpy difference, from $\Delta \mathrm{E}$ given in Eqs.2.8 and 2.9. The results calculated using Eq. 2.10 are summarized in Table 2. 2.

$$
\Delta \mathrm{E}=\Delta \mathrm{H} \approx \Delta \mathrm{G}, \Delta \mathrm{G}=-\mathrm{RT} \ln \mathrm{K}
$$

where $\Delta \mathrm{E}(\mathrm{kcal} / \mathrm{mol})$ is the relative energy, $\mathrm{R}$ (the gas constant $)=0.001987 \mathrm{kcal} /$ $(\mathrm{mol} \cdot \mathrm{K}), \mathrm{T}(\mathrm{K})$ is the phase temperature.

The energy difference between two trans-isomer chair conformations is 4.5 $\mathrm{kcal} / \mathrm{mol}$, while the energy between $c i s$-isomer chair conformations is $0.2 \mathrm{kcal} / \mathrm{mol}$, Eq. 2.8 and 2.9.

The temperatures and pressures generated during cavitation vary depending on the reaction conditions, including solvent, saturating gas, and irradiating frequency. For the purpose of the studies herein specific temperatures were selected for the three cavitation regions on the basis of literature reports: bulk solution $\left(283^{\circ} \mathrm{K}\right)$, gas-liquid interface $(\sim$ 
$\left.2000{ }^{\circ} \mathrm{K}\right)$ and hot spot $\left(\sim 5000{ }^{\circ} \mathrm{K}\right)[47,61]$. The percentages of the different chair conformers calculated at these temperatures are summarized in Table 2.2. The fraction of the less stable isomer increases with temperature due to the rapid interconversion of the two chair conformations thus the hydrogen susceptible to hydroxyl radical attack (abstraction) can occur axial or equatorial. For the trans-isomer, there is a large energy difference between chair conformations, thus one conformer is predominant throughout the temperature range employed herein. For the cis-isomer, the $\Delta \mathrm{E}$ is small and thus for the cis-isomer the two conformations are similarly populated throughout the temperature range.

Table 2.2 Composition of chair conformers under different temperatures. (According to the equation, $\Delta \mathrm{E}=\Delta \mathrm{H} \approx \Delta \mathrm{G}, \Delta \mathrm{G}=-\mathrm{RT} \operatorname{lnK}$, where $\Delta \mathrm{E}(\mathrm{kcal} / \mathrm{mol})$ is the relative energy, $R$ (the gas constant) $=0.001987 \mathrm{kcal} /(\mathrm{mol} \cdot \mathrm{K}), \mathrm{T}(\mathrm{K})$ is the phase temperature, (a) bulk solution, (b) interfacial region, (c) hot spot.)

\begin{tabular}{|c|c|c|c|c|}
\hline \multirow{2}{*}{ MCHM } & \multirow{2}{*}{$\begin{array}{c}\text { Energy difference } \\
(\mathrm{kcal} / \mathrm{mol})\end{array}$} & \multicolumn{3}{|c|}{ Isomer content (\%) } \\
\cline { 3 - 5 } & & $283^{\circ} \mathrm{K}(\mathrm{a})$ & $2000^{\circ} \mathrm{K}(\mathrm{b})$ & $5000^{\circ} \mathrm{K}(\mathrm{c})$ \\
\hline trans- & 4.5 & 0.03 & 24.13 & 38.74 \\
\hline trans-eq-eq $^{2}$ & & 99.97 & 75.87 & 61.26 \\
\hline cis-ax-eq $^{1}$ & 0.2 & 41.71 & 48.82 & 49.53 \\
\hline cis-eq-ax $^{2}$ & & 58.29 & 51.18 & 50.47 \\
\cline { 3 - 5 } & & & &
\end{tabular}

1.Higher energy chair conformation; 2. Lower energy chair conformation.

The homolytic bond dissociation energies for the hydrogens in the cis- and transisomers were also calculated using G-311** basis set for each MCHM hydrogen atom to represent the $\mathrm{HO} \cdot$ radical abstraction degradation pathways for respective conformers. The low dissociation energies correspond to high probability hydrogen abstraction degradation products. Among the 16 hydrogens in MCHM, 15 are bonded to $\mathrm{sp}^{3}$ hybridized carbon atoms and one hydrogen to an $\mathrm{sp}^{3}$ hybridized oxygen atom. The $\mathrm{O}-\mathrm{H}$ bond is the 
strongest and least likely to undergo an abstraction reaction. The homolytic $\mathrm{C}-\mathrm{H}$ dissociation energies calculated for the $\mathrm{Csp}^{3}-\mathrm{H}$ bonds in MCHM are summarized in Table 2.3, along with the numbering of each hydrogen by position. On the basis of the computational results, abstraction of $\mathrm{H}_{2}$, and $\mathrm{H}_{3}$ and $\mathrm{H}_{8}$ require the least energy and thus are the most (reactive) likely hydrogens to be abstracted. The probability for the reaction to occur at one of these most reactive hydrogens is $>95 \%$. We assumed that entropic factors in all considered channels are similar and hence the differences in Gibbs free energies $\Delta \mathrm{G}$ were approximately taken to be equal to the differences in enthalpies $\Delta \mathrm{H}$.

Table 2.3 Homolytic C-H bond dissociation energies (model for HO- abstraction pathway) in the unit of kcal/mol of trans- and cis- lower energy conformation.

\begin{tabular}{|c|c|c|c|c|c|c|c|c|c|}
\hline \multicolumn{2}{|c|}{$\begin{array}{c}\text { Hydrogen } \\
\text { Number }\end{array}$} & $\mathrm{H}_{2}$ & $\mathrm{H}_{3}$ & $\mathrm{H}_{4}$ & $\mathrm{H}_{5}$ & $\mathrm{H}_{6}$ & $\mathrm{H}_{7}$ & $\mathrm{H}_{8}$ & $\mathrm{H}_{9}$ \\
\hline $\begin{array}{c}\text { Dissociation } \\
\text { Energy } \\
(\mathrm{kcal} / \mathrm{mol})\end{array}$ & trans & 90.0 & 94.0 & 94.1 & 94.2 & 94.2 & 94.2 & 91.2 & 97.8 \\
\cline { 2 - 10 } & 90.0 & 92.0 & 94.4 & 93.7 & 94.1 & 93.7 & 88.8 & 96.5 \\
\hline
\end{tabular}

To simulate the HO- radical mediated hydrogen abstraction in bulk solution at a temperature of $283^{\circ} \mathrm{K}$, rate constants were calculated from the equation $\mathrm{k}=\mathrm{A} e^{-\frac{E}{R T}}$ (the pre-exponential Arrhenius factor is assumed to be constant) [89]. Table 2.2 indicates the ratio of the two conformers for the cis- and trans-isomers at $283 \mathrm{~K}$. Under the conditions the most stable conformation of trans-isomer of MCHM accounts for $99.97 \%$ with only 
$0.03 \%$ in higher energy conformer, while lower energy conformer of the cis-isomer accounts for $58.29 \%$ with the higher energy conformer populated at $41.71 \%$. The calculation of the reactivities of these hydrogens in the cis- and trans- isomer including the proportion of each conformer are summarized in Table 2.4.

Table 2.4 The most reactive hydrogens towards $\cdot \mathrm{OH}$ abstraction for different isomers and conformations based on relative homolytic dissociation energies in $\mathrm{kcal} / \mathrm{mol}$.

\begin{tabular}{|c|c|c|c|}
\hline $\mathrm{T}=283 \mathrm{~K}$ & $\mathrm{H}_{8}$ & $\mathrm{H}_{3}$ & $\mathrm{H}_{2}$ \\
\hline trans-eq-eq & $5.72 \%$ & $0.04 \%$ & $94.00 \%$ \\
\hline trans-ax-ax & $0.02 \%$ & $0.00 \%$ & $0.00 \%$ \\
\hline total trans-(ax-ax+eq-eq) & $5.74 \%$ & $0.04 \%$ & $94.00 \%$ \\
\hline cis-eq-ax & $47.50 \%$ & $0.15 \%$ & $10.61 \%$ \\
\hline cis-ax-eq & $1.20 \%$ & $5.64 \%$ & $34.81 \%$ \\
\hline total cis-(eq-ax+ax-eq) & $48.70 \%$ & $5.79 \%$ & $45.42 \%$ \\
\hline
\end{tabular}

The results indicated that at $283 \mathrm{~K}, 94.00 \%$ hydrogen abstraction on trans-MCHM conformer occurs on $\mathrm{H}_{2}$, and $5.74 \%$ occurs on $\mathrm{H}_{8}$ and all other hydrogens account for less than $0.5 \%$ of the reaction pathways. For the cis-isomer under these conditions, $48.70 \%$ of the abstraction occurs on $\mathrm{H}_{8}$, a tertiary hydrogen, $45.42 \%$ on $\mathrm{H}_{2}$ and $5.79 \%$ on $\mathrm{H}_{3}$. Computational results indicate reactions at the remaining hydrogens are insignificant $(<$ $0.5 \%$ ). Generally, tertiary hydrogens are more reactive than primary hydrogens. The $\mathrm{H}_{2}$ atoms although $1^{\circ}$, are alpha to powerful electron withdrawing oxygen atom which inductively weakens the $\mathrm{C}-\mathrm{H}$ bond making them more susceptible to hydrogen abstraction. Once abstraction occurs the resulting radical is stabilized by a resonance effect of the lone pairs of electrons on the adjacent oxygen atom. The oxygen atom has kinetic and thermodynamic effects on hydrogen abstraction. The other hydrogens, $1^{\circ}$ or $2^{\circ}$ and without an adjacent oxygen atom, are much less reactive. 
In addition to the hydrogen abstraction degradation pathways, high temperatures produced during the cavitational collapse lead to pyrolytic degradation of organic compounds during ultrasonic irradiation. Pyrolysis generally occurs by homolytic cleavage and decreases with increasing bond strengths from least to most reactive $\mathrm{H}-\mathrm{O}<\mathrm{C}-\mathrm{O}<\mathrm{C}$ $\mathrm{H}<\mathrm{C}-\mathrm{C}$. Electronic effects from the oxygen atom and substitution patterns $\left(1^{\circ}, 2^{\circ}, 3^{\circ}\right)$ can have a pronounced influence on the bond strengths and susceptibility towards pyrolysis. Homolysis of the weaker $\mathrm{C}-\mathrm{C}$ bonds is expected to be predominant from pyrolysis pathways induced by ultrasound treatment (extreme temperatures). Homolytic cleavage results in carbon centered radicals which can undergo subsequent unimolecular fragmentation.

The energy differences between starting material and products were calculated to determine the probability of pyrolytic bond cleavage of the different C-C bonds in MCHM. The results establish the most probable pyrolytic pathways process with energies 73.9 $\mathrm{kcal} / \mathrm{mol}$ leads to methyl-cyclohexane radical and methanol radical (Pathway A in Figure. 2.10) during the pyrolysis for trans- and cis- MCHM. The formation of cyclohexane methanol and methyl radicals, another probable pyrolytic pathway, requires higher energies, 79.0 and $76.7 \mathrm{kcal} / \mathrm{mol}$ for trans- and cis- isomers respectively (Pathway B in Figure. 2.10). On the basis of the energy differences, $78.01 \%$ of trans-MCHM and $67.00 \%$ of cisMCHM are calculated to form methyl-cyclohexane radical and methanol radical (Pathway A) at $2000 \mathrm{~K}$ (gas-liquid interface), and $62.40 \%$ of trans-MCHM and $57.03 \%$ of cisMCHM at 5000K (hot spot). The methyl-cyclohexane radical can readily form the observed product 4-methyl-cyclohexanone in the presence of oxygen. 
The initial C-C homolytic bond cleavage results in the formation of carbon centered radicals, which can spontaneously undergo beta scission (a secondary $\mathrm{C}-\mathrm{C}$ bond cleavage) as shown in Figure.2.10 [90]. The most energetically favorable products produced from the beta (secondary) C-C bond cleavage are 1-butene radical and propylene (Eq.2.11 in Figure. 2.10). 1,5-hexadiene and methyl radicals will be formed in a less favorable competing pathway (Eq.2.12 in Figure.2.10). These competing reaction pathways depend on transition state (TS) energies and the different substitution on the cyclohexane ring. The computational results indicate the two most favorable pathways yield 1-butene radical (Eq. 2.11) and 1, 5-hexadiene (Eq. 2.14). Propylene is unique for Pathway 1 while 2-propen-1ol is a unique product of Pathway 2.

On the basis of the calculated energies of the formation of the products, 33.8 $\mathrm{kcal} / \mathrm{mol}$ is required to form 1-butene radical and propylene (Eq. 2.11) and $38.8 \mathrm{kcal} / \mathrm{mol}$ to form 1,5-hexadiene and methyl radical (Eq. 2.12) from methyl-cyclohexane radical in Pathway A. Therefore, formation of 1-butene radical and propylene is the more favorable reaction pathway from methyl-cyclohexane radical. In Pathway $\mathrm{B}, 35.8 \mathrm{kcal} / \mathrm{mol}$ is required to produce 1-butene radical and 3-propenol (Eq.2.13) while $33.7 \mathrm{kcal} / \mathrm{mol}$ to form 1, 5-hexadiene and methanol radical from cyclohexane methanol radical (Eq.2.14). The low molecular weight hydrocarbons were not detected as they can undergo combustion under the reaction conditions and thus their detection is not plausible. 


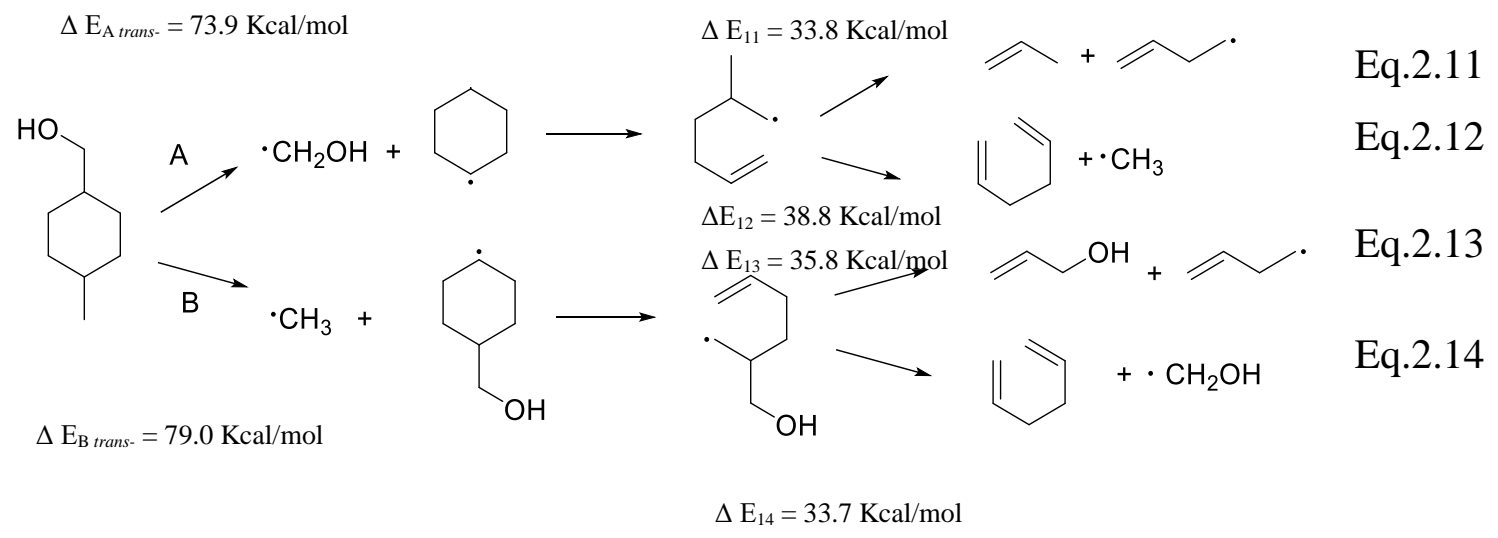

Figure. 2.10 Energetically favored MCHM C-C homolytic bond pyrolytic pathways on the basis of Gaussian 09 computations.

\subsection{Conclusions}

The ultrasonic treatment of the isomeric mixture of MCHM leads to rapid and extensive degradation by hydroxyl radical and pyrolytic processes. The degradation is accurately modeled by pseudo-first order kinetics. Within $30 \mathrm{~min}$, more than $50 \%$ of both trans- and cis- MCHM is decomposed when the initial concentration was up to $\sim 100$ $\mu \mathrm{mol} / \mathrm{L}$. The observed primary products, (4-methylcyclohexenyl) methanol and 4methylcyclohexanone, are consistent with hydroxyl radical mediated and pyrolytic reaction pathways.

On the basis of excellent modeling of the experimental data over a range of concentrations using the heterogeneous Freundlich model it appears the degradation process occurs predominantly at the gas-liquid interface and involves non-uniform distribution of MCHM within this reactive indicative of solute-solute type clustering supercritical region. 
Computational studies provide support and insight about the energetics and partitioning of competing reaction processes. The most favorable pyrolytic products are 1,5-hexadiene and methanol, other products such as 1-butene, 3-propenol, propylene and methane may also be produced during the pyrolysis but likely undergo combustion. The obtained results also suggest application of kinetic models can likely be extended for predicting ultrasonic treatment of a variety of hydrocarbon pollutants. 
Chapter 3 Fundamental study of the ultrasonic induced degradation of the popular antihistamine, diphenhydramine (DPH) 


\subsection{Abstract}

Diphenhydramine (DPH) the active ingredient in Benadryl ${ }^{\circledR}$, has been detected in streams, rivers and other surface water sources. As a bioactive compound, DPH impacts human health even at low concentrations. Ultrasonic irradiation at $640 \mathrm{kHz}$ leads to the rapid degradation of DPH in aqueous solution. Radical scavenging experiments and detailed product studies indicate the DPH degradation involves direct pyrolysis and degradation reactions mediated by the hydroxyl radicals produced during cavitation. The degradation can be modeled by pseudo-first order kinetics yielding rate constants $\mathrm{k}$ of $0.210,0.130,0.082,0.050,0.035,0.023 \mathrm{~min}^{-1}$ at the initial concentrations of 2.8, 5.2, 13.9, 27.0, 61.0, $160.0 \mu \mathrm{mol} \cdot \mathrm{L}^{-1}$, respectively. The degradation process follows the LangmuirHinshelwood (heterogeneous) model with a partition coefficient, $\mathrm{K}_{\mathrm{L}-\mathrm{H}}=0.06 \mu \mathrm{mol} \cdot \mathrm{L}^{-1}$ and reactivity constant $\mathrm{k}_{\mathrm{r}}=1.96 \mu \mathrm{mol} \cdot \mathrm{min}^{-1} \cdot \mathrm{L}^{-1}$. A competition kinetic study conducted employing the hydroxyl radical trap, coumarin, illustrates that DPH was degraded primarily by hydroxyl radical mediated processes. Computational studies employing Gaussian 09 basis set provide fundamental insight into the partitioning of the reaction pathways and the degradation mechanisms. The study demonstrates the ultrasonic degradation of DPH is rapid, follows simple kinetic expressions and is accurately modeled using computational methods.

\subsection{Introduction}

One of the most widely used over the counter drugs, diphenhydramine (DPH) (2(diphenylmethoxy)-N,N-dimethylethanamine), is the active ingredient in Benadryl $^{\circledR}$. Diphenhydramine has been extensively used to treat allergies, hives, itching and insomnia 
since 1946 and is regularly detected in natural water, treated water and wastewater effluent. [91] Diphenhydramine has also been detected in surface drinking water sources and treated water from wastewater treatment plants (WWTP) [92]. Kinney et al. reported DPH as one of the four most commonly detected pharmaceuticals in Colorado[93]. Diphenhydramine also has high persistence in soil[94]. Huerta et al. reported the presence of DPH in fish muscle [95]. The co-occurrence of DPH and other trace amounts of pharmaceuticals in water systems can have negative impacts on aqueous organisms [96].

Traditional wastewater treatment processes do not effectively remove DPH [92]. Adsorption and ion exchange methods often require extended contact times and are often cost prohibitive for removal of DPH from drinking water sources [92]. The UV treatment of DPH leads to only $26 \%$ degradation at fluxes of $1272 \mathrm{~mJ} \cdot \mathrm{cm}^{-2}$ [97]. Photo-Fenton degradation of DPH can be effective, but requires careful preparation for optimization of the photo-catalyst [98].

Advanced oxidation processes (AOPs) can effectively degrade a wide variety of pollutants [44]. The production of reactive species, primarily $\mathrm{HO}$ radicals with smaller amounts of oxidants, such as $\mathrm{H}_{2} \mathrm{O}_{2}, \mathrm{O}_{2}{ }^{--}$is central to the effectiveness of AOPs. These reactive species lead to oxidative transformation and mineralization of the target pollutants. AOPs have shown tremendous promise for degradation of a wide variety of organic pollutants during water purification $[23,99,100]$. Ultrasonic irradiation is a unique AOPs as it generates hydroxyl radicals directly from water molecules and thus does not require addition of catalyst or oxidant common to the majority of AOPs [61,101]. Ultrasonic irradiation can penetrate and be used to treat turbid and highly colored solutions, while the 
application of photochemical AOPs such as UV/peroxide is limited to relatively clear solutions which allow penetration of photons deep into the solution.

As ultrasonic waves pass through a solution, gas bubbles undergo local expansion and compression cycles $[102,103]$. The size of the bubble increases with the number of expansion-compression cycles, leading to a pressure differential and eventually the bubbles collapse, a process referred to as cavitation [48]. At collapse, three zones have been defined: the region at the center of the cavitation site referred to as the hot-spot, the gas-liquid interface and the bulk solution. The hot-spot possesses extremely high temperatures (above $5000{ }^{\circ} \mathrm{C}$ ) and pressures (above $500 \mathrm{~atm}$ )[101-103] which leads to the pyrolysis of water vapor and produces hydroxyl radicals (HO·) as well as other oxidative species; the gasliquid interface has high temperatures (above $2000^{\circ} \mathrm{C}$ ) and high pressures (above $200 \mathrm{~atm}$ ) leading to pyrolysis and generation of hydroxyl radicals and other oxidative species; the bulk solution possesses relatively mild conditions close to ambient temperature and pressure where target compounds are only transformed upon reaction with radical species that diffuse from the cavitation site $[42,46,104-106]$. Ultrasonic degradation of DPH has yet to be published. Herein we report for the first time the fundamental kinetic studies, adsorption isotherms and the product studies of the ultrasonically induced decomposition of DPH. A computational method was also employed to complement product studies and established the partitioning of competing reaction pathways. Our study demonstrates that the ultrasonically induced degradation of DPH is rapid and the result of hydroxyl radical mediated and pyrolytic reaction pathways. 


\subsection{Materials and Experiments}

\subsubsection{Chemicals}

The source of DPH was diphenhydramine hydrochloride, purchased from MP Biomedicals, LLC. Acetonitrile (HPLC grade) was purchased from Burdick\& Jackson, while acetonitrile (optima LC/MS), ammonium formate (99\%) and formic acid (optima LC/MS) were purchased from Fisher Chemical. Coumarin was purchased from MP Biomedicals, LLC. $\mathrm{NaH}_{2} \mathrm{PO}_{4}(99 \%)$ was purchased from Merck\& Co. Inc and 7hydroxycoumarin (99\%) purchased from Acros Organics. All aqueous solutions were prepared with millipore filtered water $(18 \mathrm{M} \Omega . \mathrm{cm})$ and used at natural solution $\mathrm{pH}$ unless stated otherwise.

\subsubsection{Method and Experiments}

A pulsed mode ultrasonic transducer UES 1.5-660 Pulsar (Ultrasonic Energy Systems Inc., Panama City, Florida) equipped with disk shaped horn attached glass reactor $(500 \mathrm{~mL})$ was employed for all experiments. Operating conditions were previously optimized and set at pulse duration of $0.62 \mathrm{~s}$, pulse repetition of $2.5 \mathrm{~s}$ and frequency of $640 \mathrm{kHz}$ under operational power of $396 \mathrm{~W}$. Power density of the sonication was 7.9 W/cm ${ }^{2}$ with ultrasonic horn diameter of $9 \mathrm{~cm}$. Ultrasound traveled through $5 \mathrm{~cm}$ of water and $38 \mu \mathrm{m}$ of the polyethylene film to reach the $500 \mathrm{~mL}$ solution inside reaction vessel with $9 \mathrm{~cm}$ diameter. The reactor was submerged in an ice bath and the monitored temperature range inside the reaction vessel was $10 \pm 2{ }^{\circ} \mathrm{C}$ throughout the reaction. More details of the ultrasound equipment were described previously[107]. The aqueous solution 
containing the target compound was added into the reaction vessel, saturated by gentle bubbling with $\mathrm{O}_{2}$ for $15 \mathrm{~min}$. Samples were taken at specific treatment intervals and analyzed immediately or stored in the refrigerator until analyses.

A Varian Pro star 210 HPLC with a diode array detector was employed to monitor the concentration of DPH. A $250 \times 4.60 \mathrm{~mm} 5 \mu$ C18 column (S.N.410920-29) using mobile phase A (acetonitrile $(\mathrm{ACN}))$ and $\mathrm{B}$ (water, $20 \mathrm{mM} \mathrm{NaH}_{2} \mathrm{PO}_{4}$ at $\left.\mathrm{pH}=2.8\right)(40: 60(\mathrm{v} / \mathrm{v}))$ at a flow rate of $1 \mathrm{ml} / \mathrm{min}$ with the detection wavelength of $219 \mathrm{~nm}$ was used to monitor the concentration of DPH. Carefully prepared standards were employed to confirm the retention times and calibrate the HPLC. Agilent 6530 Accurate mass spectrometer equipped with an Agilent Infinity 1290 Infinity Binary Pump equipped with a $3.0 \times 100 \mathrm{~mm}$ $1.8 \mu \mathrm{C} 18$ column was used for the product studies. The mobile phase for the LC-MS product study was composed of solvent A (water, $5 \mathrm{mM}$ ammonia formate, $0.1 \%(\mathrm{v} / \mathrm{v})$ formic acid) and solvent B (acetonitrile /water, $0.1 \%(\mathrm{v} / \mathrm{v})$ formic acid 90:10 (v/v)) with a flow rate of $0.4 \mathrm{ml} / \mathrm{min}$ and a gradient program $0-1 \mathrm{~min}: 95 \% \mathrm{~A} ; 1-10 \mathrm{~min}$ : from 95 to $5 \%$ A. The column temperature was $30^{\circ} \mathrm{C}$.

To monitor the concentration of DPH accurately, a calibration curve was carefully developed from 2 to $2000 \mu \mathrm{mol} \cdot \mathrm{L}^{-1}$. A $1000 \mathrm{mg} / \mathrm{L}$ stock solution was prepared using volumetric flasks and stored in the refrigerator. Different concentration solutions were obtained from the dilution of stock solution employing adjustable pipettes and volumetric flasks. The DPH degradation was monitored over a range of initial DPH concentrations of 2.8, 5.2, 14.0, 27.0, 62.0 and $160.0 \mu \mathrm{mol} \cdot \mathrm{L}^{-1}$. The sampling times were adjusted according to the extent of degradation at different initial concentrations. For $[\mathrm{DPH}]_{0}=2.8$ and 5.2 
$\mu \mathrm{mol} \cdot \mathrm{L}^{-1}$, samples were taken at $0,1,2,3,4,6$ and 8 mins of the treatment; $[\mathrm{DPH}]_{0}=14.0$ and $27.0 \mu \mathrm{mol} \cdot \mathrm{L}^{-1}$, samples were taken at $0,2,4,6,8$ and $10 \mathrm{mins}$; for the $62.0 \mu \mathrm{mol} \cdot \mathrm{L}^{-1}$, samples were taken at $0,4,8,12$ and 16 mins while for $[\mathrm{DPH}]_{0}=160.0 \mu \mathrm{mol} \cdot \mathrm{L}^{-1}$, samples were analyzed at 0, 5,10, 20 and 30 mins. Samples for the product studies using LC-MS were taken at 0 and $30 \mathrm{mins}$ for the $14.0 \mu \mathrm{mol} \cdot \mathrm{L}^{-1} \mathrm{DPH}$ solution.

\subsection{Results and Discussions}

\subsubsection{Degradation Kinetics}

The ultrasonically induced degradation of DPH was effective over a range of initial concentrations, from 2.8 to $160.0 \mu \mathrm{mol} \cdot \mathrm{L}^{-1}$ under $\mathrm{O}_{2}$ saturation at $\sim 5^{\circ} \mathrm{C}$. The degradations of DPH as a function of treatment time at different initial concentrations are illustrated in Figure.3.1. The extent of degradation decreases with increasing initial concentration. The treatment time required to degrade $50 \%$ of the initial concentration varied from 3.9 to 33.3 min for the initial DPH concentrations of 2.8 to $160.0 \mu \mathrm{mol} \cdot \mathrm{L}^{-1}$, respectively.

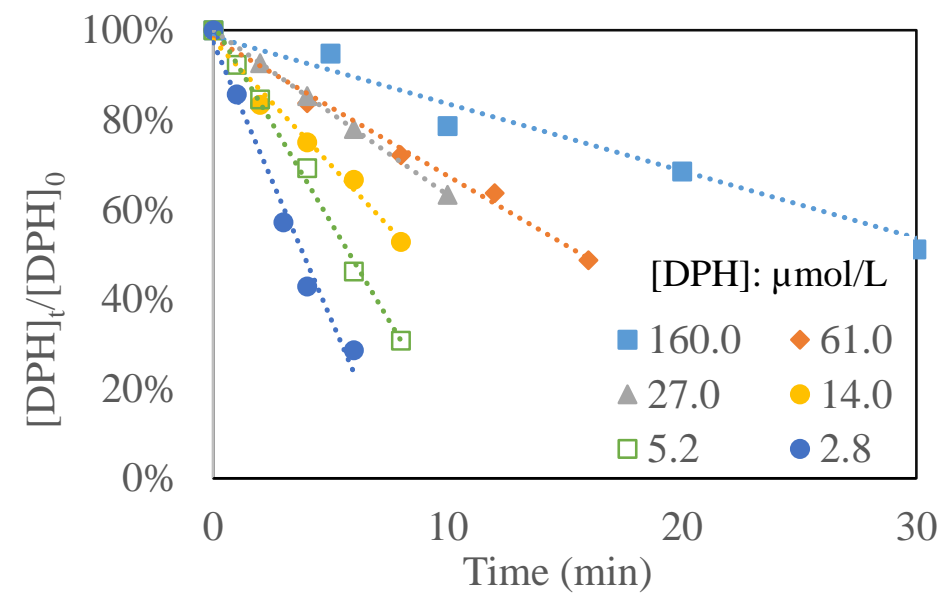

Figure. 3.1 Ultrasonically mediated degradation of DPH as a function of treatment time $\left(640 \mathrm{kHz}, 396 \mathrm{~W}, 5^{\circ} \mathrm{C}, \mathrm{O}_{2}\right.$ saturated). 
Previous studies have established that the ultrasonic mediated degradation of a variety of organic compounds follows pseudo-first kinetics at a given initial concentration. $[52,62,108-110]$ Pseudo-first-order kinetics are represented by the mathematical equation $\ln \frac{C_{t}}{C_{0}}=-k t\left(\mathrm{k}\left(\min ^{-1}\right)\right.$ where $\mathrm{C}_{\mathrm{t}}$ and $\mathrm{C}_{0}\left(\mu \mathrm{mol} \cdot \mathrm{L}^{-1}\right)$ are the concentration at treatment time t and the initial concentration, respectively. The pseudo-first-order kinetic plot (Figure. 3.2) of the degradation of DPH yields rate constants of $0.21,0.13,0.082,0.050,0.035$ and 0.023 $\min ^{-1}$ corresponding to the initial concentrations of $2.8,5.2,14.0,27.0,61.0$ and 160.0 $\mu \mathrm{mol} \cdot \mathrm{L}^{-1}$, respectively. The observed rate constants decreased by approximately 10 -fold as the initial concentration increased by about 80 times. The rate constant does not change significantly with initial concentration for a true first order type reaction process. However, variations in the reaction rate constant as a function of initial concentration have been previously reported for heterogeneous processes [67,111]. The anomaly has been rationalized on the basis of mass transfer limitations and saturation effects for heterogeneous processes occurring at or near the gas-liquid interface [112].

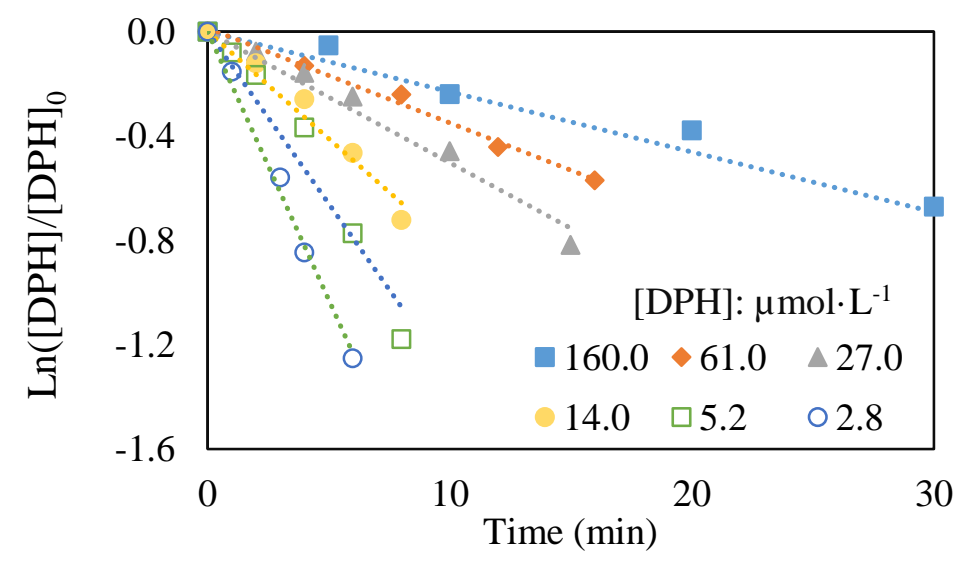

Figure. 3.2 Pseudo-first order kinetic plots of ultrasonically mediated degradation of DPH at different initial concentrations $\left(640 \mathrm{kHz}, 396 \mathrm{~W}, 5^{\circ} \mathrm{C}, \mathrm{O}_{2}\right.$ saturated). 


\subsubsection{Heterogeneous Kinetic Modeling}

The ultrasonically mediated degradation of pollutants in aqueous media involves two primary processes, direct pyrolysis of target compounds and degradation mediated by the reactive species generated during cavitation. The extent of these degradation pathways is dependent on the partitioning of the target compounds to the gas, gas-liquid interface and bulk liquid regions $[61,101]$. Diphenhydramine has relatively low vapor pressure and is not expected to partition to the hot spot (gas region) during cavitation. The gas-liquid interface however also possesses high temperatures (>2000 K) and high pressures $(>300$ atm) during cavitational collapse, above the supercritical points (680 K and $218 \mathrm{~atm})$ for water and thus it exists in a supercritical state. $[47,62,63]$ Water in the supercritical state exhibits hydrophobic rather than the hydrophilic solvation properties associated with water under ambient conditions. In general, ultrasonic mediated degradation is initiated by reactive oxygen species generated at the hot spot and G-L interfacial regions. Alternatively, neutral hydrophobic species can partition to the G-L interface where direct pyrolysis can occur because of the high temperatures produced during cavitation. Since the degradation reactions will primarily occur at or near the liquid-gas interface, the LangmuirHinshelwood (L-H) kinetic model for heterogeneous reactions was employed (Eq. 3.1) to the degradation process. [51,77] For the purposes of kinetic modeling, we define the liquidgas interface as the reaction surface where DPH can partition to and from. The L-H model assumes (1) all sites on the surface (interface) are equivalent (2) each site is occupied by one molecule and forms a monolayer (uniform partitioning) (3) the molecules have no 
interactions with the ones on the adjacent sites (4) the adsorption and desorption process is in an equilibrium.

$$
\frac{1}{\mathrm{r}_{0}}=\frac{1}{\mathrm{k}_{\mathrm{r}} \mathrm{K}_{\mathrm{L}-\mathrm{H} \mathrm{c}_{0}}}
$$

where $r_{0}\left(\mu \mathrm{mol} \cdot\left(\mathrm{L}^{-1} \cdot \mathrm{min}^{-1}\right)\right)$ is the initial rate, $\mathrm{c}_{0}\left(\mu \mathrm{mol} \cdot \mathrm{L}^{-1}\right)$ is the initial $\mathrm{DPH}$ concentration, $\mathrm{k}_{\mathrm{r}}\left(\mathrm{L} \cdot \mathrm{min} \cdot \mu \mathrm{mol}^{-1}\right)$ is the reactivity coefficient and $\mathrm{K}_{\mathrm{L}-\mathrm{H}}\left(\mu \mathrm{mol} \cdot \mathrm{L}^{-1}\right)$ is the equilibrium constant.

The initial rates of degradation were monitored over the initial $20 \%$ of the degradation of DPH to minimize competition from the degradation products. The observed degradation rates as a function of initial concentrations $\left(\mathrm{c}_{0}\right)$ were used to construct the L$\mathrm{H}$ plot, $1 / \mathrm{r}_{0}(\mathrm{~min} \cdot \mathrm{L} / \mu \mathrm{mol})$ as a function of $1 / \mathrm{c}_{0}(\mathrm{~L} / \mu \mathrm{mol})$ which yields a linear relationship as shown in Figure. 3.3(a). The intercept equals $1 / \mathrm{k}_{\mathrm{r}}$ and the slope is $1 /\left(\mathrm{k}_{\mathrm{r}} \mathrm{K}_{\mathrm{L}-\mathrm{H}}\right)$. The $\mathrm{L}-\mathrm{H}$ plot yields a reactivity constant $\mathrm{k}_{\mathrm{r}}=1.96 \mu \mathrm{mol} \cdot \mathrm{min}^{-1} \cdot \mathrm{L}^{-1}$ and the partitioning constant $\mathrm{K}_{\mathrm{L}}$ $\mathrm{H}$, was $0.06 \mu \mathrm{mol} \cdot \mathrm{L}^{-1}$. The reactivity constant and partitioning constant are empirical values to describe the apparent reactivity and the partitioning factors according to the L-H model. 

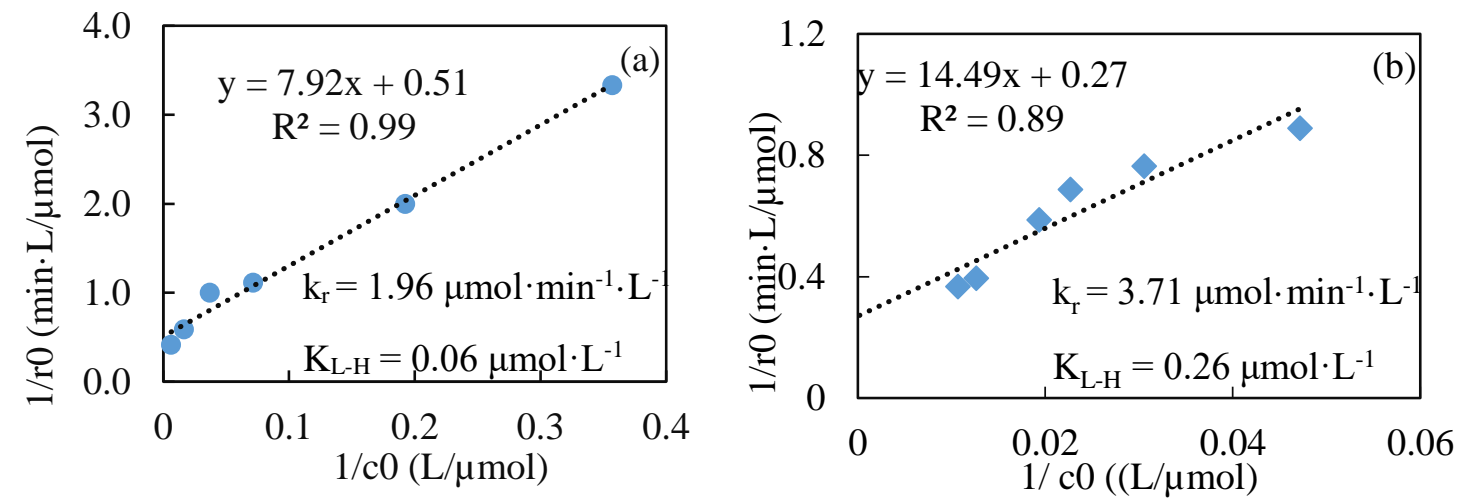

Figure. 3.3 Langmuir-Hinshelwood plot of DPH (a) and COU (b) degradation in aqueous media under ultrasonic irradiation $\left(640 \mathrm{kHz}, 396 \mathrm{~W}, 5^{\circ} \mathrm{C}, \mathrm{O} 2\right.$ saturated $)$.

\subsubsection{Hydroxyl Radical Competition Study}

Hydroxyl radicals produced during cavitation are critical to the effective degradation of organic compounds during ultrasonic treatment. To assess the role of HO• in the degradation of $\mathrm{DPH}$, coumarin (COU), a hydroxyl radical trap, was added to the solution during the ultrasonic treatment of DPH. The rates of ultrasonic induced degradation of coumarin were monitored under different initial concentrations: $25,40,50$, 60, 80, and $100 \mu \mathrm{mol} / \mathrm{L}$. The observed degradation rates as a function of initial concentrations were modeled using the Langmuir-Hinshelwood model described earlier. The L-H plot of the observed degradation of coumarin, illustrated in Figure. 3.3 (b), yields a linear relationship indicating the degradation occurs at or near the reaction surface (gasliquid interface). The slope and intercept of the L-H plot yield the following apparent kinetic parameters, reactivity constant $\mathrm{k}_{\mathrm{r}}=3.71 \mu \mathrm{mol} \cdot \mathrm{min}^{-1} \cdot \mathrm{L}^{-1}$ and a partitioning constant $\mathrm{K}_{\mathrm{L}-\mathrm{H}}=0.26 \mu \mathrm{mol} \cdot \mathrm{L}^{-1}$. By comparison the $\mathrm{L}-\mathrm{H}$ kinetic parameters of $\mathrm{COU}$ were significantly higher than those observed for DPH under the same conditions. The 
ultrasonically induced degradation of DPH and COU fit to the L-H model, however the better fit of DPH to the L-H indicates COU may not follow the specific L-H model assumptions as well. DPH and COU process hydrocarbon functionality and thus both can partition to the hydrophobic G-L interface. COU will be uncharged under the experimental conditions, while DPH possesses an aliphatic amine with $\mathrm{pKa}=8.98$ and thus exists in protonated (positive) form at neutral solution $\mathrm{pH}$. [94] Since DPH is positively charged it is not expected to partition to the hydrophobic G-L interface like neutral COU. Coumarin is neutral and thus more likely to partition to the G-L interface than the positively charged DPH. In addition, COU is more volatile than DPH and more likely to partitioning to the hot spot region. Higher partitioning of COU to the G-L and hot spot regions is consistent with a larger observed $\mathrm{K}_{\mathrm{L}-\mathrm{H}}$ compared to the less volatile charged DPH. Coumarin thus should exhibit greater partitioning to the hot spot and G-L interfacial regions, have greater $\mathrm{L}-\mathrm{H}$ reactivity, and degrade faster than DPH. On the basis of these results, COU will be effective as a probe for the HO' mediated DPH degradation pathways.

A kinetic competition study between DPH and COU was conducted. The degradation of $0.1 \mathrm{mmol} \cdot \mathrm{L}^{-1} \mathrm{DPH}$ was monitored in both the absence and presence of an equimolar amount of $\mathrm{COU}$, as illustrated in Figure. 3.4. The degradation rate of 0.1 $\mathrm{mmol} \cdot \mathrm{L}^{-1} \mathrm{DPH}$ in the absence of COU was $2.82 \mu \mathrm{mol} \cdot \mathrm{L}^{-1} \cdot \mathrm{min}^{-1}$. In the presence of an equimolar amount of COU the observe DPH degradation rate dropped $57.8 \%$ to 1.19 $\mu \mathrm{mol} \cdot \mathrm{L}^{-1} \cdot \mathrm{min}^{-1}$. The observed rates of reaction of hydroxyl radical with COU and DPH also depend on the bimolecular rate constants. On the basis of replicate experiments, the reproducibility of the kinetic results is within 5-7 \% experimental error. The bimolecular 
hydroxyl radical rate constants for $\mathrm{HO} \cdot+\mathrm{COU}$ is $\mathrm{kCOU}+\mathrm{HO}=1.05 \times 10^{10} \mathrm{M}^{-1} \mathrm{~s}^{-1}$ and $\mathrm{HO} \cdot+$ $\mathrm{DPH}$ is $\mathrm{k}_{\mathrm{DPH}}+\mathrm{HO} \cdot=0.71( \pm 0.2) \times 10^{10} \mathrm{M}^{-1} \mathrm{~s}^{-1} \cdot[113-115]$ The relative magnitude of the rate constants at a 1:1 ratio of COU to $\mathrm{DPH}$ in homogeneous solution COU would be 1.48 times more reactive and a $59.7 \%$ decrease of degradation rate is expected. The observation of a $57.8 \%$ decrease corresponds to the theoretical value also indicates that the reaction between DPH and hydroxyl radical dominates the degradation process. The theoretical and experimental are in excellent agreement indicating the pyrolysis pathway is not affected by the HO. scavenger.

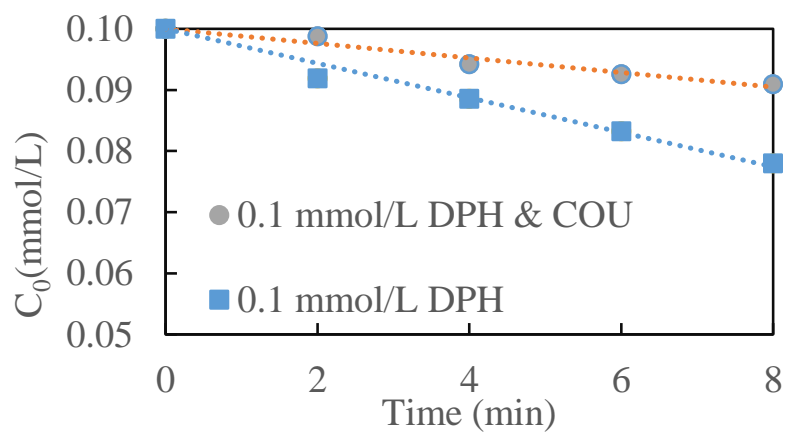

Figure. 3.4 Degradation of DPH with and without the co-existence of the hydroxy radical scavenger, COU. (640 kHz, $396 \mathrm{~W}, 5^{\circ} \mathrm{C}, \mathrm{O}_{2}$ saturated). Linearity fit is represented by dotted line.

\subsection{4 $\mathrm{pH}$ effect on the degradation rate of DPH}

The ultrasonically induced degradation of DPH was run over a range of initial $\mathrm{pH}$ of 3.7, 5.7, 7.7, and 10.7. The $\mathrm{pH}$ of DPH solution prepared in pure Millipore water without adjustment was 7.7. The $\mathrm{pH}$ of the solutions was adjusted by addition of $1 \mathrm{~mol} / \mathrm{L} \mathrm{HCl}$ or $\mathrm{NaOH}$ to achieve the desired solution $\mathrm{pH}$. The degradation of $\mathrm{DPH}$ at each of the solution $\mathrm{pH}$ was monitored as a function of treatment time (Figure.3.5). The degradation of DPH 
was fastest under acidic conditions (3.7 and 5.7), leading to $55 \%$ degradation within15 min, at $\mathrm{pH}=7.7 \sim 40 \%$ of the starting $\mathrm{DPH}$ was degraded within 15 mins and $35 \%$ degradation within 15 mins at $\mathrm{pH}$ 10.7. The $\mathrm{pKa}$ of DPH is 8.7, which means under neutral or acidic conditions, DPH is protonated (positively charged) and less hydrophobic compared to the neutral form which is predominant under alkaline conditions. The protonated form of DPH exists under acidic and neutral conditions. In general, charged species are less likely to partition to the hydrophobic interfacial and hot-spot regions generated during cavitation where degradation pathways are prevalent. Hydrophobic neutral species can exhibit enhanced degradation because of a tendency to localize near the hydrophobic interface where radical and pyrolytic processes can occur, however in the case of DPH the trend was opposite with an increase in the degradation under more acidic $\mathrm{pH}$ where the DPH exists in a more hydrophilic positively charged state. We proposed that the charged DPH species may have enhanced reactivity with negatively charged reactive species generated during ultrasonic treatment, specifically superoxide anion radical, which can readily diffuse into the bulk solution to react with protonated DPH. Differences in the production of reactive oxygen species at different solution $\mathrm{pH}$ could also lead to the observed differences in the degradation of DPH in the protonated and neutral species.

Even though there was a difference between different initial $\mathrm{pH}$, part of the degradation undergoes pyrolysis was not affected by $\mathrm{pH}$. 


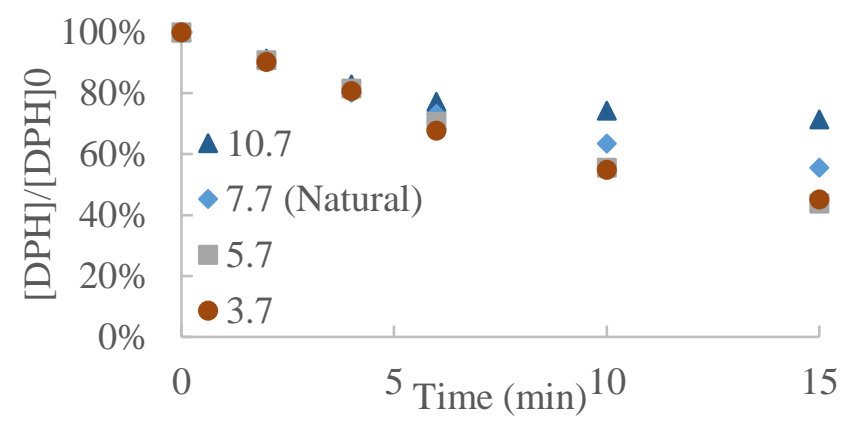

Figure. 3.5 DPH degradation under different $\mathrm{pH}$ value.

\subsubsection{Product Study}

Hydroxyl radical mediated processes are central to the effective degradation of pollutants by ultrasonic treatment. Hydroxyl radicals react with organic pollutants through three possible pathways: hydroxyl radical addition, hydrogen abstraction and electron transfer. Hydroxyl radical addition to electron rich aromatic systems is generally 10-100 times faster than hydrogen abstraction, and electron transfer is uncommon except for exceedingly electron rich systems. Using relative reaction rates for these competing pathways hydroxyl radical will react primarily with DPH through addition and hydrogen abstraction pathways. Product studies were completed by LC-MS after $90 \%$ of the starting material was degraded. The retention time of DPH is $6.554 \mathrm{~min}$ with an accurate mass/charge ratio of 256.1623, corresponding to the molecular weight peak. (Figure.3.6) Although the LC/MS raw data represents accurate mass of the protonated species, $\mathrm{m} / \mathrm{z}=$ M+1 values, for the purpose of this manuscript, we will refer the accurate mass as the molecular weight for the remainder of the paper. The total ion chromatogram exhibits several well resolved peaks indicative of degradation products. On the basis of the observed 
accurate mass measurements and key fragmentations in the MS, specific structures were assigned to the reaction products as described herein.
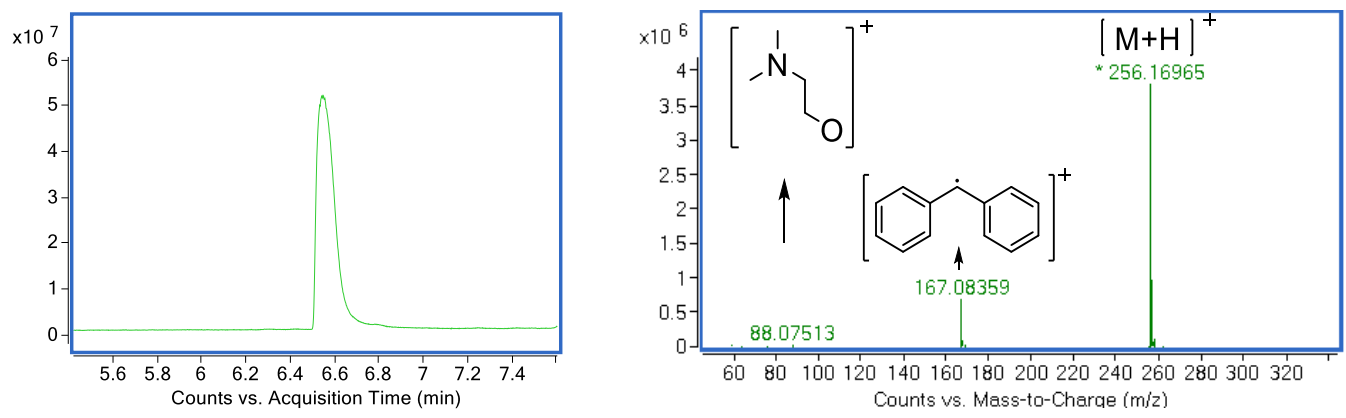

Figure. 3.6 DPH chromatograph and mass spectra of untreated solution.

\subsubsection{Hydroxyl Radical Addition Products}

Hydroxyl radical is a powerful electrophile and readily adds to aromatic rings. Hydroxyl radical addition to the aromatic ring with subsequent elimination of $\mathrm{H}$. is a common reaction pathway for aromatic compounds (Figure. 3.7). The HO addition can occur at meta, ortho and para positions [116]. Among the observed products are three clearly resolved peaks with identical molecular weights, $\mathrm{m} / \mathrm{z}$ of 272.1693 and retention times of $5.665,5.784$ and $6.044 \mathrm{~min}$, corresponding to the the mono-hydroxylation products. All three mass spectra exhibited fragment peaks at $\mathrm{m} / \mathrm{z}=183.08$ indicating hydroxylation of the benzene ring and are assigned to para-, meta- and ortho- phenolic adducts. Aravindakumar's group reported similar isomeric phenols for DPH and HO• generated by $\mathrm{UV} / \mathrm{H}_{2} \mathrm{O}_{2}[117]$. 
a)<smiles>C[C@H](O)[C@H](C)OC(c1ccccc1)c1ccccc1</smiles>

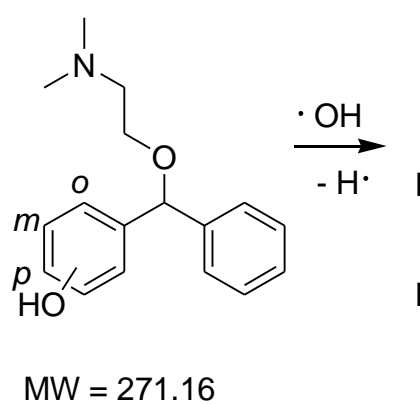<smiles>CNCCOC(c1ccccc1)c1ccc(O)cc1</smiles>

b)
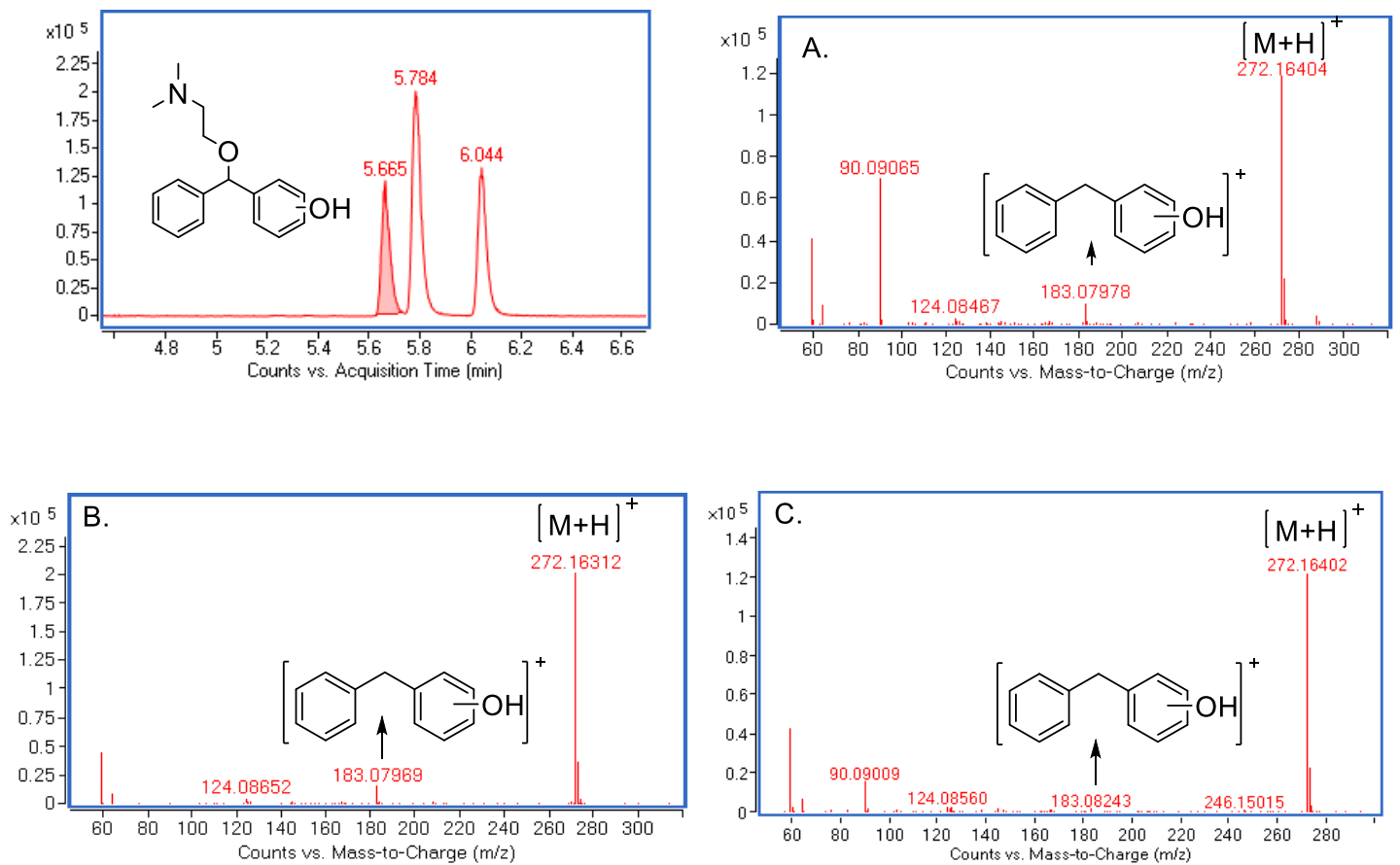

c)

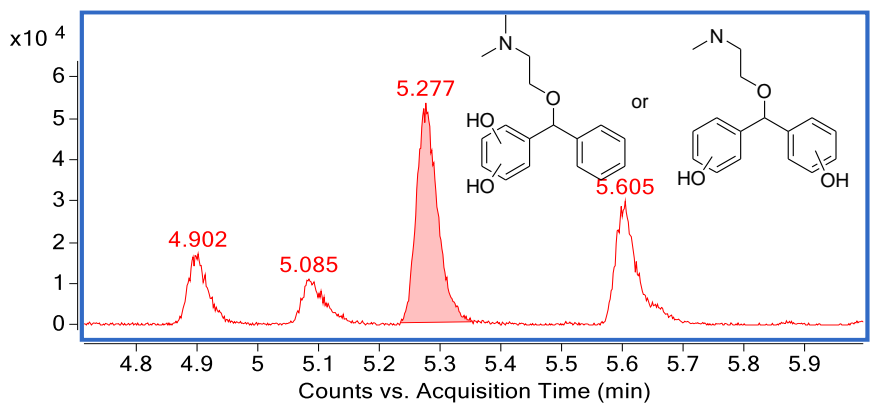



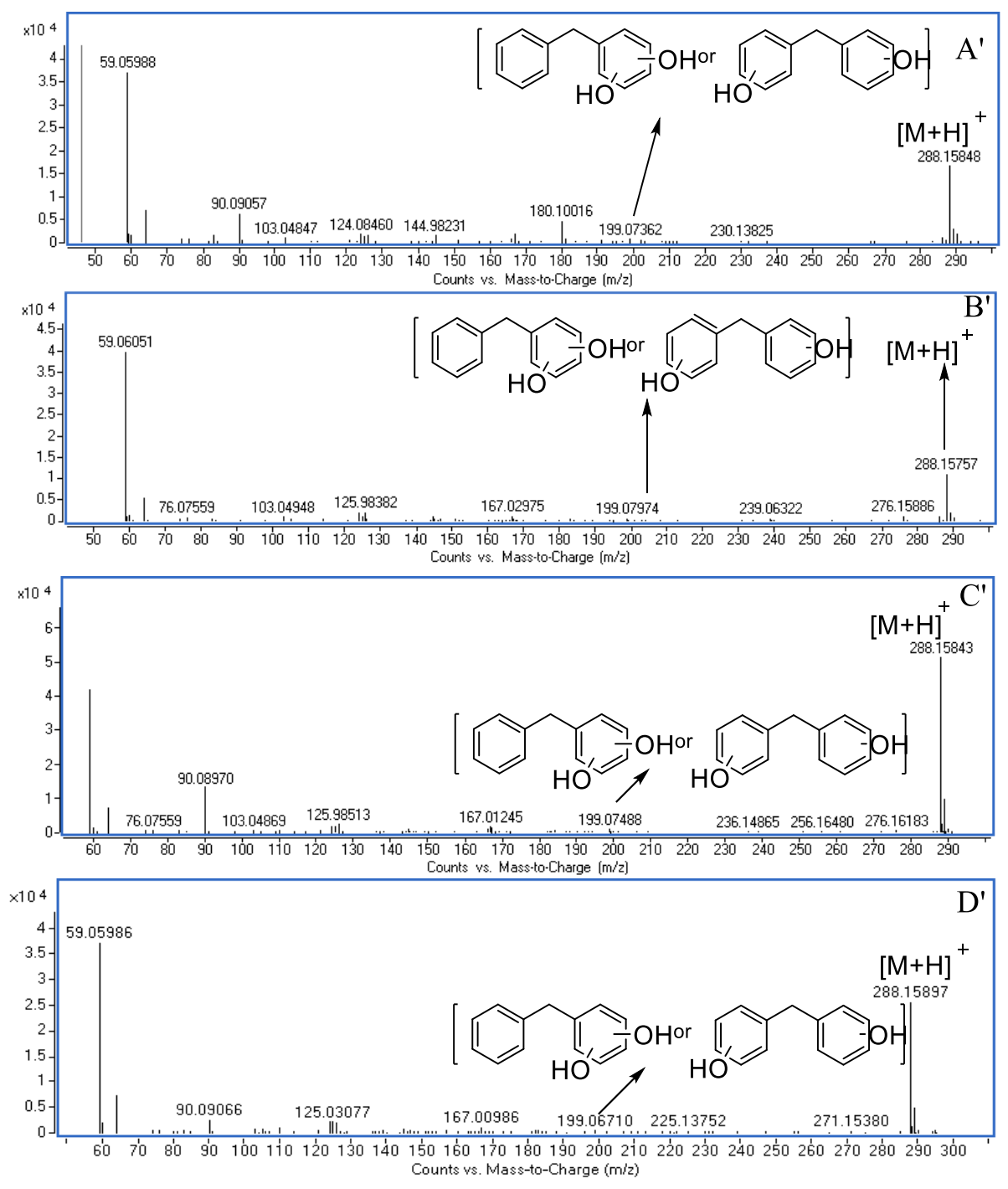

Figure. 3.7 a) Hydroxylation of DPH yielding mono and di-hydroxylation products. The $o, m, p$ represent ortho, meta and para substitution; b) The chromatograph of monohydroxylation of DPH and (A), (B), (C) are MS spectra of three isomers corresponding to the retention times of 5.665,5.784 and 6.044 min respectively; c). Chromatogram and MS spectra of di-hydroxylation products. (A'), (B'), (C') and (D') are MS spectra of four isomers corresponding to the retention times of 4.902,5.085, 5.277 and $5.605 \mathrm{~min}$ respectively. 
Mono-hydroxylation increases the electron rich character of the aromatic ring making the product more reactive to a second electrophilic $\mathrm{HO}$ addition reaction. Products with molecular weight (MW) 287.15 were also observed among the predominant products and correspond to di-hydroxylation products of DPH as shown in Figure. 3.7. Addition of the second $\mathrm{HO}$ - can occur at mono-hydroxylated ring leading to a di-hydroxylated benzene ring, while reaction at the phenyl ring (non-hydroxylated) will produce two monohydroxylated benzene within one DPH molecule, as illustrated in Figure. 3.7. These products, constitutional isomers have identical molecular weights Three isomers were detected and reported in previous work [118]. However, for the dihydroxylation of single benzene ring in DPH there are seven possible constitutional isomers. Six constitutional isomers are possible from the mono-hydroxylated of the two benzene rings within DPH. Given the identical molecular weights and a large number of possible isomers for dihydroxylated DPH, it is difficult to separate, distinguish and assign the individual dihydroxylated isomers. However, four unique peaks with MW of 287.16 were observed in the product mixture corresponding to the di-hydroxylated products. The retention times of the resolved chromatographic peaks for the di-hydroxylated products were 4.908, 5.080, 5.283 and $5.614 \mathrm{~min}$. Given enhanced reactivity of the mono-hydroxylated aromatic ring (compared to non-hydroxylated aromatic ring), we expect dihydroxylation of a single aromatic ring will be dominant in the reaction mixture. While specific assignment of these isomers is difficult, it is likely that additional dihydroxylation products are formed which are below the detection limit or overlapping with the observed peaks. 


\subsubsection{Hydrogen Abstraction Reaction Products}

While hydroxyl radical addition to the aromatic rings leading to phenolic products appears to be the predominant reaction pathway, hydroxyl abstract of the benzyl hydrogen is also possible.

A DPH degradation product was observed with MW of $193.11 \mathrm{~g} / \mathrm{mol}$ and a retention time at $4.823 \mathrm{~min}$. This product can be the result of a radical chain oxidation process at the highly reactive benzylic hydrogen (Figure.3.8). The fragments at $\mathrm{m} / \mathrm{z}=$ 105.04 and $\mathrm{m} / \mathrm{z}=121.03$ are indicative of the ester group functionality the proposed product. A product with $\mathrm{MW}=199.08$ was observed and assigned as a dihydroxylation adduct of benzophenone, a secondary degradation product of DPH which could be produced by abstraction of the benzylic hydrogen. Such an adduct has been previously reported [118]<smiles>CCC(C)(OCCN(C)C)c1ccccc1C(O)(OCCN(C)C)c1ccccc1</smiles>

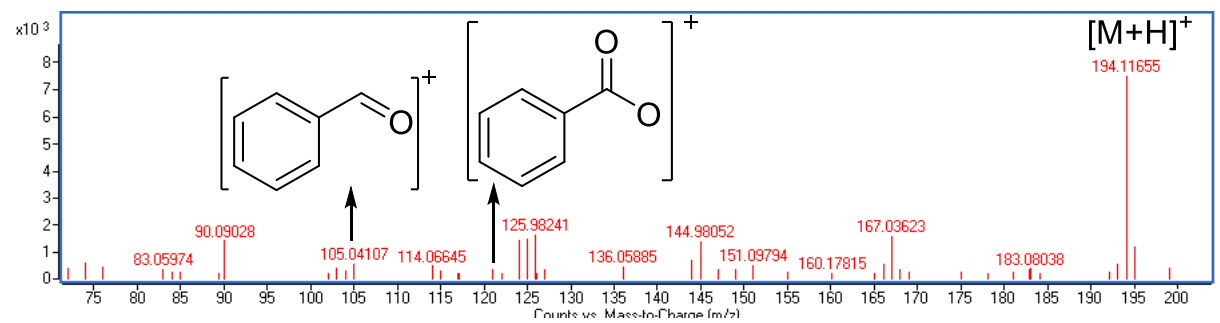

Figure. 3.8 The degradation pathway and mass spectra of the product with MW $193.1102 \mathrm{~g} / \mathrm{mol}$ 


\subsubsection{Pyrolysis Products}

With the high temperatures at the hot-spot and gas-liquid interfacial regions produced during cavitation, pyrolysis can also play a role in ultrasonically induced degradation processes. Given the low vapor pressure of DPH and positive charge under the experimental conditions, it is not expected to partition onto vapor phase (hot spot), but rather reside primarily in the G-L interface and/or bulk regions. Under the temperatures generated at the G-L interface homolytic bond cleavage can occur within the DPH molecule. The weakest bonds within DPH on the basis of typical homolytic bond cleavage energies are the alkyl $\mathrm{Csp}^{3}-\mathrm{Csp}^{3}$ bonds and the $\mathrm{Csp}^{3}-\mathrm{Nsp}^{3}$ bonds, compared to the $\mathrm{Csp}^{2}$ $\mathrm{Csp}^{2}$ and Csp2-H bonds within the aromatic rings [119]. A product with MW 241.15 was observed with a retention time of 6.428 min which corresponds to M-14 indicative of loss of a $\mathrm{CH}_{2}$ and assigned to the conversion of the $\mathrm{N}-\mathrm{CH}_{3}$ to $\mathrm{N}-\mathrm{H}$ shown in Figure. 3.9.
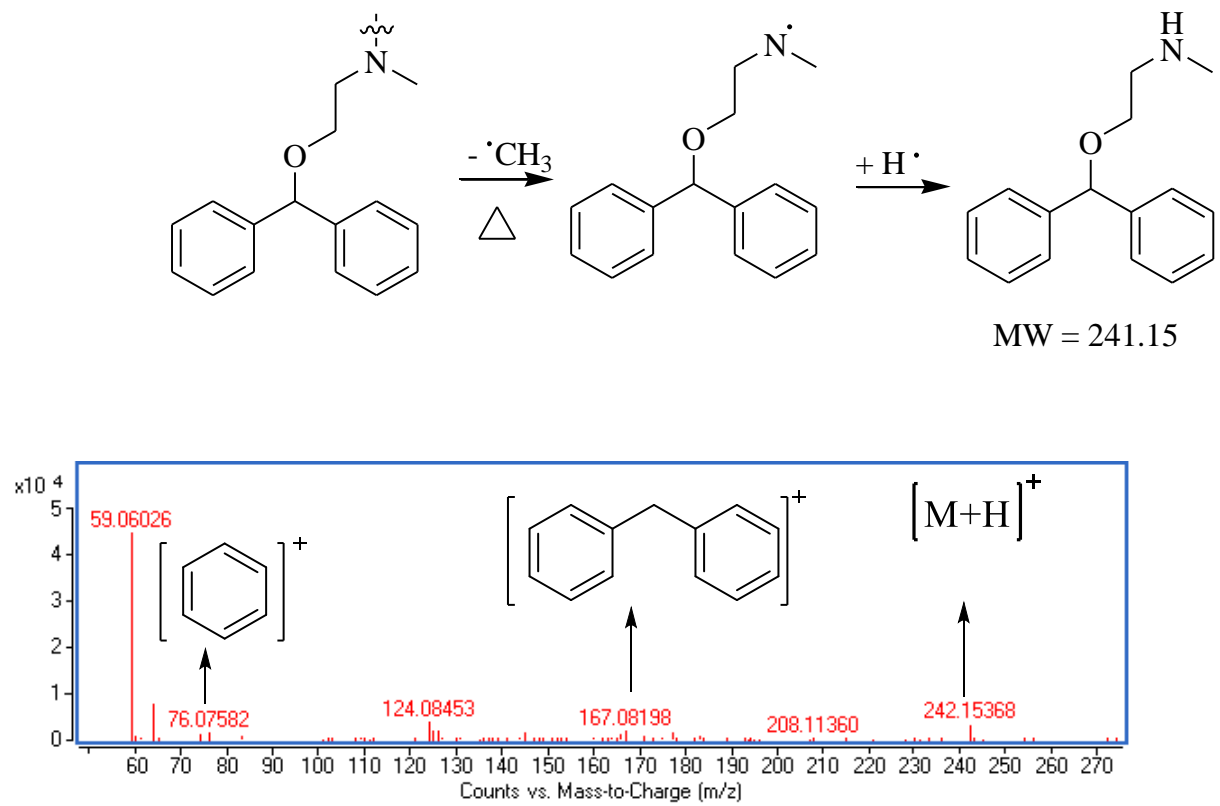

Figure. 3.9 The degradation pathway and mass spectra yielding the product with MW 241.1466. 
The product with MW = 182.07 is consistent with benzophenone containing characteristic fragments $\mathrm{m} / \mathrm{z}=105.041$ and [M-77] (Figure. 3.10). Among possible pathways the formation of benzophenone can also occur by hydroxyl mediated radical chain oxidation at the benzylic carbon [120].
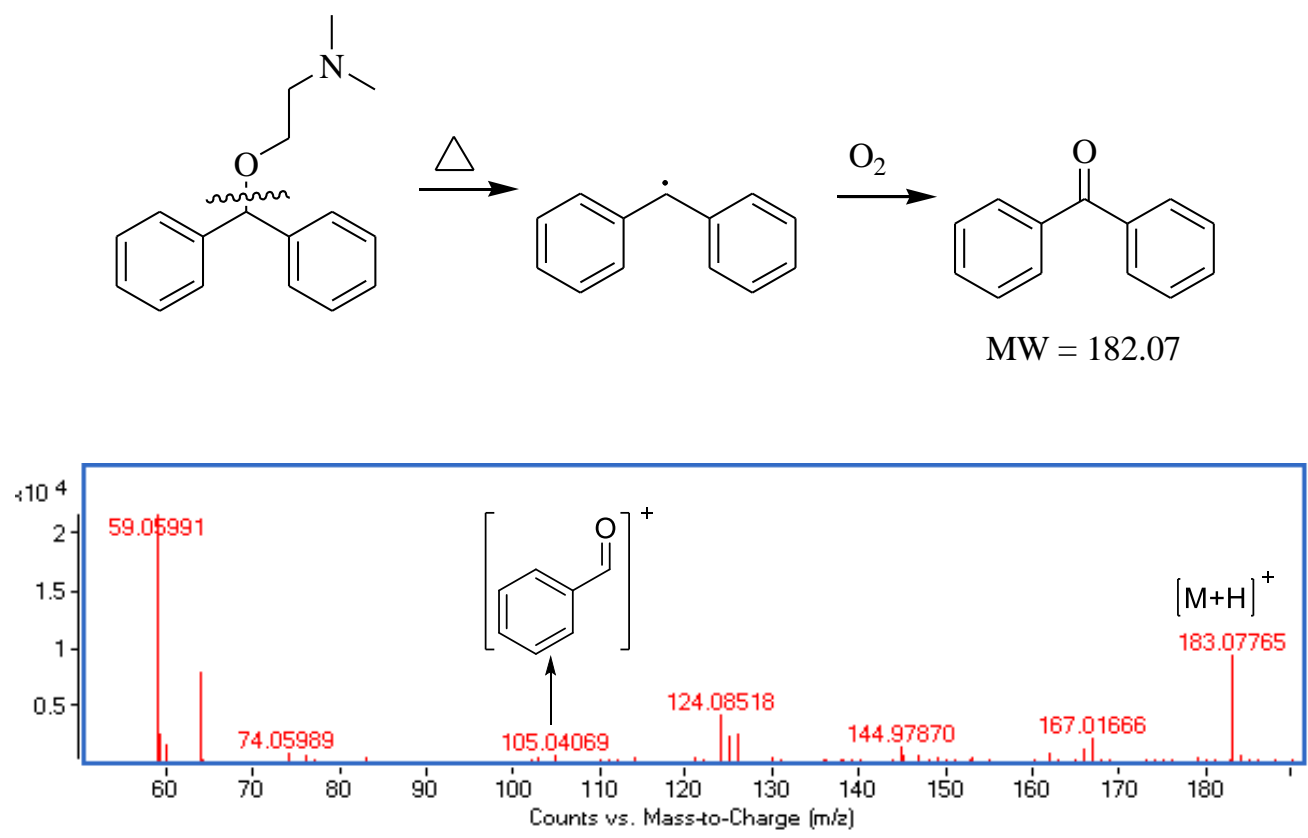

Figure. 3.10 The pyrolysis pathway yielding benzophenone (MW 182.0731g/mol).

\subsubsection{Computational Study of Competing Degradation Pathways}

Detailed computational studies were performed at the B3LYP/6-311G** level of theory using the Gaussian 09 program package to have a better understanding of the pyrolysis and hydroxyl radical mediated degradation pathways. On the basis of the product studies, the computational experiments focus on the hydroxyl radical addition and hydrogen atom abstraction reaction pathways to determine the energetics and partitioning of the $\mathrm{DPH}+\mathrm{HO}^{*}$ reaction pathways. Computational studies were also carried-out to 
correlate the energies required for homolytic bond cleavages for individual bonds in DPH to determine the partitioning of pyrolytic degradation pathways during ultrasonic treatment.

\subsubsection{Hydroxyl Radical Addition to Aromatic Ring}

The addition of hydroxyl radical to aromatic systems commonly occurs at near diffusion-controlled rates, with bimolecular rates constants of $\sim 10^{9}-10^{10} \mathrm{M}^{-1} \mathrm{sec}^{-1}$. The aromatic phenyl groups present in DPH are highly susceptible to addition by hydroxyl radical. DPH has two identical mono alkyl substituted benzene rings with addition possible at the ipso, ortho, meta, and para positions. Although hydroxylation at the ipso position is proposed for addition of water to the radical cation of DPH [118], direct addition of hydroxyl radical at the ipso position is generally not competitive with the ortho, meta, and para reaction pathways. Hydroxyl radical addition leading to hydroxylation of the aromatic rings in DPH has been reported [117] but isomers are difficult to distinguish by MS. Computational studies were conducted to identify the most probable sites on DPH for $\mathrm{HO}$ - radical addition to the aromatic rings. In order to trace the reaction pathways between DPH and $\mathrm{HO} \cdot$, three series of separate calculations simulating $\mathrm{HO} \cdot$ radical attack at ortho, meta, and para positions, were performed (Figure. 3.7). The initial reactants are DPH + $\mathrm{HO}$, the intermediates are $\mathrm{HO} \cdot$ adducts and the final products are obtained by the loss of the hydrogen atom from the attacked position in the radical $\mathrm{HO}$ adducts.

The results of calculations of the transition state energies (TS) for formation of the $\mathrm{HO}$ - adducts are represented as the activation energy $\left(\mathrm{E}_{\mathrm{a}}\right)$ and the adduct formation energy $\left(\Delta_{\mathrm{r}} \mathrm{H}\right)$ calculated as $11.0,13.0,10.3 \mathrm{kcal} \cdot \mathrm{mol}^{-1}$ for the $o, m$ and the $p$-position. The activation barriers for the ortho and para postion are slightly lower than that for the meta 
position, which means that the ortho and para additions are modestly favored for $\mathrm{HO}$ addition. The ortho and para position are electron rich compared to the meta position because of the electron donating effect (directing) of the alkyl subsitutent. Since HO' is electrophilic the rate of reaction should be modestly faster at the more electron rich ortho and para postions consistent with the computation results. The activation energies are similar for all three isomers indicating likely formation of all which is further supported by the LC-MS results which indicate the presence of three isomeric forms of monohydroxylated DPH products during the degradation process.

\subsection{Hydrogen Abstraction Reaction Pathways}

Hydroxyl radical mediated hydrogen abstractions can occur at a number of sites within the DPH molecule. The aromatic rings present in DPH contain $\mathrm{Csp}^{2}-\mathrm{H}$ bonds which are significantly stronger than the aliphatic $\mathrm{Csp}^{3}-\mathrm{H}$ bonds. Given the $\mathrm{Csp}^{2}-\mathrm{H}$ bonds are dramatically less reactive towards hydrogen abstraction, they were not taken into consideration. Abstraction of the different $\mathrm{Csp}^{3}-\mathrm{Hs}$ will lead to four different radical products. The partitioning of these competing reaction pathways can be predicted on the basis of the homolytic bond dissociation energies (H-elimination). The relative reactivities calculated for $\mathrm{Csp}^{3}-\mathrm{H}$ DPH reaction sites are summarized in Figure. 3.11. The most reactive site towards hydrogen abstraction is $\mathrm{C}-\mathrm{H}_{1}$, the benzylic hydrogen. The benzylic properties and additional electron withdrawing effect of the oxygen atom alpha to the hydrogen weaken the $\mathrm{C}-\mathrm{H}_{1}$ bond which has a calculated bond dissociation energy of 75.4 $\mathrm{kcal} \cdot \mathrm{mol}^{-1}$. The calculated bond strengths for the $\mathrm{Csp}^{3}-\mathrm{H}_{2}$ bond $\alpha$ with $\mathrm{O}$ is $90.1 \mathrm{kcal} \cdot \mathrm{mol}^{-}$

${ }^{1}$ and the $\mathrm{Csp}^{3}-\mathrm{H}_{3}$ and $\mathrm{Csp}^{3}-\mathrm{H}_{4}$ bonds adjacent to nitrogen atom are $88.1 \mathrm{kcal} \cdot \mathrm{mol}^{-1}$. The 
calculated differences in the bond strengths for $\mathrm{H}_{2}, \mathrm{H}_{3}$, and $\mathrm{H}_{4}$ are within the expected margins of error of 3-4 $\mathrm{kcal} \cdot \mathrm{mol}^{-1}$ typical for $\mathrm{B} 3 \mathrm{LYP} / 6-311 \mathrm{G}^{* *}$ calculations. These reactions are assumed to have similar entropies since the transformations involve $\mathrm{Csp}^{3}-\mathrm{H}$ bonds and differ only by the position of abstraction. Since the $\mathrm{H}$ abstraction reactions proceed via loose variational transition states, relative yields of the radicals should be approximately proportional to $\mathrm{e}^{-\Delta \mathrm{E} / \mathrm{RT}}$, where $\Delta \mathrm{E}$ is the calculated $\mathrm{C}-\mathrm{H}$ bond strength for each $\mathrm{H}$ elimination channel, $\mathrm{R}=0.001987 \mathrm{kcal} \cdot \mathrm{mol}^{-1} \cdot \mathrm{K}^{-1}$ is the gas constant, and $\mathrm{T}(\mathrm{K})$ is the phase temperature[89]. On the basis of the computational results of the $\mathrm{C}-\mathrm{H}$ bond energies the partitioning of the different hydrogen abstraction channels at the different regions within the cavitation site were determined. In the bulk solution at $278 \mathrm{~K}$ the results indicate the abstraction occurs at $\mathrm{H}_{1}$.

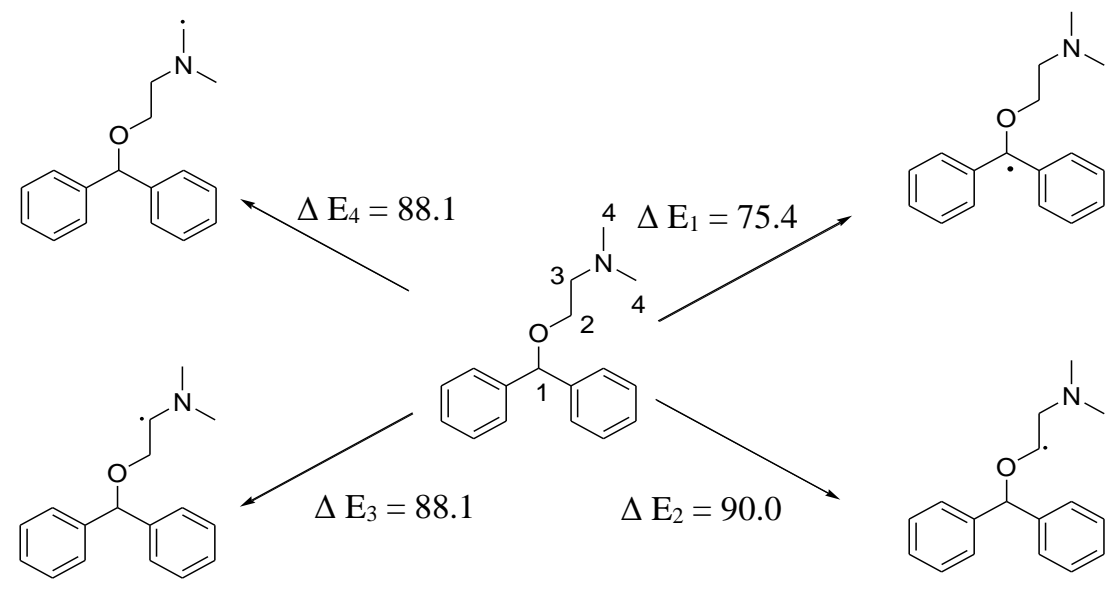

\begin{tabular}{|c|c|c|c|c|}
\hline & $\mathrm{H} 1$ & $\mathrm{H} 2$ & $\mathrm{H} 3$ & $\mathrm{H} 4$ \\
\hline $278 \mathrm{~K}$ & $100.00 \%$ & $0.00 \%$ & $0.00 \%$ & $0.00 \%$ \\
\hline $2000 \mathrm{~K}$ & $73.38 \%$ & $3.55 \%$ & $5.72 \%$ & $17.36 \%$ \\
\hline $5000 \mathrm{~K}$ & $27.45 \%$ & $12.38 \%$ & $14.98 \%$ & $45.19 \%$ \\
\hline
\end{tabular}

Figure. 3.11 DPH molecule hydrogen abstraction energies ( $\Delta \mathrm{E}$ is given in $\mathrm{kcal} \cdot \mathrm{mol}-1)$ at $278 \mathrm{~K}, 2000 \mathrm{~K}$ and $5000 \mathrm{~K}$. 
The temperature can have a pronounced effect on the partitioning of the hydroxyl radical mediated reaction pathways. At the gas-liquid interfacial region of the cavitation site temperatures can reach $2000 \mathrm{~K}$, yielding the following calculated partitioning of the hydrogen abstract pathways, $73.38 \%$ occurs at $\mathrm{H}_{1}, 3.55 \%$ at $\mathrm{H}_{2}$ (two hydrogens), $5.72 \%$ at $\mathrm{H}_{3}$ (two hydrogens) and $17.36 \%$ involves $\mathrm{H}_{4}$ (six hydrogens). At the hot-spot with temperatures reaching $5000 \mathrm{~K}, 27.45 \%$ of $\mathrm{H}$ abstraction involves $\mathrm{H}_{1}, 12.38 \%$ involve $\mathrm{H}_{2}$, $14.98 \%$ and $\mathrm{H}_{3}$, and the remaining $45.19 \%$ involves $\mathrm{H}_{4}$. Since there are six identical hydrogens at $\mathrm{H}_{4}$ position, there is a higher possibility of the abstraction occurring at $\mathrm{H}_{4}$ than $\mathrm{H}_{2}$ from the perspective of statistics. The homolytic bond dissociation (HBD) and $\mathrm{H}^{\cdot}$ abstraction (removal of $\mathrm{H}^{\cdot}$ ) results in the same carbon centered radicals can also occur via $\mathrm{H}$ abstraction reactions, $\mathrm{DPH}+\mathrm{HO}^{\cdot} \rightarrow \mathrm{DPH}^{\cdot}+\mathrm{H}_{2} \mathrm{O}$. Relative product yields for $\mathrm{H}$ abstraction pathways are likely thermodynamically controlled because the barriers for the $\mathrm{H}$ abstraction reactions by $\mathrm{HO}^{*}$ are normally either very low or even submerged below the reactants. The $\mathrm{H}$ abstraction by $\mathrm{HO}$ should be exothermic since the strength of the $\mathrm{O}-\mathrm{H}$ bond formed, $117.6 \mathrm{kcal} \cdot \mathrm{mol}^{-1}$, is higher than the strength of $\mathrm{C}-\mathrm{H}$ bonds broken. In the case of the thermodynamic control, the relative yields of the radicals discussed above is determined by their relative energies and hence should be identical to the relative yields evaluated for the $\mathrm{H}$ homolytic bond dissociation.

\subsection{Fragmentation of Carbon Centered Radicals}

The carbon centered radicals produced by hydroxyl radical mediated hydrogen abstraction can undergo $\beta$-scission or react with $\mathrm{O}_{2}$ to produce peroxyl radicals. The unimolecular fragmentation channels for each of the carbon centered were calculated to 
predict the most probable degradation pattern. The benzylic radical produced by abstraction of $\mathrm{H}_{1}$ is predicted to undergo $\mathrm{C}-\mathrm{O}$ bond fragmentation to yield benzophenone and a primary carbon center radical with $\mathrm{E}_{\mathrm{a}}$ of $19.9 \mathrm{kcal} \cdot \mathrm{mol}^{-1}$. The primary radical can undergo $\beta$-scission to yield ethylene and a nitrogen centered radical. These reaction pathways and relative energies are summarized in Figure. 3.12. The presence of benzophenone as a primary reaction product was confirmed by LC/MS. The low molecular products are highly volatile and can readily escape solution under experimental conditions.
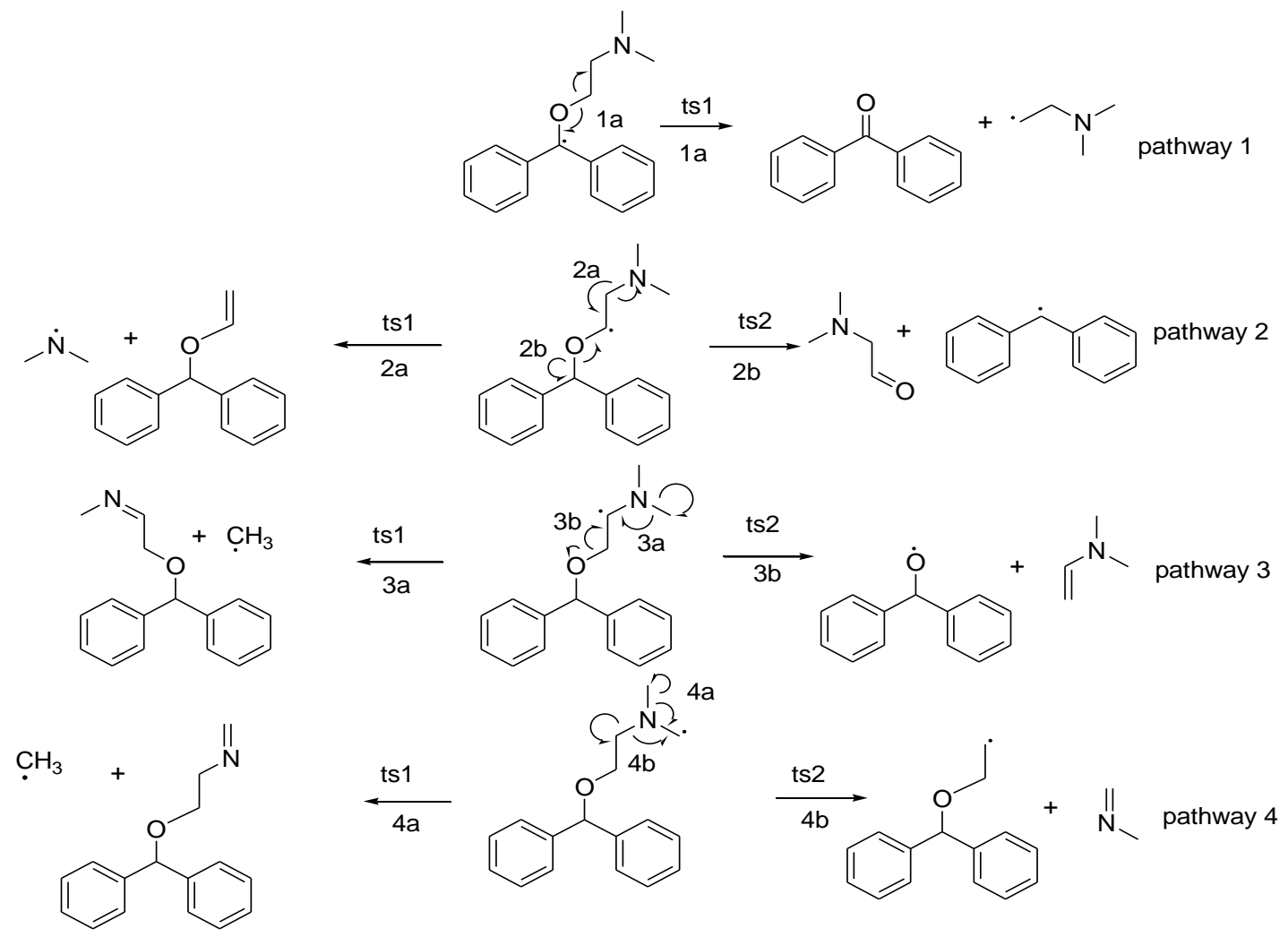

\begin{tabular}{|c|c|c|c|c|c|c|c|}
\hline Reaction Pathway & $1 \mathrm{a}$ & $2 \mathrm{a}$ & $2 \mathrm{~b}$ & $3 \mathrm{a}$ & $3 \mathrm{~b}$ & $4 \mathrm{a}$ & $4 \mathrm{~b}$ \\
\hline Transition State Energy (ts) & 19.9 & 18.3 & 9.8 & 24.5 & 10.6 & 26.9 & 26.4 \\
\hline$\Delta \mathrm{E}_{\text {products- starting material }}$ & 8.7 & 10.2 & -16.3 & 11.2 & 10.5 & 14.8 & 14.5 \\
\hline
\end{tabular}

Figure. 3.12 Pyrolysis pathway for carbon centered radical intermediates 1,2,3 and 4 formed by $\mathrm{H}$-abstraction. Energies of transition states and products are shown in $\mathrm{kcal} / \mathrm{mol}$. 
Computational studies indicate the carbon centered radical formed by extraction of $\mathrm{H}_{2}$ can undergo C-N fragmentation ( $\beta$-scission, pathway 2a) leading to diphenyl(vinyloxy)methane and dimethylamine radical in competition with $\beta$-scission of the C-O bond (pathway 2b) yielding the diphenylmethyl radical and 2-dimethylamino acetaldehyde (Figure. 3.12). The activation energy for pathway $2 \mathrm{a}$ and $2 \mathrm{~b}$ are 18.3 $\mathrm{kcal} \cdot \mathrm{mol}^{-1}$ and $9.8 \mathrm{kcal} \cdot \mathrm{mol}^{-1}$ respectively. The benzylic radical species formed in pathway $2 \mathrm{~b}$, can react with molecular oxygen ultimately leading to benzophenone via radical chain oxidation pathways. According to the computational results pathway $2 \mathrm{~b}$ is heavily favored over 2a.

The carbon centered radical produced by abstraction of $\mathrm{H}_{3}$ is also subject to two competing $\beta$-scission pathways, first fragmentation of the $\mathrm{C}-\mathrm{N}$ bond leading to imine and methyl radical products with $\mathrm{E}_{\mathrm{a}}$ of $24.5 \mathrm{kcal} \cdot \mathrm{mol}^{-1}$. In a favored process fragmentation of the C-O yields, and oxygen centered benzophenone radical and N, N-dimethyl-N-ethylene amine with $\mathrm{E}_{\mathrm{a}}=10.6 \mathrm{kcal} \cdot \mathrm{mol}^{-1}$. The oxygen centered radical undergoes rapid 1,2hydrogen shift to yield the favored benzyl radical which upon radical chain oxidation can readily produce benzophenone.

The $\beta$-scission pathways for the carbon centered radical obtained from $\mathrm{H}_{4}$ both involve C-N bond fragmentation. The activation energy for the $\mathrm{N}-\mathrm{CH}_{3}$ bond and $\mathrm{N}-\mathrm{CH}_{2}$ bond are nearly identical 26.9 and $26.4 \mathrm{kcal} \cdot \mathrm{mol}^{-1}$ respectively. These competing pathways also produce energetically similar carbon centered radicals and imine products. The calculated barriers for the $\beta$-scission processes are quite low; thus, the unimolecular decomposition of the initial carbon centered radicals should be very fast at the temperatures 
associated with cavitation. A number of predicted products were not observed in LC-MS. The reason these products escaped detection is attributed to low yields in a complex mixture of different pyrolysis and hydroxyl mediated reaction products, their rapid degradation and/or high volatility such that they escape as a gas.

\subsubsection{Computation of Pyrolytic Degradation Pathways}

The high temperatures produced during cavitation can lead to the pyrolysis by carbon-carbon $(\mathrm{C}-\mathrm{C})$, carbon-oxygen $(\mathrm{C}-\mathrm{O})$, or carbon-nitrogen $(\mathrm{C}-\mathrm{N})$ bond fragmentation pathways. The energies required for $\mathrm{C}-\mathrm{C}, \mathrm{C}-\mathrm{O}$, and $\mathrm{C}-\mathrm{N}$ bond cleavage depends on bond strengths. $\mathrm{C}-\mathrm{H}$ bond are stronger and less likely to go fragmentation. The $\mathrm{Csp}^{2}-\mathrm{Csp}^{2}$ bonds in the aromatic rings are among the strongest in DPH and unlikely to undergo fragmentation. The $\mathrm{Csp}^{2}-\mathrm{Csp}^{3}$ bonds are also relatively strong with a calculated activation energy of $73.8 \mathrm{kcal} \cdot \mathrm{mol}^{-1}$ for their bond fragmentation. Even though $\mathrm{C}-\mathrm{O}$ bonds are generally stronger than $\mathrm{C}-\mathrm{C}$ bonds, the lowest activation energy is $55.4 \mathrm{kcal} \cdot \mathrm{mol}^{-1}$ for the $\mathrm{C}_{\text {benzylic- }} \mathrm{O}$ bond cleavage leading to an oxygen centered radical and a highly stabilized resonance benzylic radical. The other $\mathrm{C}-\mathrm{O}$ bond fragmentation (non-benzylic carbon) required an activation energy of $74.0 \mathrm{kcal} \cdot \mathrm{mol}^{-1}$. For competing $\mathrm{C}-\mathrm{N}$ bond fragmentation pathways elimination of the methyl radical $\left(66.8 \mathrm{kcal} \cdot \mathrm{mol}^{-1}\right)$ is slightly favored over elimination of the dimethylamine radical $\left(68.4 \mathrm{kcal} \cdot \mathrm{mol}^{-1}\right)$. The activation energy required for $\mathrm{Csp}^{3}-\mathrm{Csp}^{3}$ fragmentation is $67.7 \mathrm{kcal} \cdot \mathrm{mol}^{-1}$. The computational results, summarized in Figure. 3.13, clearly indicate the fragmentation producing the diphenylmethyl (benzylic) radical species is a highly favored pathway in the direct pyrolysis of DPH which yields benzophenone(observed) in the presence of $\mathrm{O}_{2}$. 


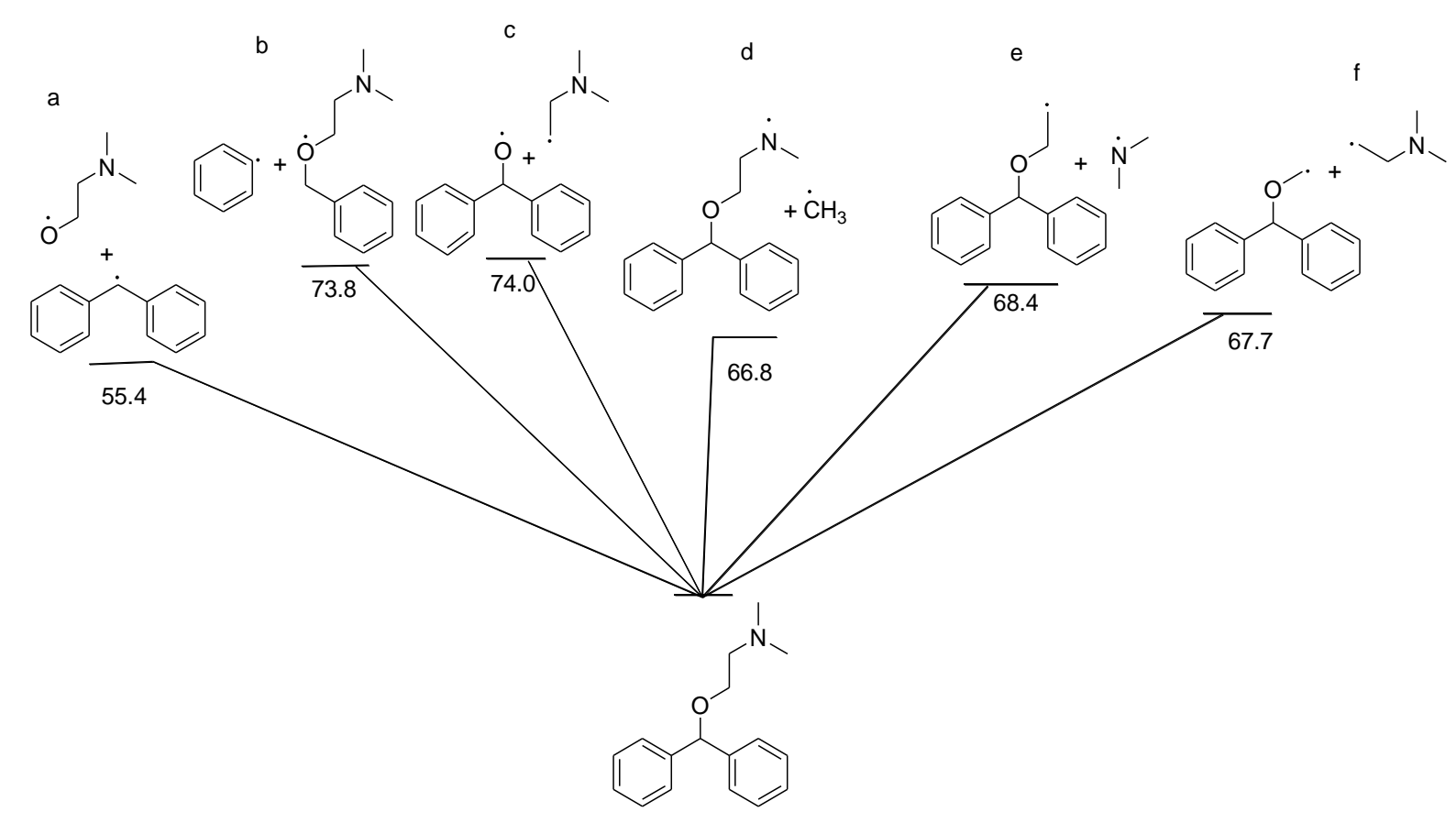

Figure. 3.13 Direct pyrolysis pathway under high temperature. Relative energies of various species are shown in $\mathrm{kcal} \cdot \mathrm{mol}^{-1}$.

\subsection{Conclusions}

Diphenhydramine, the first-generation antihistamine, is commonly found in drinking water sources and treated waste waters. The ultrasonic treatment of DPH leads to the rapid degradation and follows pseudo-first-order kinetics at a given initial concentration. The rate constant was observed to be dependent on the initial DPH concentration and decreased with increasing DPH concentration. Such kinetic behavior is consistent with previous studies involving heterogeneous treatment systems. The degradation was also accurately modeled by Langmuir-Hinshelwood kinetics. Diphenhydramine is effectively degraded by ultrasonic degradation even at high concentrations. Detailed product studies illustrated mono-hydroxylation of the aromatic rings in DPH yields three isomers as a 
primary degradation pathway. Subsequent hydroxylation leads to a mixture of dihydroxylated isomers. Benzophenone was also detected and likely produced from DPH as a favored pyrolytic reaction pathway. The computational studies are consistent with the product studies and provide additional insight relating to the competing reaction pathways. The results demonstrated ultrasound is an effective predictable method to degrade DPH from aqueous systems. 
Chapter 4 Ultrasound-induced remediation of the second-generation antihistamine, Cetirizine 


\subsection{Abstract}

Cetirizine, a second-generation antihistamine, has been detected in surface water and wastewater treatment eluent. Ultrasonic induced degradation of cetirizine can be attributed to both pyrolysis and hydroxyl radical oxidation. Detailed kinetic studies of ultrasound induced degradation of cetirizine were conducted. The degradation process followed pseudo-first order kinetics. Modeling of the degradation process with the Langmuir-Hinshelwood heterogenous model yields a reactivity constant $\mathrm{k}_{\mathrm{r}}=1.64 \mu \mathrm{mol} \cdot \mathrm{L}^{-}$

1. $\min ^{-1}$, and partitioning constant $\mathrm{K}=0.10 \mathrm{~L} / \mu \mathrm{mol}$. A competition experiment between hydroxyl radical scavenger and cetirizine during ultrasound was conducted to study the hydroxyl radical in the degradation process. Saturation gas effect study of degradation rate showed that the was faster when the solution was saturated by $\mathrm{Ar}$ and $\mathrm{O}_{2}$ than air. The degradation reaction mechanism was proposed based on the degradation products were confirmed by LC-MS method. We herein report that ultrasound remediation is a rapid and effective method to remove cetirizine from contaminated water.

\subsection{Introduction}

The natural occurrence of biologically active pharmaceuticals has drawn a lot of concern, especially since the 1990s [121,122]. Cetirizine HCl (CET), with a brand name "Zyrtec", is a second-generation antihistamine. Cetirizine relieves the hypersensitivity reaction due to allergies $[123,124]$. However, more than $80 \%$ of cetirizine is excreted with urine and metabolites from human bodies due to the poor metabolism [125]. Cetirizine has already been detected in the eluent of wastewater plant, surface and groundwater, and even drinking water resources at different concentrations, from ppb to ppm level [126-128]. A 
higher concentration of CET was detected in water during the spring when there was a higher occurrence of allergies [129]. The studies on exposing cetirizine in natural environments are not sufficient, as there are major concerns: 1) potential health effects on sensitive populations, such as children, pregnant women and fetuses; 2) the mixed effect when CET cooccurs with other pollutants; 3) unknown environmental influence on aquatic systems [130].

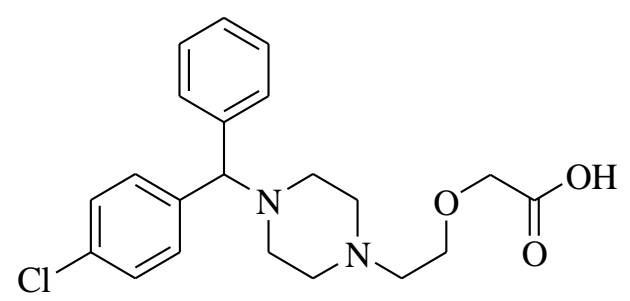

Figure. 4.1 Structure of CET

Conventional wastewater treatment plants are not able to remove CET efficiently [131]. Various methods had been used in the removal of CET from water. Adsorptive removal by activated carbon showed a short equilibrium time; however, the regeneration of adsorbent and further treatment of collected cetirizine need to be addressed [132]. Photodegradation of CET strongly depends on the incoming irradiation wavelength, and the half-life is $30 \mathrm{~h}$ [133]. Ultrasound assisted enzyme catalyzed degradation of CET requires adjustment of the temperature, $\mathrm{pH}$ and other parameters to reach the optimum conditions, and the degradation half-life was more than $2 \mathrm{~h}$ at the initial concentration of $5 \mathrm{ppm}$ [134].

Advanced oxidation processes (AOPs) are developed as promising and efficient methods which are widely used in the treatment of water pollutants. The generation of strong oxidants during different methods makes the remediation of persistent pollutants 
plausible [36]. Compared to ozonolysis and photocatalysis, sonolysis is the most environmental friendly since no additional chemicals are necessary. The application of ultrasonically induced degradation is fulfilled by adding ultrasound to the solutions and producing acoustic cavitation [46]. Micro bubbles are formed during the oscillation of soundwaves, and the bubble size is changed along with the expansion and compression cycles, leading to the final collapse [46]. The collapse of cavitation bubbles generated three zones: hot-spot, gas-liquid interface and bulk solution. The high temperature and pressure of hot-spot vary according to the different solution and applied frequency. Generally, in aqueous solution, an excess of $5000 \mathrm{~K}$ and $1000 \mathrm{~atm}$ at the hot-spot has been reported $[42,135]$. The gas-liquid interface also generates high temperature ( $>2000 \mathrm{~K})$ and pressure (>300 atm) which exceeds the water supercritical conditions. The hydrophobicity of super critical water has changed from hydrophilic to hydrophobic; therefore, this region provides a good surface for organic compounds to partition to. The bulk solution remains at ambient temperature. The hydroxyl radicals produced at the gas-liquid interface and in the hot-spot are released into bulk solution and react with the pollutants.

In this paper, we focus on the fundamental studies of ultrasound degradation of CET, modeling the degradation kinetics with pseudo-first order kinetics and the LangmuirHinshelwood model. A detailed competition study was conducted by adding hydroxyl radical scavengers to probe the role that hydroxyl radicals played in the degradation process. A saturated gas effect study was also performed. The product study was employed to predict the reaction mechanisms. 


\subsection{Experiments and Chemicals}

\subsubsection{Chemicals}

Cetirizine dihydrochloride (5g, >99 \%) was purchased from Alfa Aesar company and used without further purification. All aqueous solutions were prepared in Millipore water. 2-hydroxyterephthalic acid (1g, $98 \%)$ was purchased from Ark Pharm. Terephthalic acid disodium salt ( $250 \mathrm{~g}, 96 \%$ ) was purchased from Aldrich Chemical Company. $\mathrm{KH}_{2} \mathrm{PO}_{4}$ (500 g) was purchased from Fisher Scientific. Coumarin (50 g) was purchased from MP Biomedicals, LLC. 7- hydroxycoumarin (25 g, $99 \%$ ) was purchased from Acros Organics.

\subsubsection{Ultrasound Equipment}

A UES Model 15-660 ultrasound generator purchased from Ultrasonic Energy System Company of Panama City, Florida, was used for sonication. A 580mL glass vessel connecting to the generator was placed into a 10-gallon water cooling bath which maintained the temperature at $5-10{ }^{\circ} \mathrm{C}$. The aqueous solutions containing the target compound were added into the reaction vessel, saturated by gentle bubbling with $\mathrm{O}_{2}$ for 15 min and applied ultrasound at $396 \mathrm{~W}, 640 \mathrm{kHz}$. During sonication, $1.5 \mathrm{~mL}$ samples were taken from the reactor at different time intervals using a glass syringe for chemical analysis. Samples were stored in the refrigerator until analysis.

\subsubsection{Analytical Apparatus and Methods}

The HPLC system consisted of a Varian Pro star 210 pump with a diode array detector was used to monitor the concentration of CET. The separation was performed on a $250 \times 4.60 \mathrm{~mm} 5$ н C18 column (S.N.410920-29) using mobile phase A (acetonitrile 
$(\mathrm{ACN}))$ and $\mathrm{B}\left(\right.$ water, $50 \mathrm{mM} \mathrm{KH} \mathrm{PO}_{4}$ at $\left.\mathrm{pH}=3.7\right)(40: 60(\mathrm{v} / \mathrm{v}))$ at a flow rate of $1 \mathrm{ml} \cdot \mathrm{min}^{-}$

${ }^{1}$ with the detection wavelength of $205 \mathrm{~nm}$.

Agilent 6530 Accurate mass spectrometer combined with an Agilent Infinity 1290 Infinity Binary Pump equipped with a $3.0 \times 100 \mathrm{~mm} 1.8 \mu \mathrm{C} 18$ column were used for the product study. The mobile phase of LC-MS was composed A (water, $0.1 \%(\mathrm{v} / \mathrm{v})$ formic acid) and $\mathrm{B}$ (acetonitrile) in a gradient program at a flow rate of $0.4 \mathrm{ml} / \mathrm{min}$ : 0-1 $\mathrm{min}$ : $95 \%$ A; 0.1-5.0 min: 95-0\% A;5.1-6.0 min: 95\% A. The column temperature was $30^{\circ} \mathrm{C}$. [136] The samples were subjected to LC-MS analysis to obtain the chromatograph and MS spectra.

A fluorometric method was used to monitor the production of 7-hydroxyl coumarin $(7-\mathrm{OHC})(\lambda($ excitation $)=342 \mathrm{~nm}, \lambda($ emission $)=455 \mathrm{~nm})$ with Cary Eclipse Fluorescence Spectro-photometer from Agilent Technologies. [137] The production of 2hydroxyterephthalic acid (2-HTPA) was monitored by the fluorometer $(\lambda($ excitation $)=315$ $\mathrm{nm}, \lambda($ emission $)=425 \mathrm{~nm})[138]$.

\subsection{Results and Discussions}

\subsubsection{Effect of Initial CET Concentrations}

To study the effect of initial CET concentration on degradation, six initial concentrations, varying from 4.3 to $65.0 \mu \mathrm{mol} / \mathrm{L}$, were selected. The percentage of the concentration of CET at time t over initial concentration was plotted as a function of treatment time and the result is demonstrated in Figure.4.2. The half-life time (time to achieve $50 \%$ degradation of initial concentration) increases as the initial concentration 
increases. When the initial concentrations of CET were below $21.7 \mu \mathrm{mol} / \mathrm{L}$, the half-life time was less than 12 min. Only about $25 \%$ CET was degraded within 15 min when the concentration was $65.0 \mu \mathrm{mol} / \mathrm{L}$.

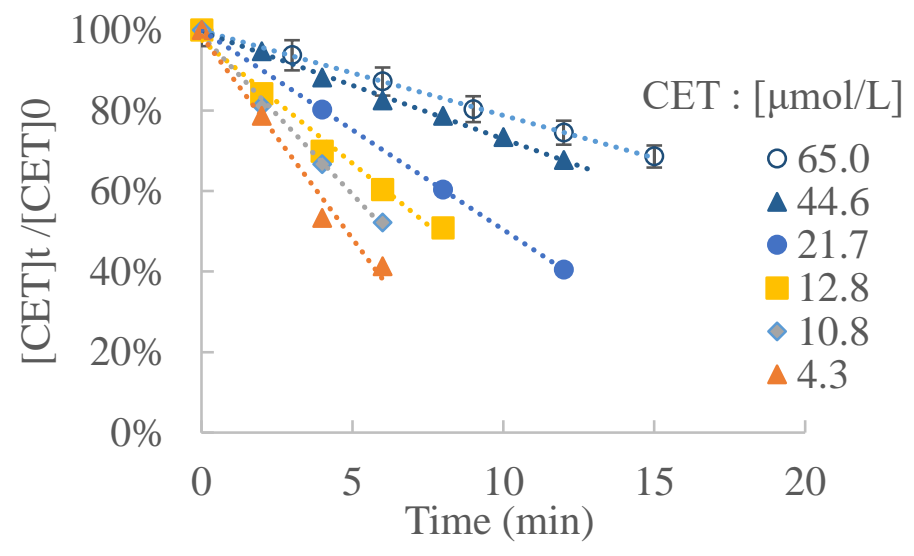

Figure. 4.2 Degradation plots dependent of initial concentration. Triplicate trials were applied to $65.0 \mu \mathrm{mol} / \mathrm{L}$ solution and the reproducibility was $\pm 4 \%$.

The reaction between the target compound and hydroxyl radicals in sonolysis is often modeled by pseudo-first order kinetic. [77,139] The kinetic of degradation of CET was plotted following Eq.4.1 as a function of time, and the rate constants were determined as the slope of the linear and are listed in Table 4.1.

$$
\frac{\ln C_{t}}{\ln C_{0}}=k t
$$

Eq. 4.1 
Table 4.1 Determine rate constant $\mathrm{k}\left(\mathrm{min}^{-1}\right)$ for ultrasonic degradation of CET.

\begin{tabular}{|c|c|}
\hline $\begin{array}{c}\text { Initial Concentration } \\
(\mu \mathrm{mol} / \mathrm{L})\end{array}$ & $\begin{array}{c}\text { Rate Constant } k \\
\left(\mathrm{~min}^{-1}\right)\end{array}$ \\
\hline 4.3 & 0.1481 \\
\hline 10.8 & 0.1061 \\
\hline 12.8 & 0.0852 \\
\hline 21.7 & 0.0762 \\
\hline 44.6 & 0.0315 \\
\hline 65.0 & 0.0246 \\
\hline
\end{tabular}

The results in Table 4.1 indicated that the rate constant decreases as the initial concentration increases, which doesn't follow the true pseudo-first order process. This behavior is related to the heterogeneous process occurring at or near the gas-liquid interface. The amount of produced hydroxyl radicals produced under the same ultrasound conditions is considered constant. The change of rate constant with different CET starting concentrations can be explained by saturation effect and mass transfer limitation.

\subsubsection{Heterogeneous Process Modeling by Langmuir-Hinshelwood Isotherm}

Under supercritical conditions, the gas-liquid interface is considered as a hydrophobic surface with high temperature. The high temperature leads to the pyrolysis of water molecules, as well as the pyrolytic degradation of the target compound. The hydroxyl radicals produced during cavitation process react with the compounds partitioned to the g1 interface to achieve oxidative degradation. To have an insight into the heterogenous process, Langmuir-Hinshelwood (L-H) kinetic was applied as a simulation of the partitioning of CET to the g-l interface [77,109]. The L-H model assumes that the g-1 interface provides many equivalent sites; the partition of the target molecules forms a 
monolayer; the molecule that occupies each site has no interaction with adjacent sites; the partition and desorption process is in an equilibrium. The Langmuir-Hinshelwood kinetic equation is shown in Eq.4.2.

$$
\frac{1}{r_{0}}=\frac{1}{k_{r} K C_{0}}+\frac{1}{k_{r}}
$$

where $\mathrm{r}_{0}(\mu \mathrm{mol} /(\mathrm{L} \cdot \mathrm{min}))$ is the initial rate, $\mathrm{C}_{0}(\mu \mathrm{mol} / \mathrm{L})$ is the initial $\mathrm{DPH}$ concentration, $\mathrm{k}_{\mathrm{r}}(\mu \mathrm{mol} / \mathrm{L} \cdot \mathrm{min})$ is the reactivity coefficient and $\mathrm{K}(\mu \mathrm{mol} / \mathrm{L})$ is the equilibrium constant.

The kinetic data obtained from the degradation of the concentrations of 4.3 to 65.0 $\mu \mathrm{mol} \cdot \mathrm{L}^{-1}$ was plotted into $\mathrm{L}-\mathrm{H}$ model with a $\mathrm{R}^{2}$ value of 0.99 (Figure.4.3). Calculated from the slope and intercept, the equilibrium constant was $0.10 \mu \mathrm{mol} \cdot \mathrm{L}^{-1}$ and the reactivity coefficient was $1.64 \mu \mathrm{mol} \cdot \mathrm{L}^{-1} \cdot \mathrm{min}^{-1}$.

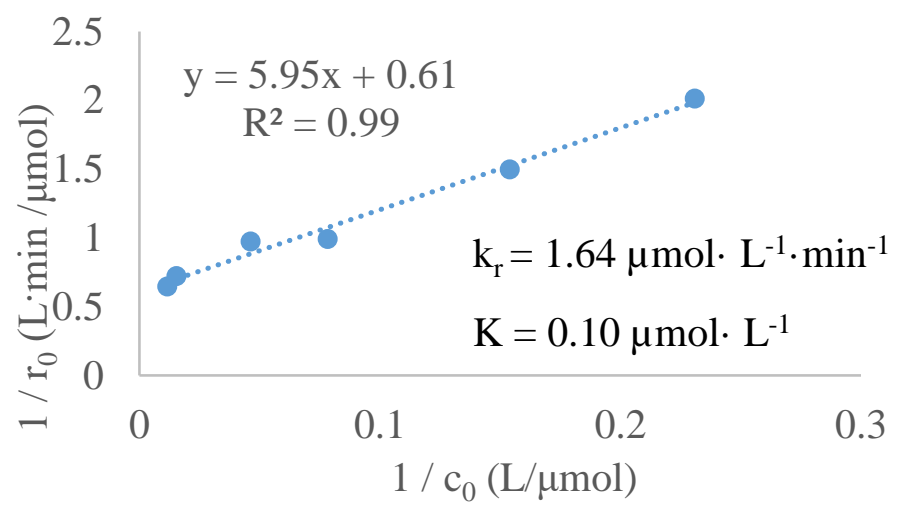

Figure. 4.3 Langmuir-Hinshelwood kinetic plot of ultrasonic degradation of CET. 


\subsubsection{Effect of HO on the Degradation Process}

As the major reactive oxidative species produced during cavitation, hydroxyl radicals play an important role during the degradation process. The short life-time $\left(10^{-9} \mathrm{~s}\right)$ makes it not plausible to directly measure the production of $\mathrm{HO} \cdot$. In recent years, many probes have been identified to scavenge the HO using indirect detection methods. Two sensitive and specific scavengers, terephthalate (TPA) and coumarin (COU), were selected to assess the $\mathrm{HO}$. at different cavitation regions. TPA and COU are barely fluorescent parent compounds, but yield highly fluorescent adducts upon reacting with HO [140-142]. The production of $\mathrm{HO}$ - follows zero-order kinetic, and is not affected by the concentration of other compounds [143]. The hydroxyl radicals formed in the hot-spot and gas-liquid interface can react with the target compounds or other radicals that are also formed during cavitation, and the rest are released into the bulk solution. TPA, a dianion in the aqueous solution, resides in the hydrophilic area and captures only the hydroxyl radicals in the bulk solution [144]. The hydrophobic COU can partition to the g-l interface and react with the HO. [137,145].

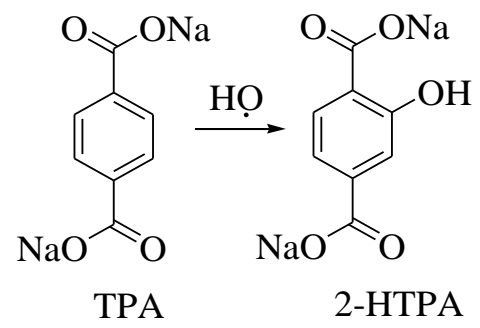

Figure. 4.4 Terephthalate reacts with $\mathrm{HO} \cdot$ and forms 2-hydroxyterepthalate. 


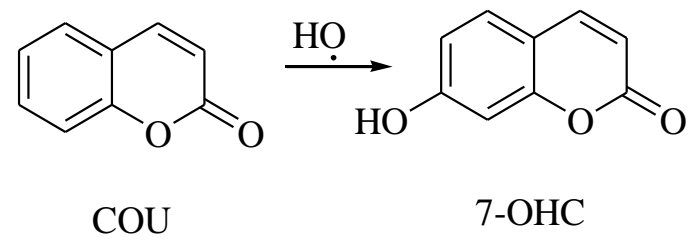

Figure. 4.5 Coumarin reacts with HO- and forms 7-hydroxycoumarin.

\subsubsection{HO• trapping study by coumarin (COU)}

An experiment was conducted to study the competition between COU and CET over HO by monitoring the production of 7-OHC. A calibration curve of 7-OHC was carefully made from 0.01 to $2 \mu \mathrm{mol} / \mathrm{L}$, as $\mathrm{y}=291 \mathrm{x}+3.2$ with $\mathrm{R}^{2}=0.9995$, shown in Figure.4.6. Ultrasound was applied to a $0.1 \mathrm{mmol} / \mathrm{L} \mathrm{COU}$ solution with and without the existence of $0.1 \mathrm{mmol} / \mathrm{L} \mathrm{CET}$, respectively. Samples were taken at specific time intervals. The concentrations of 7-OHC were plotted as a function of time, illustrated in Figure.4.7. The slopes of the plots described the formation rate of 7-OHC, which was 0.026 $\mu \mathrm{mol} /(\mathrm{L} \cdot \mathrm{min})$ without $\mathrm{CET}$ and $0.014 \mu \mathrm{mol} /(\mathrm{L} \cdot \mathrm{min})$ with $\mathrm{CET}$. The addition of 0.1 $\mathrm{mmol} / \mathrm{L} \mathrm{CET}$ to $0.1 \mathrm{mmol} / \mathrm{L} \mathrm{COU}$ created a $1: 1$ ratio solution. For the COU mostly partitions and competes with CET at the g-l interface, The rate constant of COU and HO was reported as $1.05 \times 10^{10} \mathrm{M}^{-1} \mathrm{~s}^{-1}[113,114]$. A $46 \%$ decrease of the formation of 7OHC was observed, which indicated that the rate constant of CET and HO- was $8.94 \times 10^{9}$ $\mathrm{M}^{-1} \mathrm{~s}^{-1}$. 

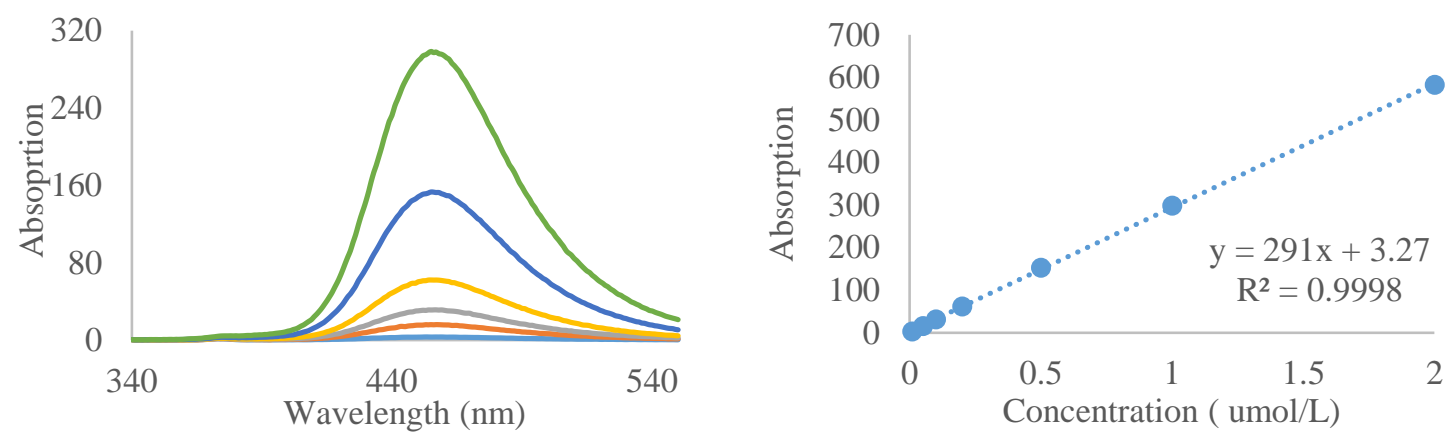

Figure. 4.6 Calibration curve of 7-OHC was determined as $\mathrm{y}=291 \mathrm{x}+3.27$.

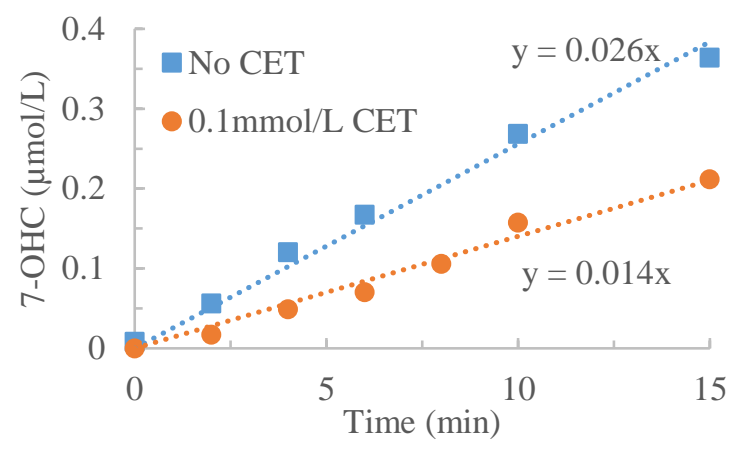

Figure. 4.7 The production of 7-OHC in $0.1 \mathrm{mmol} / \mathrm{L} \mathrm{COU}$ solution with and without $0.1 \mathrm{mmol} / \mathrm{L} \mathrm{CET}$. Triplicate experiments were conducted and the reproducibility was within $\pm 3 \%$.

\subsubsection{HO trapping by terephthalic acid (TPA)}

Similar experiments were conducted using TPA as the HO- scavenger. The calibration curve of 2-HTPA was made and plotted in Figure. 4.8. The 2-HTPA was produced at the rate of $0.249 \mu \mathrm{mol} /\left(\mathrm{L}^{\cdot} \mathrm{min}\right)$ in the $0.1 \mathrm{mmol} / \mathrm{L}$ TPA solution in the sonication system at $640 \mathrm{kHz}, 396 \mathrm{~W}$ (Figure. 4.9 )[140,146]. When the $0.1 \mathrm{mmol} / \mathrm{L} \mathrm{TPA}$ was mixed with the $0.1 \mathrm{mmol} / \mathrm{L} \mathrm{CET}$ solution, the production of 2-HTPA was $0.025 \mu \mathrm{mol} /$ (L· min). A nearly $90 \%$ decrease was observed when TPA was used as the scavenger, indicating that $90 \% \mathrm{HO}$ reacted with CET during the cavitation. As discussed above, CET 
not only reacts with the $\mathrm{HO}^{*}$ at g-l interface, but also competes with TPA over $\mathrm{HO}^{*}$ in the bulk solution, which explains the observation of this significant decrease of 2-HTPA production.
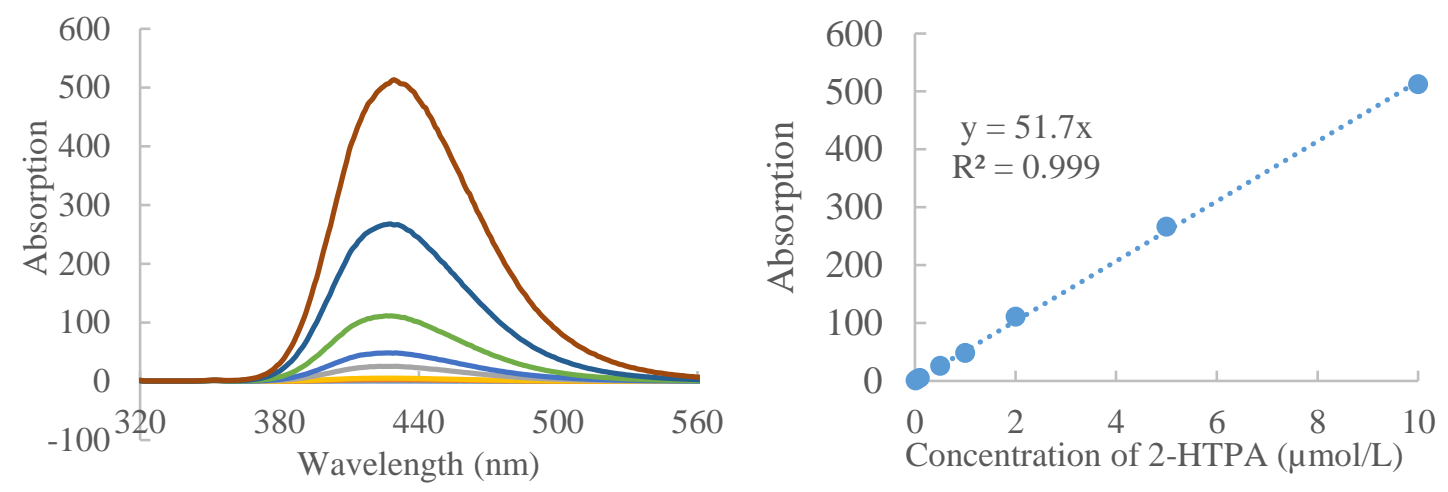

Figure. 4.8 Calibration curve of 2-HTPA

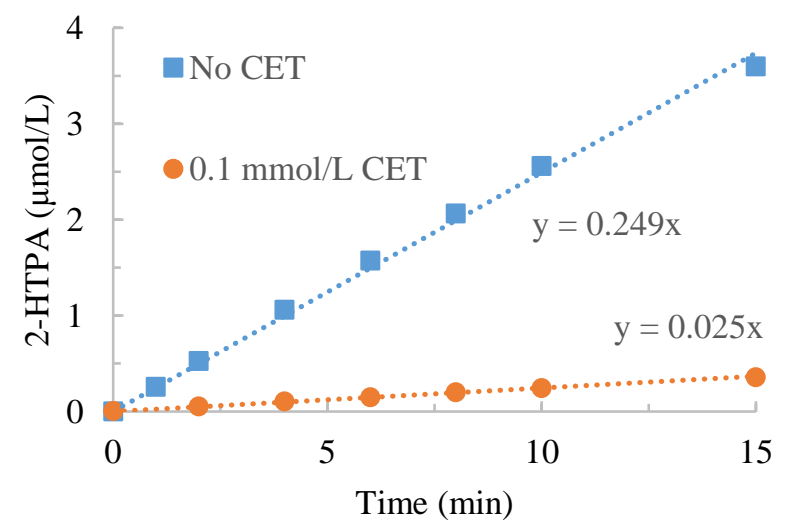

Figure. 4.9 The production of 2-HTPA in $0.1 \mathrm{mmol} / \mathrm{L} \mathrm{TPA}$ blank and in $0.1 \mathrm{mmol} / \mathrm{L}$ TPA and $0.1 \mathrm{mmol} / \mathrm{L}$ CET mixture solution $(0.1 \mathrm{v} 0.1)$. Triplicate experiments were applied and the reproducibility was within $\pm 4 \%$.

\subsubsection{Saturation Gas Effect}

The properties of saturation gas, such as the adiabatic ratio, thermal conductivity, solubility in water and the content of the gas, are closely related to the cavitation event, 
which can lead to different degradation rates [80]. To have a better understanding of saturation gas effect on the degradation of CET, experiments were carried out by applying ultrasound (640 kHz, 396W) to $10 \mathrm{ppm}$ CET solutions bubbled with Ar, air, $\mathrm{N}_{2}$ and $\mathrm{O}_{2}$, respectively. The properties of different gases are listed in Table 4.2. The adiabatic ratio $\gamma$ is an important factor that determines the temperature in the cavitation hot-spot. The hotspot temperature in the Ar-saturated solution $(\gamma=1.67)$ can be five times higher than in the $\mathrm{N}_{2}(\gamma=1.40)$ under the same condition [147]. The heat in the hot-spot transduces through the bubble and is adsorbed during phase change and pyrolysis reactions. Thermal conductivity determines how fast the heat goes from the hot-spot to the bulk solution. The gas solubility has an effect on the bubble surface tension, which means the more soluble the gas is, the more nucleation sites are created and more cavitation are produced. [148] The degradation of CET under different saturation gases was plotted in Figure.4.10, indicating the percentage of remaining CET in the solution as a function of time. The results showed that the degradation rate of CET is the fastest under the $\mathrm{O}_{2}$-saturated solution, $\mathrm{Ar}$ is the second and $\mathrm{N}_{2}$ is the slowest.

Table 4.2 Physical properties of saturation gases (at $1 \mathrm{~atm}, 300 \mathrm{~K}$ ) [152]

\begin{tabular}{|c|c|c|c|}
\hline $\begin{array}{c}\text { Saturation } \\
\text { Gas }\end{array}$ & $\begin{array}{c}\text { Adiabatic Ratio } \\
(\gamma)\end{array}$ & $\begin{array}{c}\text { Thermal Conductivity } \\
(\mathrm{mW} / \mathrm{mK})\end{array}$ & $\begin{array}{c}\text { Solubility in Water } \\
(1 \mathrm{~atm}, 293.15 \mathrm{~K}, \quad \text { mole } \\
\text { fraction })\end{array}$ \\
\hline $\mathrm{N}_{2}$ & 1.40 & 26.0 & $1.274 \times 10^{-5}$ \\
\hline $\mathrm{Air}$ & 1.39 & 26.3 & $/$ \\
\hline $\mathrm{Ar}$ & 1.67 & 17.9 & $2.748 \times 10^{-5}$ \\
\hline $\mathrm{O}_{2}$ & 1.40 & 26.3 & $2.501 \times 10^{-5}$ \\
\hline
\end{tabular}




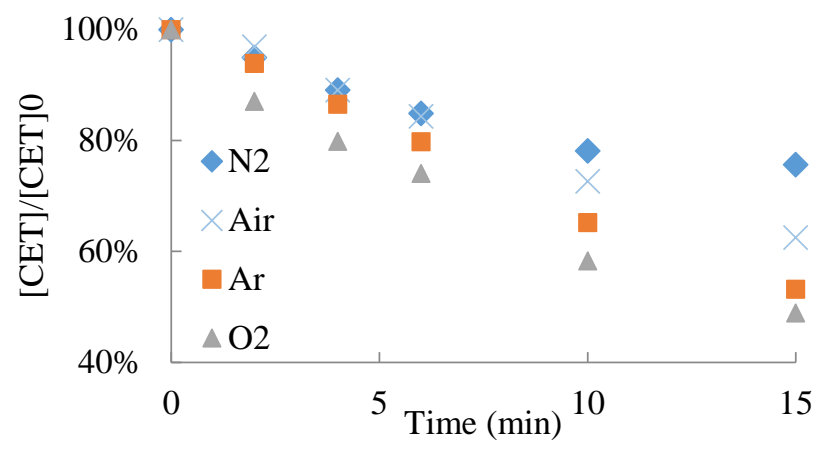

Figure. 4.10 Effect of different saturation gases on the degradation of CET.

Argon has the highest specific heat ratio, lowest thermal conductivity and the highest solubility, which provides the best environment for pyrolytic remediation of CET. However, the $\mathrm{O}_{2}$-saturated solution has a faster degradation rate than Ar. The difference can be explained by the degradation related to the hydroxyl radical oxidation process. When the solution is saturated by $\mathrm{O}_{2}$, more $\mathrm{HO}$ are produced and participate in the oxidation of CET. As discussed in 4.4.3, CET is not a volatile compound and the carboxylic tail of CET makes it partially hydrophilic and may reside in the bulk solution, therefore, the pyrolysis of CET mainly happens at the g-l interface, instead of the hot-spot. The CET in the bulk solution can only be decomposed by the produced radicals, which makes the degradation rate of $\mathrm{O}_{2}$ slightly higher than $\mathrm{Ar}$. When the solution was saturated by $\mathrm{N}_{2}$, the hot-spot temperature was lower than Ar, while the formation of $\mathrm{HO}$ was not comparable to $\mathrm{O}_{2}$. Therefore, the degradation rate was the slowest. Since air consists of $78 \% \mathrm{~N}_{2}, 21 \%$ $\mathrm{O}_{2}$ and other gases, the degradation of CET under air saturated environment is higher than $\mathrm{N}_{2}$, but not as fast as either $\operatorname{Ar}$ or $\mathrm{O}_{2}$. 


\subsubsection{Degradation Product Study}

Ultrasonic degradation of the target compound involves pyrolysis and oxidation reaction. The product study can help to predict the reaction mechanisms. Several byproducts were observed by LC-MS. The MW of CET was 388.1554, and the retention time was 3.725 min. A $1 \mathrm{ppm}$ CET solution was used for product studies after a 10-min treatment. Generally, HO attacks a compound through three different pathways, hydroxyl radical addition, hydrogen abstraction and electron transfer. Hydroxyl radical addition occurs much faster than the other two.

\subsubsection{Hydroxyl radical addition product}

There are two aromatic rings in CET, however, the deactivating group chlorine makes chlorobenzene react with hydroxyl radicals much slower than the benzene ring. Therefore, the hydroxyl radical was more likely to add to the benzene ring, shown in Figure.8. Three new peaks with $[\mathrm{MW}+\mathrm{H}]{ }^{+}$of 405.1557 were found in the products and the retention times were $3.109,3.425$, and $3.581 \mathrm{~min}$, which corresponded to the products of addition at the para, meta, and ortho positions. The peak that appeared at 3.109 min was the smallest, and the one at 3.425 min was the largest. However, all three products have similar spectra, which makes it difficult to distinguish these isomers. 

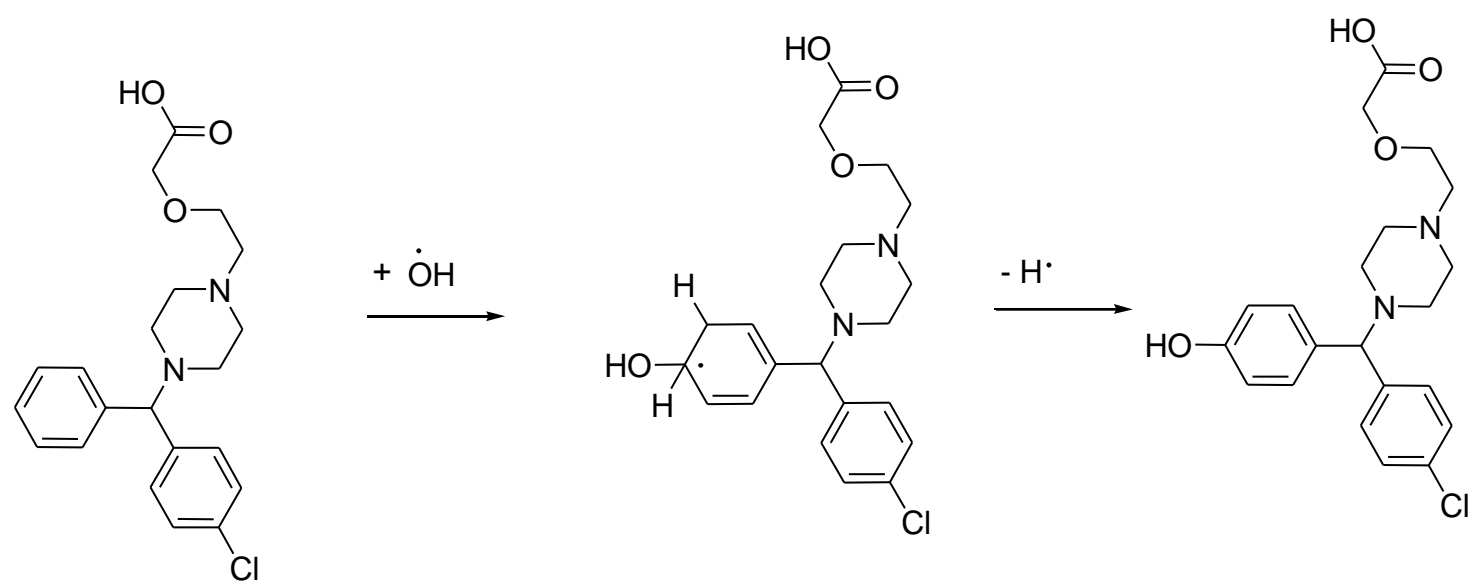

Figure. 4.11 Hydroxyl radical addition products

\subsubsection{Pyrolytic Products}

Cavitation-induced high temperature leads to the pyrolytic degradation of CET. The carboxylic group of CET makes it unlikely to evaporate to the hot-spot, however, the hydrophobicity of the two aromatic rings makes the CET partition to the g-l interface. The high temperature at g-1 interface leading to the homolytic bond cleavage of C-C and C-O bond produces other products. A MW of 330.1499 product was identified at the retention time of $3.536 \mathrm{~min}$. The related reaction pathway is shown in Figure. 4.12.<smiles>O=C(O)C(=O)OCCN1CCN(C(c2ccccc2)c2ccc(Cl)cc2)CC1</smiles>

Figure. 4.12 Pyrolytic product with MW of 330.1499

Two other pyrolytic products with MW of 286.1237 and 188.1161 were found at the retention time of 3.570 and $1.319 \mathrm{~min}$. These two compounds were both produced by C-N bond cleavage. 
<smiles>CCOCC(=O)OCCN1CCN(C(c2ccccc2)c2ccc(Cl)cc2)CC1</smiles>

Figure. 4.13 Pyrolytic product with MW of 286.1237<smiles>CC(C)CC1CC1C1CC1</smiles>

Figure. 4.14 Pyrolytic product with MW of 188.1161

\subsection{Conclusions}

The second-generation antihistamine, Cetirizine, has been detected in surface water sources. Ultrasound is rapid and effective to remediate CET in water. The degradation process followed pseudo-first-order kinetic, and was modeled by Langmuir-Hinshelwood kinetic. The hydroxyl radical competition study showed that CET reacts with $\mathrm{HO} \cdot$ at both the g-l interface and the bulk solution. Different saturation gases have an effect on the degradation rate. $\mathrm{O}_{2}$ saturated-solution showed the fastest degradation rate while $\mathrm{N}_{2}$ showed the slowest rate. Product studies indicated that three isomers were formed by the hydroxyl radical addition to the aromatic ring, and pyrolytic products. 
Chapter 5 An exploration of degradation of "GenX" using different oxidation/reduction methods 


\subsection{Abstract}

Perfluoro-2-propoxypropanoic acid (PFPrOPrA), known as 'GenX' and shown in Figure.1, is an alternative substance for the legacy perfluorinatedoctanoic acid (PFOA). The strong C-F bonds make "GenX" resistant to degradation and persistent in the environment. Typical and advanced wastewater treatment methods are unable to remove effectively or degrade "GenX". Different remediation methods were applied to degrade "GenX". Pulse-radiolysis indicated a bimolecular rate constant of $\mathrm{e}_{\mathrm{aq}}$ " and "GenX" of $5 \times$ $10^{10} \mathrm{M}^{-1} \cdot \mathrm{s}^{-1}$, however, less than $2 \%$ degradation was observed after 8 hours radiation under a variety of conditions. Photocatalysis with $\mathrm{TiO}_{2}$ at $350 \mathrm{~nm}$ under alkali environment showed slow conversion and no defluorination. The ultrasonic decomposition of "GenX" was studied in an argon-saturated aqueous solution. Upon irradiation, "GenX" at different initial concentrations, from 0.6 to $6 \mu \mathrm{mol} / \mathrm{L}$ at $670 \mathrm{~Hz}$ and $396 \mathrm{~W}$, more than $80 \%$ of starting concentration, was remediated within $60 \mathrm{~min}$, and $\mathrm{F}^{-}$was detected as the major mineralization product. Since perfluorinated compounds generally have low reactivity towards hydroxyl radicals, we propose the ultrasonic-induced degradation of "GenX" is primarily by pyrolysis. The reaction mechanisms and possible pyrolytic products were investigated using computational methods. Enthalpies of the initial $\mathrm{C}-\mathrm{C}$ and $\mathrm{C}-\mathrm{O}$ bond cleavages of GenX were calculated using density functional theory at the wb97xd/6$311 \mathrm{G}^{* *}$ level using the Gaussian 09 package. Seven possible initial competing reaction pathways were considered, followed by beta-scission reaction pathways of the initial radical species. The results indicated that pyrolysis induced by ultrasound could be an 
effective tool to remediate GenX. Similar bond cleavage/consecutive beta-scission mechanisms are also considered for related perfluorinated compounds.

\subsection{Introduction}

The legacy PFASs is a specific term that refers to the long-chain perfluoroalkyl substances (PFASs). PFASs describe a class of chemicals that use fluorine to replace some or all the hydrogens on the aliphatic carbon backbone to obtain desired physical, chemical and biological properties [17]. Over the past 60 years, legacy PFASs were widely used in the production of commercial products, food-wrapping paper coating materials, firefighting foams and so on. The extensive use of PFASs was resulted in the widespread occurrence of these chemicals in throughout environment and biological systems. The extremely persistent PFASs have been detected in drinking water sources related to industrial sites, military fire training areas, civilian airports, and waste water treatment plants [17,149-152]. With recent reports and increased incidents of negative human health effects because of the exposure to PFASs, the U.S. Environmental Protection Agency (USEPA) announced a life-time advisory level of a sum of $70 \mathrm{ng} / \mathrm{L}$ perfluorooctanoic acid (PFOA) and perfluorooctane sulfonic acid (PFOS) in drinking water [153,154]. With restrictions of legacy PFASs, their uses were declined in the US, Europe and other countries. Alternative substances commonly referred to emerging PFASs were produced to replace the legacy PFASs.

Perfluoro(2-methyl-3-oxahexanoic) acid ("PFProPrA"), Figure. 5.1, with the trade name of "GenX" was introduced by DuPont in 2009 as the sustainable replacement alternative of PFOA, and employed in the manufacturing of fluoropolymer resins and 
Teflon [19]. "GenX" introduces ether functionality by inserting an oxygen atom to the carbon backbone while the perfluoro moiety is retained. While PFOA has hydrophobic and hydrophilic properties, the short chain "GenX" was expected to have higher mobility and be less fat soluble. The manufacturing uses of emerging PFASs are well documented, however, their presence in the environment was only recently reported. "GenX" was first detected in the downstream of the Cape Fear from Fayetteville Works in 2012 [155]. Reports of "GenX" presence in surface water creeks and streams in Ohio at the concentration of $100 \mathrm{ppt}$ were reported. In the extreme, concentration as high as $4500 \mathrm{ppt}$ in drinking water were detected in North Carolina. Lab experiments indicated that "GenX" could lead to liver damage [20]. While limited work has been published regarding the removal/remediation of "GenX". Mary Jo Weiss-Errico et.al published their work using cyclodextrin to encapsulate emerging perfluoroethercarboxylic acids [156]. Their results showed that the branched head in "GenX" makes the carboxylic group hard to bond to cyclodextrin, which explained why the removal of "GenX" was more difficult than other emerging PFCs.

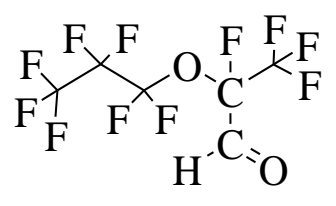

Figure. 5.1 Structure of "GenX"

Conventional water treatment methods were applied to remove PFOA from contaminated water with limited success. Activated carbons (AC) have been approved as efficient adsorbents to remove PFOA and PFOS. Using granular activated carbon (GAC) can achieve an efficiency of 99\%, and the efficiency of powdered activated carbon (PAC) 
is even higher [157]. However, further treatment is still required to destroy the PFOA and PFOS accumulated and concentrated through the adsorption. Oxidative treatment methods, using ozone, hydrogen peroxide, and Fenton reagent, showed that degradation efficiency was closely related to the functional group. Therefore, whether chemical oxidation methods can remediate short-chain PFASs still remains untested [158].

Given the resistance of "GenX" to oxidation and adsorption technologies, we chose to explore the use of gamma-radiolysis, $\mathrm{TiO}_{2}$ photocatalysis and sonolysis which can produce oxidation and reduction degradation processes. In addition, sonolytic degradation can be initiated by oxidation, reduction and pyrolysis reactions. These three remediation methods have been extensively used in water treatment. Radiolysis is a powerful method initiated involving irradiating the aqueous solution, which leads to the production of several reactive radicals [39]. The radiolysis of pure water is described in Eq.5.1 [159], where the numbers in parenthesis are the radiation chemical yields of these species (G-values) per $100 \mathrm{eV}$ absorbed energy.

$$
\begin{array}{r}
\mathrm{H}_{2} \mathrm{O} M \rightarrow \mathrm{e}_{\mathrm{aq}}{ }^{-}(0.27)+\cdot \mathrm{H}(0.06)+\cdot \mathrm{OH}(0.28)+ \\
\mathrm{H}_{2}(0.05)+\mathrm{H}_{2} \mathrm{O}_{2}(0.07)+\mathrm{H}_{\mathrm{aq}}{ }^{+}(0.27)
\end{array}
$$

The production of $\mathrm{e}_{\mathrm{aq}}{ }^{-}$and $\mathrm{H} \cdot$ can be powerful reducing agents which have been effective for reduction degradation of alkyl halides. (Eq.5.2)

$$
R-X+e^{-}=>R-X^{\bullet}=>R \cdot+X^{-}
$$

The degradation of pollutants by $\mathrm{TiO}_{2}$ photocatalysis is initiated by $\mathrm{e}_{\mathrm{B}}{ }^{-}$, and $\mathrm{h}_{\mathrm{vB}}{ }^{+}$or $\mathrm{HO}$. produced during the photocatalysis process. When $\mathrm{TiO}_{2}$ is irradiated by UV light, 
holes $\left(\mathrm{h}^{+}\right)$and electrons $\left(\mathrm{e}^{-}\right)$are formed at the valence band and the conduction band, respectively. The positively charged holes react with water and form a powerful oxidant, $\mathrm{HO} \cdot$. The degradation of PFOA by $\mathrm{TiO}_{2}$ with oxalic acid as the hole quencher has been reported [160].

Ultrasonic cavitation describes the process of formation, growth and collapse of gas bubbles by applying ultrasound waves to aqueous solutions [101-103]. The cavitation process generates three zones: 1) hot-spot, located at the interior of the cavitation bubble, which presents an extremely high temperature (> $5000 \mathrm{~K}$ ) and high pressure (> $500 \mathrm{~atm})$; 2) gas-liquid interface, the boundary layer between the solution and hot-spot, this also presents high temperatures (> $2000 \mathrm{~K}$ ) and high pressure (> $300 \mathrm{~atm})$; 3) bulk solution, which remains at an ambient temperature and pressure. Hydroxyl radicals are produced by the pyrolysis of water molecules in the hot-spot and at the gas-liquid interface. The pollutants partition to the interface and diffuse to the hot-spot and are degraded by the thermal processes $[53,105,106,109,144,161]$.

The ultrasonic and reductive transformation of a limited number of legacy PFAS have been reported [162-164], however we are unaware of any reports on the ultrasonic or reductive transformation of emerging PFAS. Herein, we reported the study of the transformation of "GenX" using radiolysis, $\mathrm{TiO}_{2}$ photocatalysis and sonolysis, and predict the reaction pathways of pyrolytic degradation of "GenX". 


\subsection{Experiment Materials and Methods}

\subsubsection{Materials}

PFPrOPrA ("GenX”) was purchased from Thermo Fisher Scientific (Waltham, MA). All solutions were prepared with millipore filtered water $(18 \mathrm{M} \Omega . \mathrm{cm})$ and volumetric glassware.

\subsubsection{Methods}

A pulsed mode ultrasonic transducer UES 15-660 Pulsar (Ultrasonic Energy Systems Inc., Panama City, Florida) equipped with disk shaped horn attached glass reactor $(500 \mathrm{~mL})$ was employed for all experiments. Operating conditions were previously optimized and set at pulse duration of $0.62 \mathrm{~s}$, pulse repetition of $2.5 \mathrm{~s}$ and frequency of $650 \mathrm{kHz}$ under operational power of $396 \mathrm{~W}$. Power density of the sonication was $7.9 \mathrm{~W} / \mathrm{cm}^{2}$ with ultrasonic horn diameter of $9 \mathrm{~cm}$. Ultrasound traveled through $5 \mathrm{~cm}$ of water and $38 \mu \mathrm{m}$ of the polyethylene film to reach the $500 \mathrm{~mL}$ solution inside reaction vessel with $9 \mathrm{~cm}$ diameter. The reactor was submerged in an ice bath and the monitored temperature range inside the reaction vessel was $10 \pm 2{ }^{\circ} \mathrm{C}$ throughout the reaction. The aqueous solution containing the target compound was added into the reaction vessel, saturated by gently bubbling with Ar for 15 min. Samples were taken at specific treatment intervals and analyzed immediately or stored in the refrigerator until analyses.

$\mathrm{F}^{-}$analysis was conducted using Thermo Scientific Orion Fluoride Ion Selective Electrode connected to a Mettler Toledo ISE meter through BNC connection. A TISAB solution was pre-made to provide a constant background ionic strength while a low-level 
Total Ionic Strength Adjustment Buffer (TISAB II) solution was used for lower concentration $\mathrm{F}^{-}$.

The pulse radiolysis experiments were performed at Notre Dame Radiation Laboratory, US Department of Energy. An 8-MeV model TBS-8/16- 1S linear accelerator from Titan Beta corporation was employed to conduct the electron pulse radiolysis. More detailed information about this set can be found in the reference article. [165] All experiments were performed in static cells with an average of 8 replicate pulses. All solutions were pre-saturated with $\mathrm{N}_{2}$ at neutral $\mathrm{pH}$ for 5 min for $\mathrm{e}_{\mathrm{aq}}{ }^{-}$measurement. To determine the rate constant of "GenX" and $\mathrm{e}_{\mathrm{aq}}$ ", a direct absorption was monitored at 720 nm.

The steady-state gamma radiolysis studies were carried out using Shepherd \& Associates Model 109-68R Irradiation ${ }^{60} \mathrm{Co}$ source at the dose of $97.0 \mathrm{~Gy} / \mathrm{min}$ calculated by Frike Dosimetry. The solutions were saturated with $\mathrm{N}_{2}, \mathrm{~N}_{2} \mathrm{O}, \mathrm{O}_{2}$ gases, respectively.

The concentration of "GenX" was determined by UPLC-MS at Valparaiso University. The UPLC-MS consisted of an Aquity UPLC, QDa detector, and a sample manager. The mobile phase was $5 \mathrm{mmol} / \mathrm{L}$ ammonium acetate (water): $5 \mathrm{mmol} / \mathrm{L}$ ammonium acetate $(80: 20=$ methanol: water) $=85: 15$ at a flow rate of $0.3 \mathrm{ml} / \mathrm{min}$.

The geometry optimization, frequency and the pyrolytic mechanisms calculations of "GenX" were carried out in wb97xd/6-311G** using density function method in Gaussian 09 program. 


\subsection{Results and Discussions}

\subsubsection{Radiolysis of "GenX"}

\subsubsection{Kinetic studies of reaction of "GenX" with aqueous electrons ( $\mathrm{eaq}^{-}$)}

Under pulse radiolysis, the rate constant of $\mathrm{e}_{\mathrm{aq}}$ " and "GenX" was determined by plotting the data to exponential decay formula, then fit to pseudo-first order kinetics. [166] The exponential decay of $\mathrm{e}_{\mathrm{aq}}{ }^{-}$was monitored at the wavelength of $720 \mathrm{~nm}$. The absorption decay of $\mathrm{e}_{\mathrm{aq}}$ - under concentration of 100 to $500 \mu \mathrm{mol} / \mathrm{L}$ of "GenX" is shown in Figure. 5. 2(a). The decay of $\mathrm{e}_{\mathrm{aq}}{ }^{-}$increases with the concentration of "GenX" (Eq.5.3), indicating a second-order kinetic process. From the pseudo-first order rate constants obtained in Figure.5.2 (a), a second-order linear relationship was plotted as a function of the concentration of "GenX" solutions, as shown in Figure.5.2 (b).

$$
\mathrm{e}_{\mathrm{aq}}{ }^{-}+\text {"GenX" } \longrightarrow \text { product }
$$
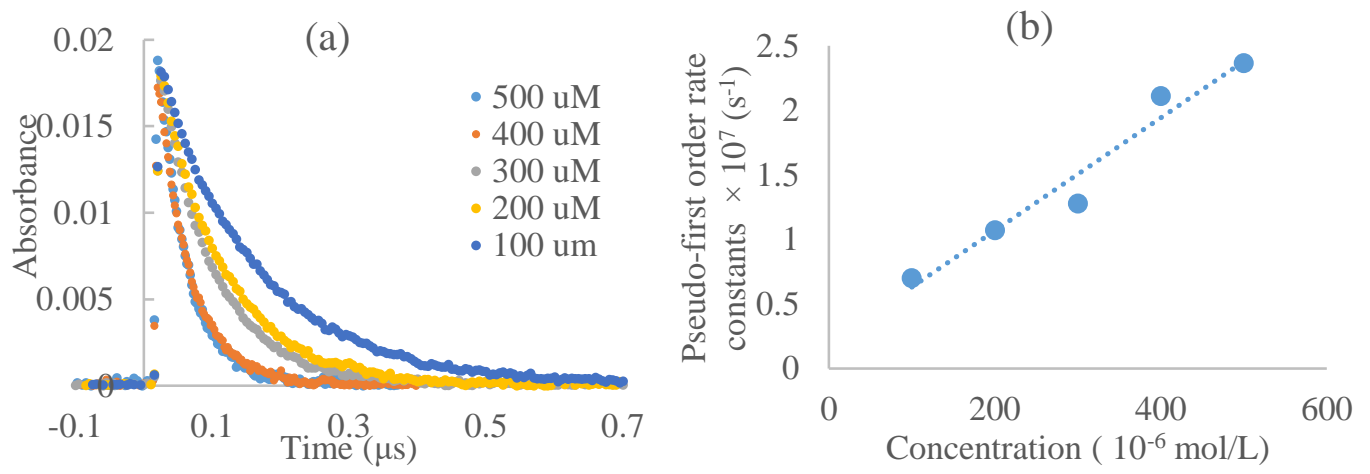

Figure. 5.2 Determination of bimolecular rate constant for "GenX" and aqueous electrons. (a) Exponential decay of the absorption at $720 \mathrm{~nm}$ in the pulse radiolysis solution of 100 to $500 \mu \mathrm{M}$ "GenX" solution. (b) Bimolecular rate constant determined as $5 \times 10^{10}$ $\mathrm{M}^{-1} \cdot \mathrm{s}^{-1}$ 


\subsubsection{Gamma radiolysis steady-state irradiation}

To study the products of the degradation of "GenX", steady-state radiolysis experiments were performed at $5 \mathrm{ppm}$ aqueous solutions. Under $\mathrm{N}_{2}$-saturated conditions, $\mathrm{e}_{\mathrm{aq}}{ }^{-}$and $\mathrm{HO} \cdot$ are the two dominant radicals produced during the radiation process. Samples were taken after $0,1,2,4,8$ hours radiation at the dosage rate of $97.0 \mathrm{~Gy} / \mathrm{min}$. The concentration of "GenX" in each sample was monitored by UPLC-MS. To measure the mineralization of "GenX", the production of $\mathrm{F}^{-}$was monitored by a $\mathrm{F}^{-}$selective electrode. The degradation of "GenX" and $\mathrm{F}^{-}$production were plotted as a function of irradiation validation dose shown in Figure. 5.3. Although the $\mathrm{k}_{\mathrm{e}}+$ "GenX" was near diffusion controlled, after 8 hours irradiation (46560 Gy), 98.2\% of "GenX" remained in the solution, and only $2.22 \mu \mathrm{mol} / \mathrm{L} \mathrm{F}^{-}(1.3 \%$ of total fluoride) was detected. LC-MS analysis of the treated solutions did not show significant disapperance of the formation of measurable products. The results indicated that $\mathrm{e}_{\mathrm{aq}}{ }^{-}, \mathrm{HO} \cdot \mathrm{O}_{2}{ }^{-}$do not lead to appreciable degradation of "GenX". Therefore, to have a better understanding of the role of $\mathrm{HO}$, a 5 ppm "GenX" solution pre-saturated with $\mathrm{N}_{2} \mathrm{O}$ to eliminate $\mathrm{e}_{\mathrm{aq}}{ }^{-}$and $\mathrm{O}_{2}{ }^{-}$.

Similar experiments were conducted, and the obtained results were plotted in Figure.5.4. After 8 hours of treatment, only $1 \%$ "GenX" disappeared. The concentrations of $\mathrm{F}^{-}$of the $0,1,2,4$-hour samples were below the detection limit, and after 8 hours, 1.76 $\mu \mathrm{mol} / \mathrm{L} \mathrm{F}^{-}$(1\% of total fluoride) was produced. Under $\mathrm{N}_{2} \mathrm{O}$ saturated aqueous solution condition, the production of $\mathrm{HO}$. was $0.59 \mu \mathrm{mol} / \mathrm{Gy}$. The dosage rate employed in this experiment was $97.0 \mathrm{~Gy} / \mathrm{min}$, which was $3.42 \mathrm{mmol} / \mathrm{L} \mathrm{HO}$ produced each hour. The 
results demonstrated that $\mathrm{HO}$ leading to slow and/or minimal degradation. Again, no intermediates were observed in LC-MS analysis of the treated solution.

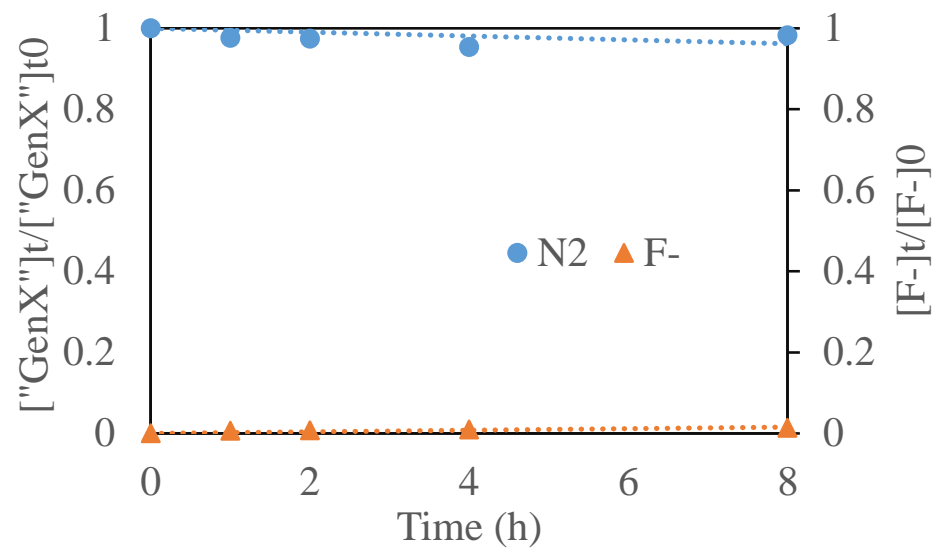

Figure. 5.3 The degradation of $5 \mathrm{ppm} \mathrm{N}_{2}$ saturated "GenX" solution and the production of $\mathrm{F}^{-}$.

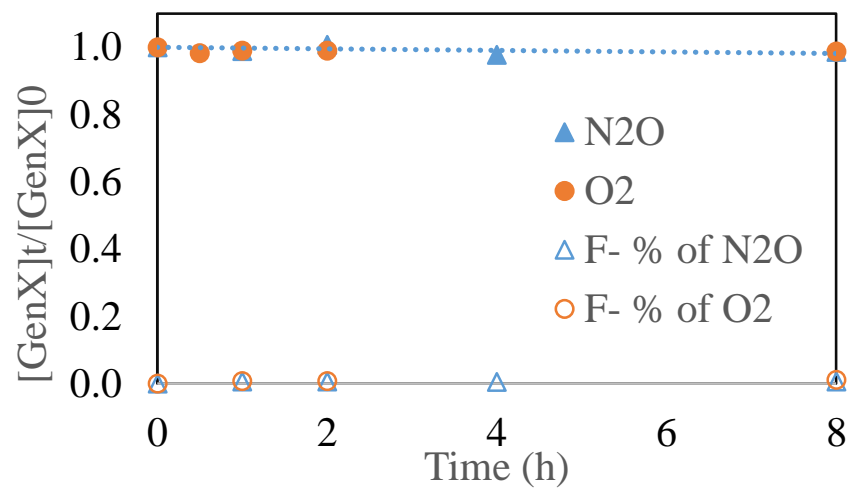

Figure. 5.4 The degradation of 5 ppm N2O and O2 saturated "GenX" solution.

During the radiation process, $\mathrm{HO} \cdot$ and $\mathrm{O}_{2}{ }^{-*}$ are produced when the aqueous solution is saturated with $\mathrm{O}_{2}$. A similar experiment was conducted to the $\mathrm{NO}_{2}$-saturated solution to assess the role of $\mathrm{O}_{2}{ }^{-}$, the results were also plotted in Figure. 5.4. After $8 \mathrm{~h}$ of treatment, approximately $1 \%$ was degraded and $1 \% \mathrm{~F}^{-}$was produced. The results obtained under 
$\mathrm{N}_{2} \mathrm{O}$ and $\mathrm{O}_{2}$ saturated conditions given no significant degradation of "GenX" ( $\left.1 \%\right)$, which indicated that neither $\mathrm{HO} \cdot$ nor $\mathrm{O}_{2}^{--}$were able to decompose "GenX" effectively.

\subsubsection{3 pH effect on the radiolysis degradation of "GenX"}

"GenX" consists of a hydrophobic carbon backbone and a hydrophilic carboxylic group, which is ionized at neutral $\mathrm{pH}$. The degradations of "GenX" were carried out at acidic $\mathrm{pH}(\mathrm{pH}=5)$, neutral $\mathrm{pH}(\mathrm{pH}=7)$ and alkali condition $(\mathrm{pH}=10)$. The degradation of "GenX" was monitored by UPLC-MS. The predicted pKa value of "GenX" is -0.06 while the experimental value is reported as 3.8 [167], which means under all three conditions, "GenX" was deprotonated. Three parallel experiments were done by saturating the solution with $\mathrm{N}_{2}, \mathrm{~N}_{2} \mathrm{O}$ and $\mathrm{O}_{2}$, respectively. The concentration of "GenX" after 8 hours of radiation was compared to the 0 hour sample and plotted in Figure. 5.5. The results showed that less than $2 \%$ disappearance of starting material was observed under the three $\mathrm{pH}$ conditions and different saturation gases. The results indicated that $\mathrm{pH}$ did not have any significant effect on the degradation.

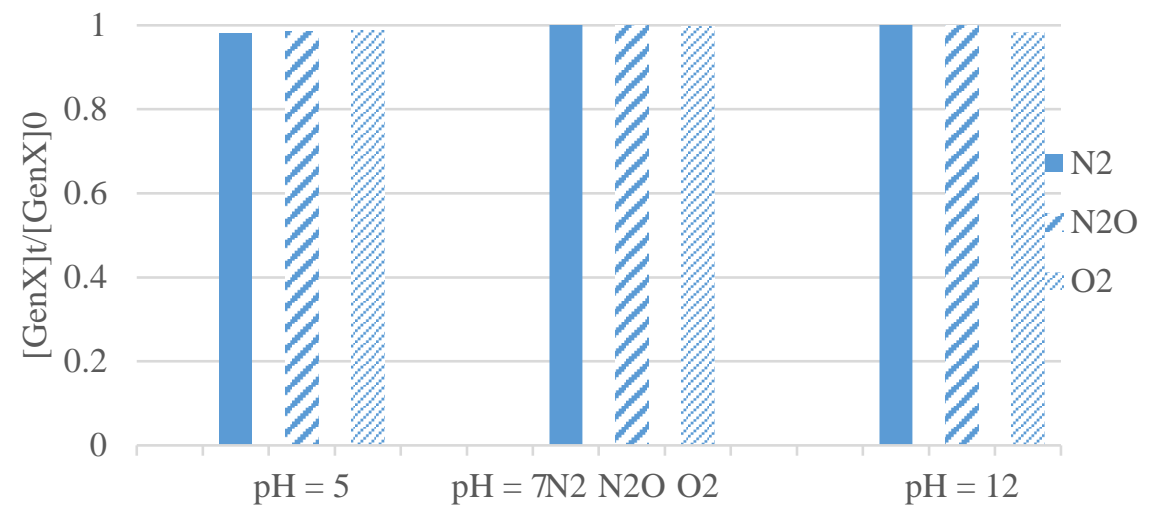

Figure. 5.5 The degradation of "GenX" under different $\mathrm{pH}$ and different saturation gases. 
As a summary, radiolysis could not effectively remediate "GenX" under either natural, neutral or alkali conditions. Neither oxidation reaction by $\mathrm{HO} \cdot$ or $\mathrm{O}_{2}{ }^{-*}$, or reduction reaction by $\mathrm{e}_{\mathrm{aq}}$ " could effectively degrade or mineralize "GenX".

\subsection{2 $\mathrm{TiO}_{2}$ photocatalysis degradation of "GenX"}

$\mathrm{TiO}_{2}$ photocatalysis involves an oxidation process by $\mathrm{HO}$. produced by the hole oxidation of water, and a reduction process by $\mathrm{e}^{-}$св. When a hole quencher is added to the solution, the production of $\mathrm{HO}$ can be reduced while promoting the reduction processes. Excess EtOH $10 \%$ (2 mmol/L) was added as hole scavengers to a $1 \mathrm{ppm}$ "GenX" solution with $\mathrm{TiO}_{2}$ concentration of $0.2 \mathrm{~g} / \mathrm{L}$. All solutions were gently bubbled with $\mathrm{N}_{2}$ to eliminate $\mathrm{O}_{2}$ to prevent $\mathrm{e}_{\text {Св }}^{-}$scavenging and the production of $\mathrm{O}_{2}{ }^{--}$, then irradiated by $350 \mathrm{~nm} \mathrm{UV}$ light. Samples were taken at prior to and $3 \mathrm{~h}$ after UV light irradiation. Another set of solutions were prepared under alkaline conditions ( $\mathrm{pH}$ 10). The concentrations of "GenX" and $\mathrm{F}^{-}$under alkaline $\mathrm{TiO}_{2}$ were analyzed by UPLC-MS and fluoride electrode, respectively. The obtained data was plotted in Figure. 5. 6.

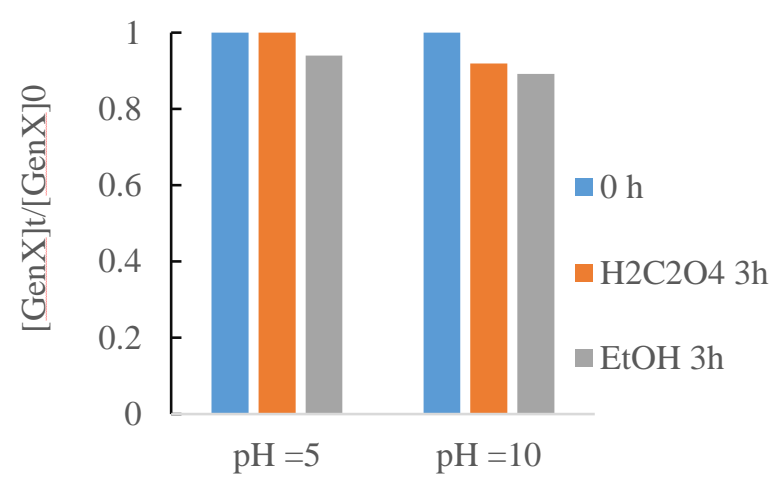

Figure. 5.6 $\mathrm{TiO}_{2}$ photocatalytic degradation of "GenX" with oxalic acid and $10 \%$ ethanol under acidic and alkaline conditions. 
Under natural $\mathrm{pH}$, no disappearance was observed when oxalic acid was added as the hole quencher, and approximately $6 \%$ disappearance was observed when EtOH was added. While under the alkali condition, $8 \%$ disappearance of the starting concentration (1ppm) was noted with oxalic acid as the hole quencher and $10 \%$ disappearance with EtOH. No fluoride was detected in any samples. This result indicated that there was minimal degradation and no mineralization of "GenX" using the $\mathrm{TiO}_{2}$ photocatalysis under our experimental conditions.

\subsubsection{Sonolytic Degradation of "GenX"}

\subsubsection{Kinetic studies of the degradation of "GenX"}

The degradation kinetic studies of sonolysis were conducted at different concentrations, $0.6,1.5,3.0,6.1 \mu \mathrm{mol} / \mathrm{L}$. The samples were taken at certain time intervals depending on the initial concentrations. The concentration of "GenX" at time t over the initial concentration was plotted as a function of time, as shown in Figure.5.7. The observed degradation rates are very similar regardless of initial concentration. The half-life of the four starting concentrations were less than $30 \mathrm{~min}$. The structure of "GenX" is a combination of a hydrophobic head and a hydrophilic carboxylic group tail, therefore, "GenX" would partition at the g-l interface while the carboxylic group sticks out in the bulk solution. Although the initial concentrations of "GenX" varied 10 times fold, the observed degradation as a function of treatment time were similar. During ultrasoundinduced degradation, the g-l interface can be viewed as an interface with vacant equivalent absorption sites. When the solution was saturated with Argon, the temperature of cavitation sites increased and less hydroxyl radicals were produced and less competition occurred 
between the low concentration of "GenX" and low concentration of $\mathrm{HO}$, which eliminated the saturation effect. In other words, there were plenty vacant sites for "GenX" to partition to and then go through the pyrolysis process.

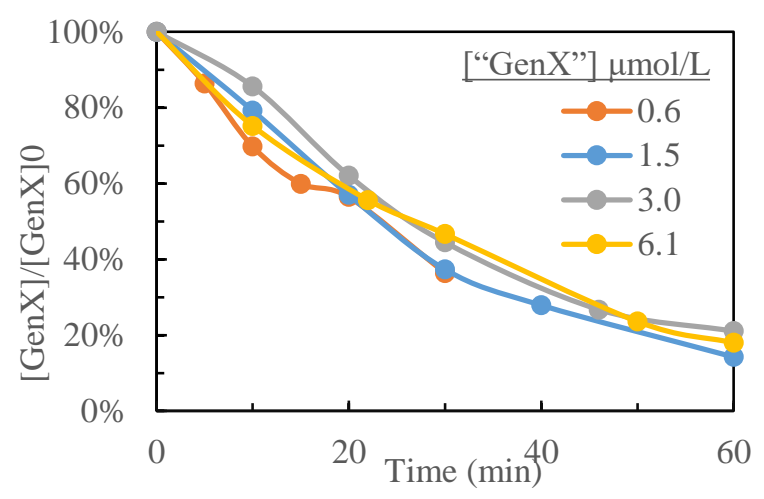

Figure. 5.7 Degradation of "GenX" at different initial concentrations.

\subsubsection{Thermal decomposition of "GenX"}

The sonolytic transformations of "GenX" were studied at the concentration range from 0.3 to $3.0 \mu \mathrm{mol} / \mathrm{L}$, and the concentration of fluoride was plotted as a function of time as the illustrated in Figure. 5.8 (a). There are eleven fluorine atoms in each "GenX" molecule, therefore, the total fluoride concentration is eleven times higher than "GenX". Samples were taken at different time intervals depending on the starting concentration. An increase of fluoride concentration was observed as the treatment time increased at all studied concentrations. The higher the concentration of the starting material, the more fluoride was produced. To determine the defluorination efficiency, the concentration of produced fluoride at time $t$ was divided by the total fluorine and then plotted in the column chart, shown in Figure.5.8 (b). Within 30 min, approximately $50 \%$ mineralization of 0.3 $\mu \mathrm{mol} / \mathrm{L}$ initial concentration was achieved, and more than $85 \%$ was achieved after 120 
min. At higher concentration, greater than $60 \%$ could be achieved by extended irradiation time. The promising results of defluorination efficiency suggested that sonolysis is an effective method to mineralize "GenX" to F".
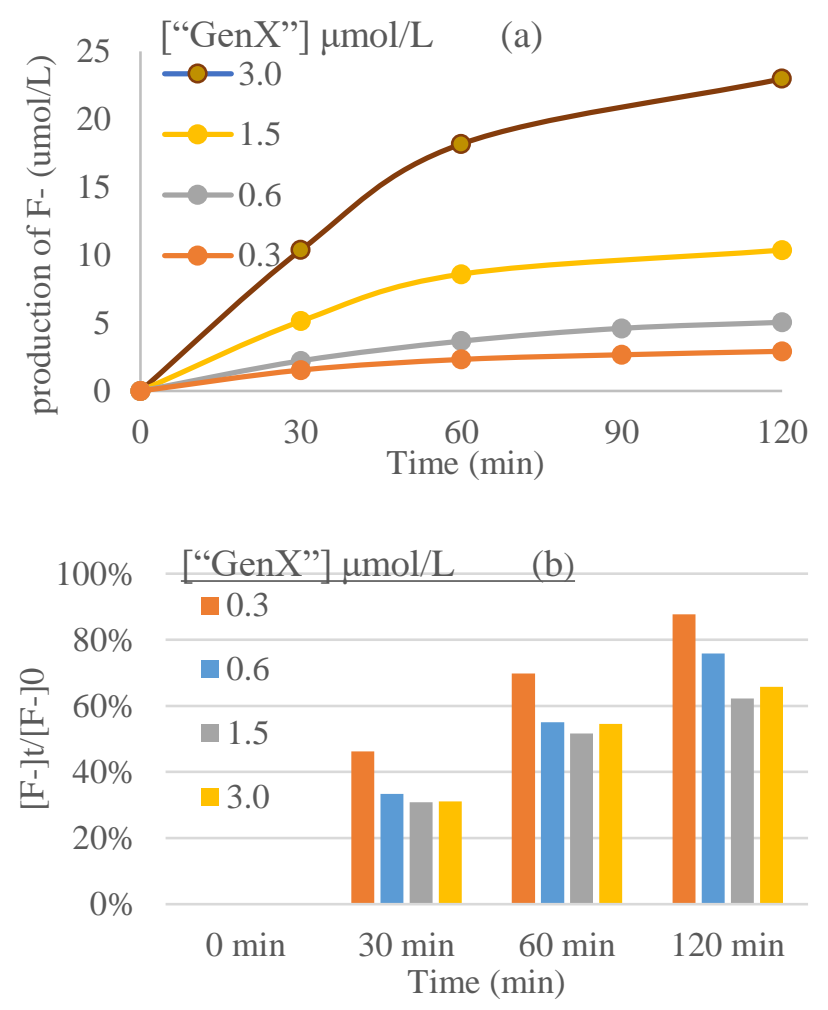

Figure. 5.8 (a) Production of fluoride at different starting concentrations of "GenX" under ultrasound ( $640 \mathrm{kHz}, 396 \mathrm{~W}$, Ar saturated). (b) Mineralization efficiency of "GenX".

\subsubsection{Computational Studies}

Product studies are very important to predict the reaction pathway. However, no intermediates were observed other than $\mathrm{F}^{-}$. The absence of detectable products makes it implausible to elucidate the reaction mechanisms at this time. Thermal process induced degradation can be predicted on the basis of homolytic bond cleavage as described below.

\subsubsection{1 "GenX" and its parent compound}

A comparison was made between "GenX" and its parent compound. The bond 
dissociation energies (BDE) of C-C, C-O, and C-F bonds involved in homolytic cleavage are listed in Table.5. 1. By comparing the BDE of bond a, b, c and d in two compounds, the results showed that the perfluorination of the parent compound strengthens both C-C and $\mathrm{C}-\mathrm{O}$ bonds. In "GenX", the $\mathrm{BDE}$ of bond $\mathrm{f}$ is $77.3 \mathrm{kcal} / \mathrm{mol}$, which is the weakest among all seven bonds; the BDE of bond $\mathrm{d}$ and e are 80.0 and $79.3 \mathrm{kcal} / \mathrm{mol}$, which are very close and lower than the others. Bond $\mathrm{g}$ is a $3^{\circ} \mathrm{C}-\mathrm{F}$ bond, the strongest among all seven. During pyrolysis, bond $\mathrm{f}$ is the most likely to be cleaved, while bond $\mathrm{d}$ and e are the second most likely. Bond $\mathrm{g}$ is the most stable with the highest BDE. Only bond e is weakened by the fluorination effect in "GenX". A patent published in 2015 reported that the carboxylic group is the most likely to dissociate in fluoroether carboxylic acid. [168] Even though the $\mathrm{BDE}$ of bond e was not the lowest and was only $2 \mathrm{kcal} / \mathrm{mol}$ lower than bond $\mathrm{f}$, it was possible for bond e to be the weakest considering the calculation error in the computational method, typically about $3 \mathrm{kcal} / \mathrm{mol}$.

Table 5.1 The bond cleavage energies of "GenX" and its parent compound.
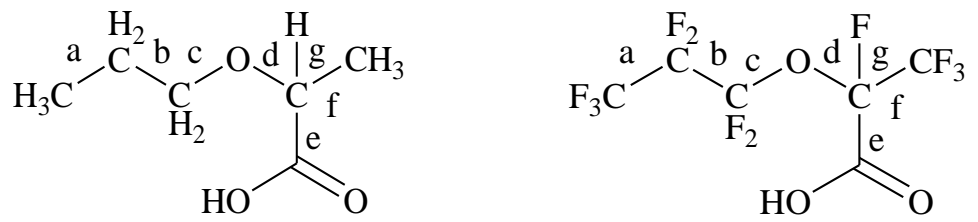

\begin{tabular}{|c|c|c|c|c|c|c|c|}
\hline bond & a & b & c & d & e & f & g \\
\hline $\begin{array}{c}\text { Parent Cpd } \\
\text { (kcal/mol) }\end{array}$ & 88.9 & 84.6 & 83.7 & 71.1 & 84.8 & 75.5 & 81.7 \\
\hline
\end{tabular}

\subsubsection{Pyrolysis mechanism of "GenX" following C-C, C-O bond cleavage}

Homolytic bond cleavage is the common pathway during pyrolysis, carbon centered radicals, are important intermediates during the pyrolysis. After the first step, 
beta-scission of these radicals occurs immediately. The final products were predicted on the basis of $\beta$-scission of the carbon centered radicals, geometry optimization and the calculated transition states. The cleavage of bond a formed radical a1 and a2. As shown in Figure. 5.9, carbon centered radical a2 went through beta-scission, and formed tetrafluoroethylene (a2-p1) and radical a2-p2. No energy barrier was found for the betascission of a2. For radical a2-p2, there were three beta-scission possibilities. The lowest energy barrier, $6 \mathrm{kcal} / \mathrm{mol}$, calculated in the first pathway, and formed trifluoroacetyl fluoride and carboxylic acid radical. The second pathway required $10 \mathrm{kcal} / \mathrm{mol}$, and formed trifluoromethyl radical and FCOCOOH. The highest energy barrier was $49.2 \mathrm{kcal} / \mathrm{mol}$, and formed a fluorine atom and trifluoromethyl formate. The third pathway was the least favorable, thus, the first two pathways were more likely to occur.

The pyrolytic pathways of bond $b$ are illustrated in Figure.5.10. The cleavage of bond $\mathrm{b}$ produces a pentafluoroethyl radical (b1) and radical b2. Radical b2 produces carbonyl fluoride and product b2-p2 with an energy barrier of $12.5 \mathrm{kcal} / \mathrm{mol}$. No welldefined transition state was discovered within the two possible continuous pyrolytic pathways of radical b2-p2. 


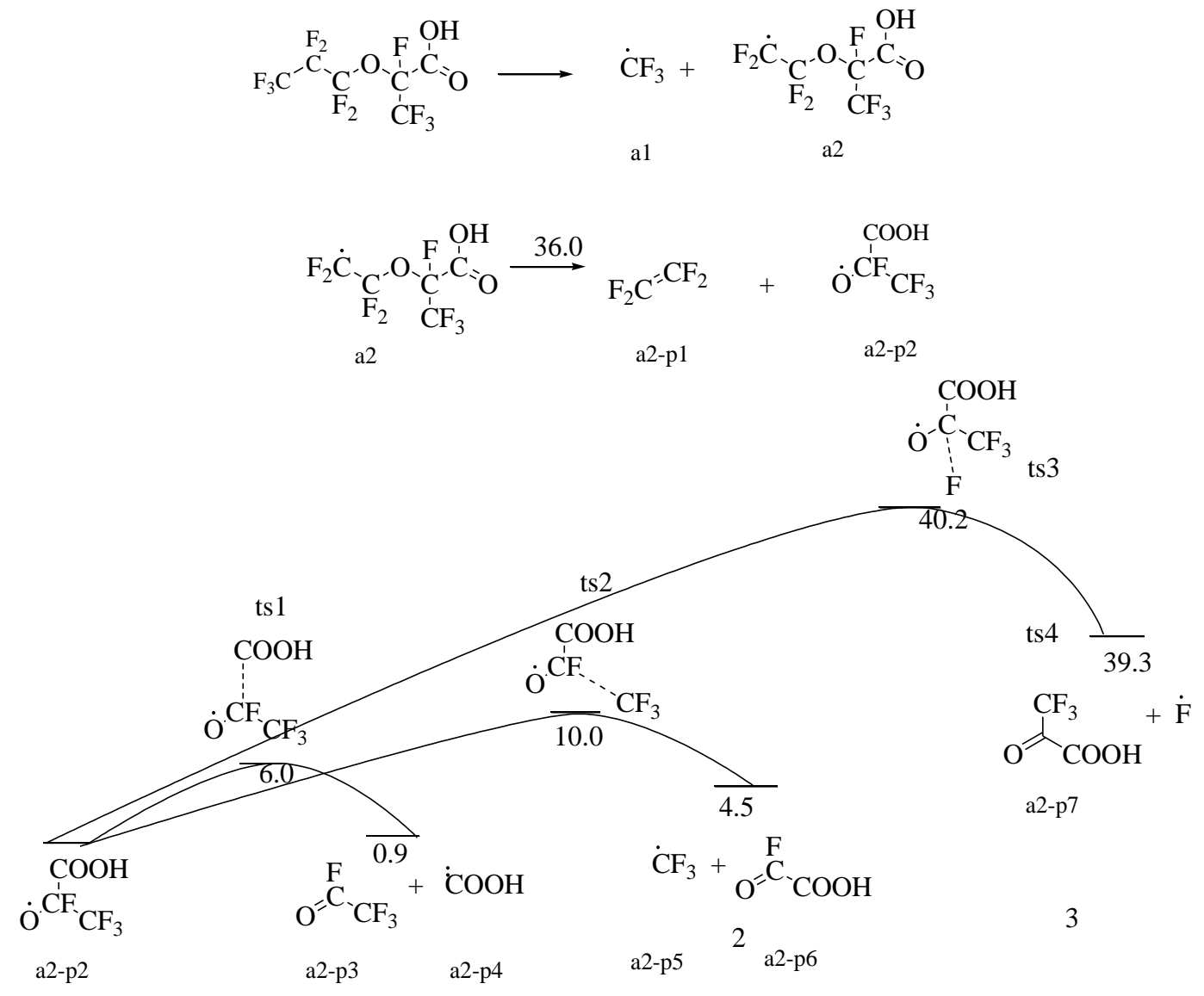

Figure. 5.9 Pyrolytic pathway of bond a

The pyrolytic mechanism of pathway 3 was illustrated in Figure.5.11. The two products, $3 \mathrm{a}$ and $3 \mathrm{~b}$, were formed by breaking bond $\mathrm{c}$. Radical $3 \mathrm{~b}$ was the same as radical a2-p2 and followed the same pyrolytic pathway. Radical 3a went through beta-scission and formed tetrafluoroethylene and trifluoromethyl radical with an energy barrier of 43.05 $\mathrm{kcal} / \mathrm{mol}$. 


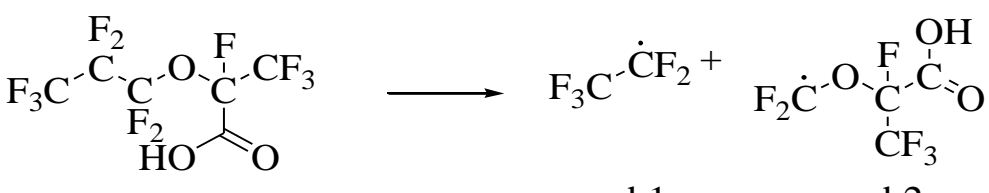

b1

b2

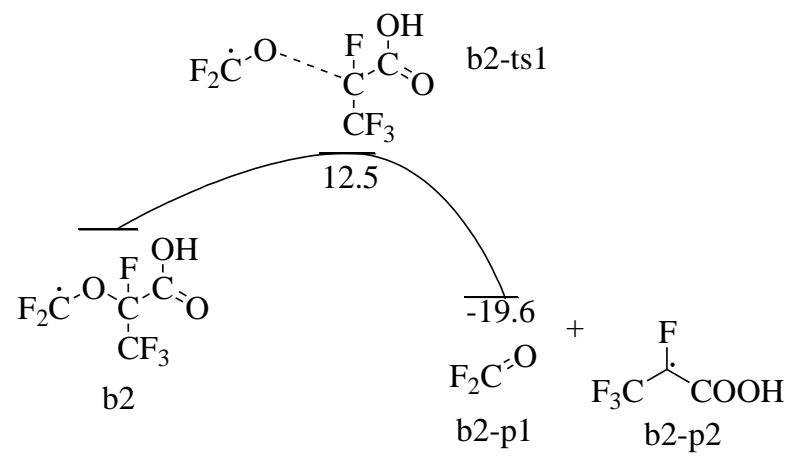

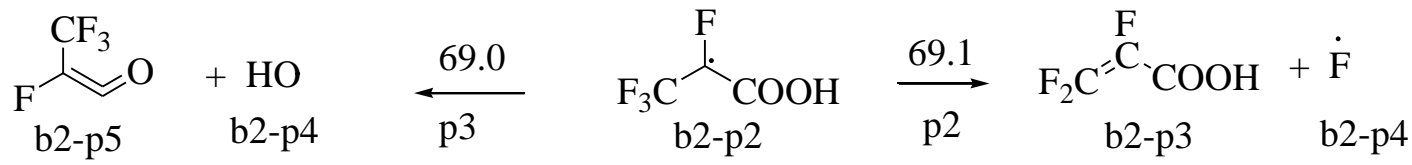

Figure. 5.10 Pyrolytic pathways of bond b.
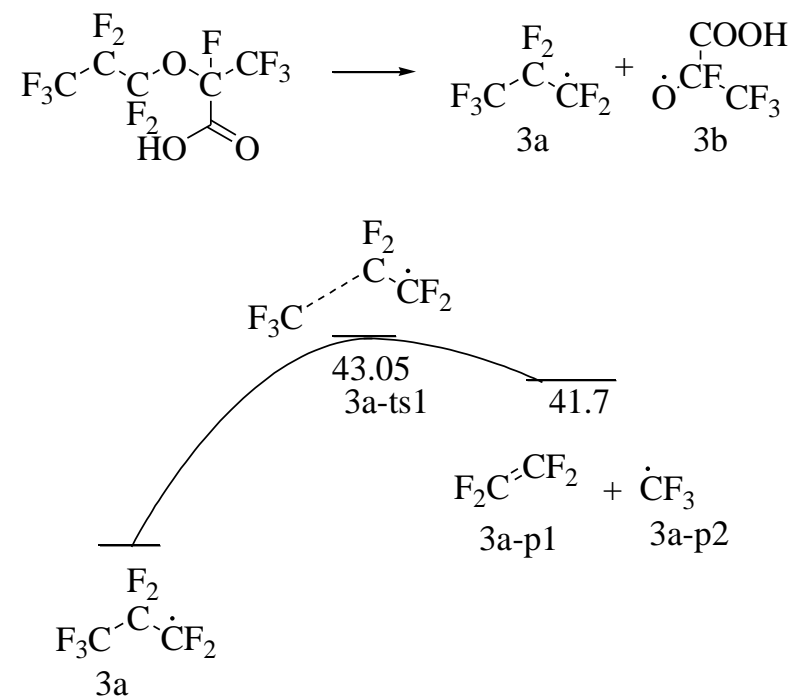

Figure. 5.11 Pyrolytic pathway of bond c. 

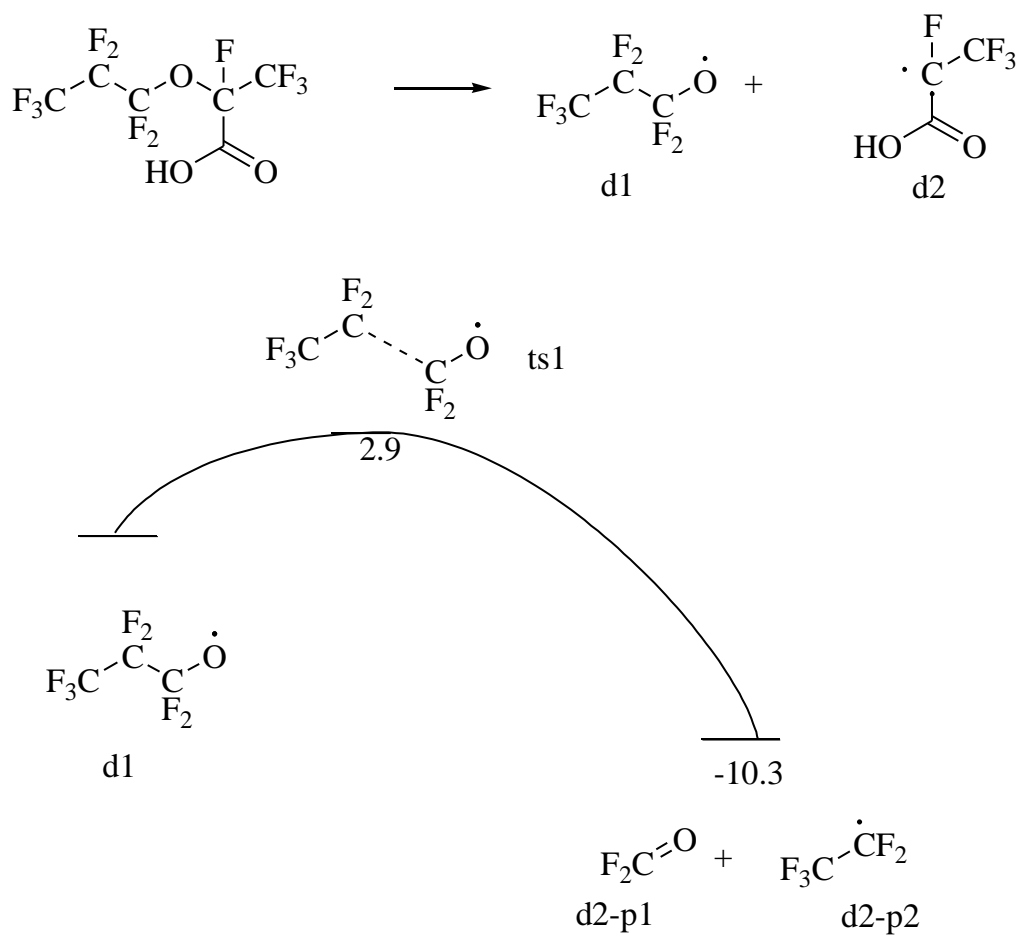

Figure. 5.12 Pyrolytic pathway of bond d

Pyrolytic pathway 4 is illustrated in Figure.5.12. Radical d1 went through an energy barrier of $2.9 \mathrm{kcal} / \mathrm{mol}$, then formed carbonyl fluoride and p2 radical. Radical $\mathrm{d} 2$ was the same as radical b2-p2 produced in pathway 2 . When pathway 1,3 and 2,4 were compared, even though the initial steps were different and energy barriers were different, the final products were the same. 


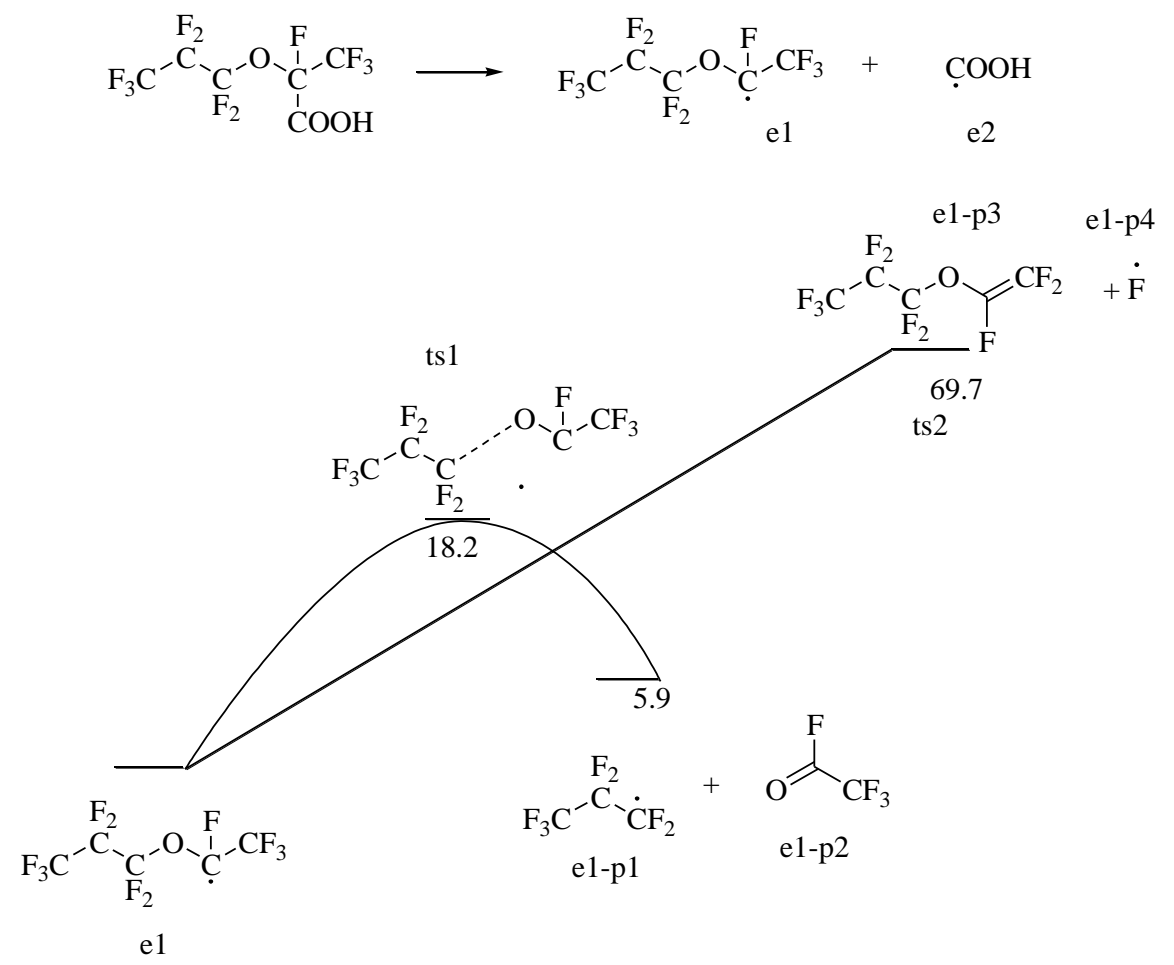

Figure. 5.13 Pyrolytic pathway of bond e.

Radical e1 and e2 were produced by the cleavage of bond e.(Figure.5.13) There were two possible pathways for radical e1. The energy barrier of the first pathway was 18.2 $\mathrm{kcal} / \mathrm{mol}$, and radical e1-p1(same as radical c1) and trifluoroacetyl fluoride were formed. No transition state was defined for the second pathway, which meant that $69.7 \mathrm{kcal} / \mathrm{mol}$ was needed to dissociate the fluorine atom from the trifluoromethyl group in radical e1 to form product e1-p3.

Radical f1 had two possible beta-scission pathways, as shown in Figure.5.14. Radical f2-p1 (same as radical c1) and $\mathrm{CFOCOOH}$ were formed following the first pathway with an energy barrier of $19.8 \mathrm{kcal} / \mathrm{mol}$. The energy barrier for the second pathway was $75.6 \mathrm{kcal} / \mathrm{mol}$, and the dissociated hydroxyl radical and product $\mathrm{f} 2-\mathrm{p} 3$ formed 
an intermediate, which was $0.4 \mathrm{kcal} / \mathrm{mol}$ lower than the transition state energy. The intermediate dissociated and formed product f2-p3 and hydroxyl radical when $2.6 \mathrm{kcal} / \mathrm{mol}$ energy was absorbed.

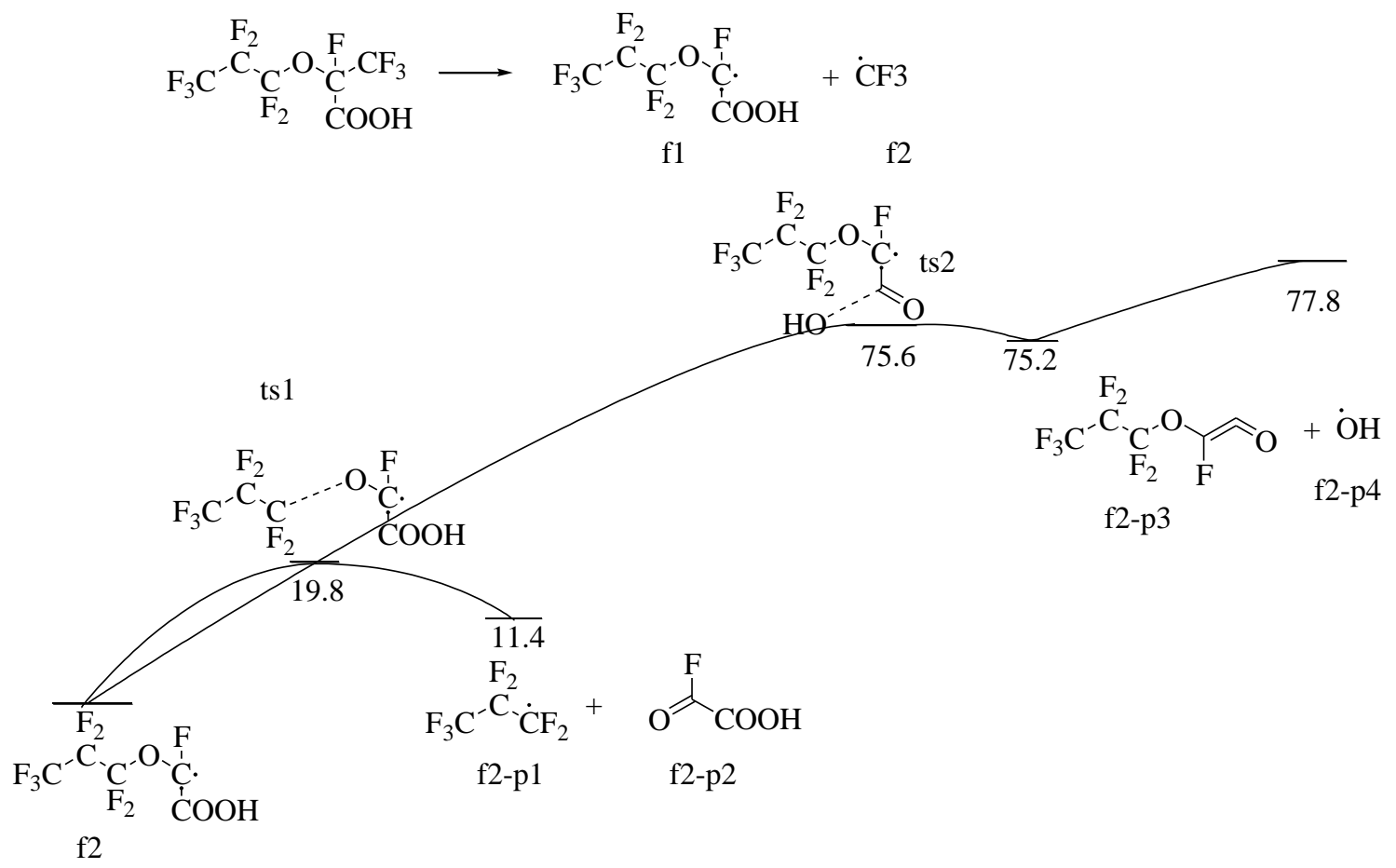

Figure. 5.14 Pyrolytic pathway of bond $\mathrm{f}$.

Radical g1, formed in the cleavage of bond g, and went through three different pyrolytic pathways. In the first pathway, an energy barrier of $27.7 \mathrm{kcal} / \mathrm{mol}$ was required to break the $\mathrm{C}-\mathrm{O}$ bond and produce radical $\mathrm{g} 1-\mathrm{p} 1$ (same as radical $\mathrm{c} 1$ ) and $\mathrm{g} 1-\mathrm{p} 2$. No energy barrier was defined in the second pathway to dissociate the fluorine from the trifluoromethyl group in radical g1-p1, and a direct energy difference $65.9 \mathrm{kcal} / \mathrm{mol}$ was calculated. In the third pathway, an energy barrier of $59.7 \mathrm{kcal} / \mathrm{mol}$ was determined, and an intermediate complex was formed $1.4 \mathrm{kcal} / \mathrm{mol}$ lower than the transition state. 
ts3

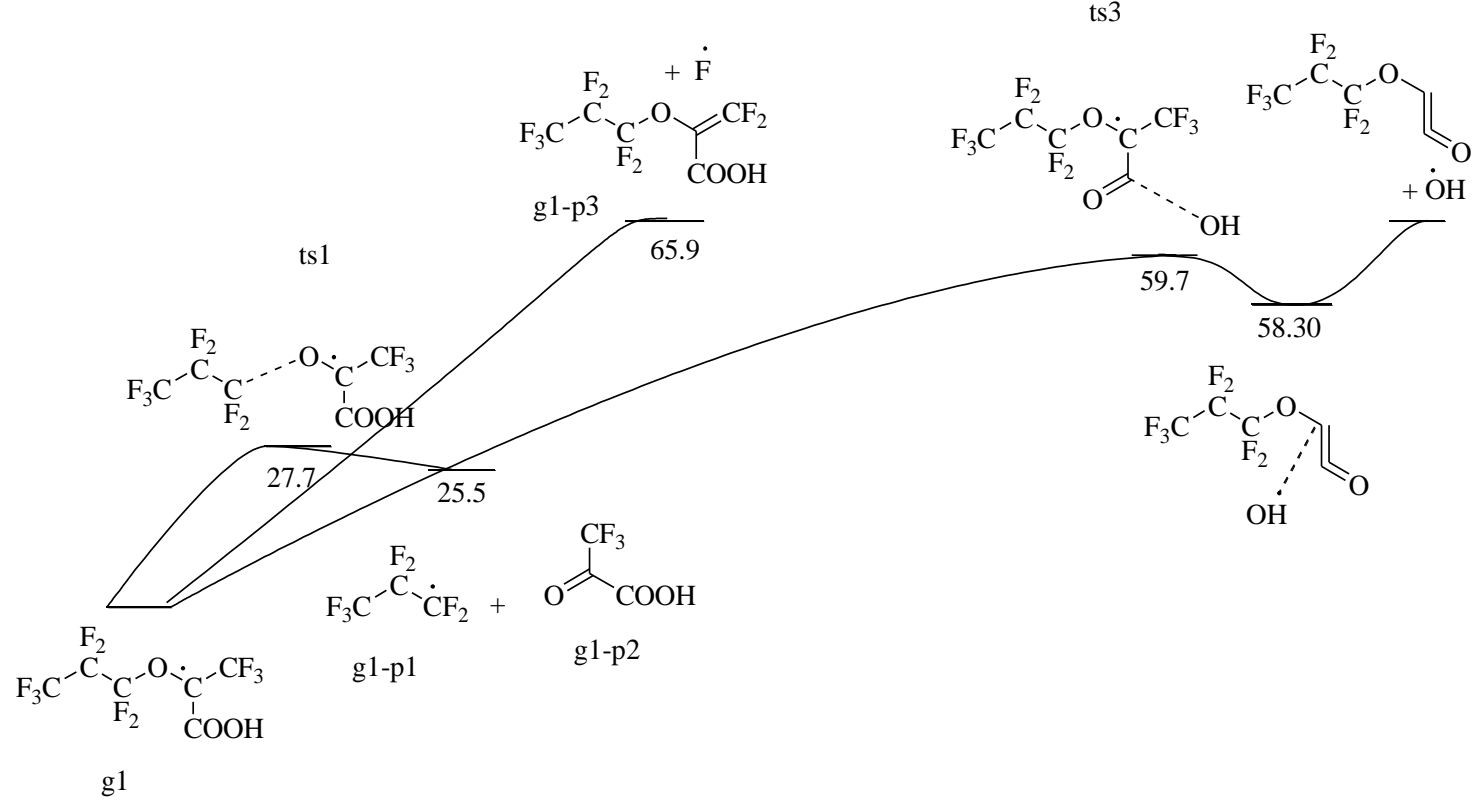

Figure. 5.15 Pyrolytic pathway of bond g.

No fluoride ions were formed during the calculated pyrolytic pathways; however, many products had the acyl fluoride functionality, which reacted with water immediately and released fluoride ions into the solution.

\subsection{Conclusions}

Our research was an exploration of the remediation of an emerging perfluorinated ether, "GenX", using different methods, including sonolysis, gamma-radiolysis, and $\mathrm{TiO}_{2}$ photocatalysis. Ultrasound-induced degradation was the most promising method to degrade "GenX". Computational studies predicted the possible reaction pathways and suggested possible intermediates. The release of $\mathrm{F}^{-}$indicated that sonolysis was able to mineralize "GenX" in a short time. Further studies need to focus on searching for and confirming possible by-products. 


\section{Chapter 6 General Conclusions}


The main component of the large chemical spill in West Virginia, crude MCHM, was degraded both rapidly and efficiently by ultrasound-induced degradation. The crude MCHM was a mixture of the trans- and cis- isomers, and the degradation of both isomers were modeled by pseudo-first order kinetics. When the concentration of starting material was less than $100 \mu \mathrm{mol} / \mathrm{L}$, the half-life times of both isomers were less than $30 \mathrm{~min}$. The Freundlich kinetic equation was used to model the heterogeneous process at the gas-liquid interface. The excellent fit indicated that the degradation involved a non-uniform distribution of the MCHM molecules. Two primary products, (4-methylcyclohexenyl) methanol and 4-methylcyclohexanone, were observed as the products of hydroxyl radical mediation and pyrolytic reaction. Detailed computational studies were applied to support the reaction processes. Some low molecular pyrolytic products, such as 1,5 -hexadiene, 1 butene and so on, may undergo combustion processes.

The first-generation antihistamine, diphenhydramine, is a problematic water pollutant that has been detected in water sources. Ultrasound is shown as a promising remediation method to destroy DPH. Even though the degradation of DPH followed pseudo-first-order kinetics at a wide concentration range, the rate constant changed along with the initial DPH concentration, which was related to the heterogeneous process involving the hydroxyl radical remediation at the gas-liquid interface. This process was accurately modeled by Langmuir-Hinshelwood kinetics which indicated a uniform distribution. The $\mathrm{pH}$ value of the solutions did not have significant effect on the degradation process. Mono-hydroxylation of the aromatic rings in DPH created three isomeric products, leading to more di-hydroxylated isomeric products. Benzophenone and other products 
were also formed by pyrolytic reaction pathways. The computational studies were carried out in Gaussian 09 to provide more details to support the reaction pathways.

The natural occurrence of the second-generation antihistamine, cetirizine, has led to concerns about its human health effects. The ultrasound- degradation of CET was carried out at a wide concentration range of 4.3 to $65.0 \mu \mathrm{mol} / \mathrm{L}$. The half-life time was less than 15 min when the concentration was below $21.7 \mu \mathrm{mol} / \mathrm{L}$. The degradation process was modeled by Langmuir-Hinshelwood kinetic with a $\mathrm{R}^{2}>0.99$. The partition coefficient was determined as $0.10 \mu \mathrm{mol} / \mathrm{L}$ while the reactivity was $1.64 \mu \mathrm{mol} \cdot \mathrm{L}^{-1} \cdot \mathrm{min}^{-1}$. Coumarin and terephthalate were added to the CET solution to quench the HO- at different cavitation regions. The results indicated that $\mathrm{CET}$ reacted with $\mathrm{HO} \cdot$ at the gas-liquid interface, as well as the bulk solution. Saturation gas has a significant effect on the degradation rate. Under $\mathrm{O}_{2}$-saturated condition, the degradation rate was almost twice than the $\mathrm{N}_{2}$-saturated condition. Several product studies were confirmed as hydroxylation and pyrolytic products.

The emerging perfluoroalkyl substances have been the subject of recent scientific studies. "GenX" is a replacement of perfluorooctanoic acid. Gamma-radiolysis, $\mathrm{TiO}_{2}$ photocatalysis and sonolysis were applied to remediate "GenX". A bimolecular rate constant of $\mathrm{e}_{\mathrm{aq}}{ }^{-}$and "GenX" was determined as $5 \times 10^{10} \mathrm{M}^{-1} \cdot \mathrm{s}^{-1}$. Little conversion and mineralization was observed when steady-state radiolysis was used to irradiate the "GenX" solution under different $\mathrm{pH}$ condition and saturation gases. $\mathrm{TiO}_{2}$ photocatalysis with EtOH $10 \%$ and oxalic acid as hole quenchers showed a slow degradation of "GenX". Ultrasound was applied to solutions from 0.6 to $6.1 \mu \mathrm{mol} / \mathrm{L}$. The degradation rates were similar with half-lives of approximately $30 \mathrm{~min}$. Fluoride was detected as the major product during the 
degradation. Computational studies were conducted to predict the pyrolytic pathways. The results showed that ultrasound was a promising method to degrade "GenX" in aqueous solution. 


\section{Reference}

[1] N. V Fedoroff, D.S. Battisti, R.N. Beachy, P.J.M. Cooper, D.A. Fischhoff, C.N. Hodges, V.C. Knauf, D. Lobell, B.J. Mazur, D. Molden, M.P. Reynolds, P.C. Ronald, M.W. Rosegrant, P. a Sanchez, A. Vonshak, J.-K. Zhu, Radically rethinking agriculture for the 21st century, Science. 327 (2010) 833-834. doi:10.1126/science.1186834.

[2] M.G. Anderson, J. Mcdonnell, C. Ximing, S. a Cline, W.W. Balance, J. Rockstrom, G.C. Daily, P.R. Ehrlich, C. a Reidy, M. Dynesius, C. Revenga, L. Dams, E. Reichel, M.A. Global, P. Green, J. Salisbury, R.B. Lammers, S. Kanae, T. Oki, a Y. Hoekstra, P. Eichert, K.C. Abbaspour, a B. Zehnder, A. Kitoh, M. Hosaka, K. a Dunne, a V Vecchia, C. Valeo, K. Heal, I. Science, M. Bengtsson, Y. Agata, H. Kim, E. Science, The Challenge of Micropollutants in Aquatic Systems, Sci. Technol. (2006) 10721077. doi:10.1126/science.1127291.

[3] D. Molden, Water responses to urbanization, Paddy Water Environ. 5 (2007) 207209. doi:10.1007/s10333-007-0084-8.

[4] N.W. Arnell, Climate change and global water resources: SRES emissions and socio-economic scenarios, Glob. Environ. Chang. 14 (2004) 31-52. doi:10.1016/j.gloenvcha.2003.10.006.

[5] R.P. Schwarzenbach, T. Egli, T.B. Hofstetter, U. von Gunten, B. Wehrli, Global Water Pollution and Human Health, Annu. Rev. Environ. Resour. 35 (2010) 109136. doi:10.1146/annurev-environ-100809-125342.

[6] N. Gruber, J.N. Galloway, An Earth-system perspective of the global nitrogen cycle, Nature. 451 (2008) 293-296. doi:10.1038/nature06592.

[7] G.M. Filippelli, The Global Phosphorus Cycle : Past, Present, and Future, Elements. 4 (2008) 89-95.

[8] M. Ricart, D. Barceló, A. Geiszinger, H. Guasch, M.L. de Alda, A.M. Romaní, G. Vidal, M. Villagrasa, S. Sabater, Effects of low concentrations of the phenylurea herbicide diuron on biofilm algae and bacteria, Chemosphere. 76 (2009) 1392-1401. doi:10.1016/j.chemosphere.2009.06.017.

[9] C.G. Daughton, Non-regulated water contaminants: Emerging research, Environ. Impact Assess. Rev. 24 (2004) 711-732. doi:10.1016/j.eiar.2004.06.003.

[10] O.S. Amuda, A.A. Giwa, I.A. Bello, Removal of heavy metal from industrial wastewater using modified activated coconut shell carbon, Biochem. Eng. J. 36 (2007) 174-181. doi:10.1016/j.bej.2007.02.013.

[11] E. Eliopoulou, A. Papanikolaou, Casualty analysis of large tankers, J. Mar. Sci. Technol. 12 (2007) 240-250. doi:10.1007/s00773-007-0255-8.

[12] A. Kot-Wasik, J. Debska, J. Namieśnik, Analytical techniques in studies of the environmental fate of pharmaceuticals and personal-care products, TrAC - Trends 
Anal. Chem. 26 (2007) 557-568. doi:10.1016/j.trac.2006.11.004.

[13] E. Villaroel, J. Silva-agredo, C. Petrier, G. Taborda, R.A. Torres-palma, Ultrasonic degradation of acetaminophen in water: Effect of sonochemical parameters and water matrix, Ultrason. Sonochem. 21 (2014) 1763-1769. doi:10.1016/j.ultsonch.2014.04.002.

[14] R. Xiao, Sonochemical Degradation of Pharmaceuticals and Personal Care Products in Water, (2012) 270.

[15] J.B. Ellis, Pharmaceutical and personal care products (PPCPs) in urban receiving waters, Environ. Pollut. 144 (2006) 184-189. doi:10.1016/j.envpol.2005.12.018.

[16] C. G.Daughton, Thomas A.Ternes, Pharmaceuticals and Personal Care Products in the Environment: Agents of Subtle Change?, Environ. Health Perspect. 107 (1999) 907-938. doi:10.1021/bk-2001-0791.

[17] R.C. Buck, J. Franklin, U. Berger, J.M. Conder, I.T. Cousins, P. De Voogt, A.A. Jensen, K. Kannan, S.A. Mabury, S.P.J. van Leeuwen, Perfluoroalkyl and polyfluoroalkyl substances in the environment: Terminology, classification, and origins, Integr. Environ. Assess. Manag. 7 (2011) 513-541. doi:10.1002/ieam.258.

[18] M. Sun, E. Arevalo, M. Strynar, A. Lindstrom, M. Richardson, B. Kearns, A. Pickett, C. Smith, D.R.U. Knappe, Legacy and Emerging Perfluoroalkyl Substances Are Important Drinking Water Contaminants in the Cape Fear River Watershed of North Carolina, Environ. Sci. Technol. Lett. 3 (2016) 415-419. doi:10.1021/acs.estlett.6b00398.

[19] DuPont Marketing, DuPont GenX Processing Aid for Making Fluoropolymer Resins, (2010) 4.

[20] S. If, N. Carolina, C. Dhhs, GenX Health Information, (2017).

[21] Z. Moore, Health Effects of GenX and Related Compounds in the Lower Cape Fear River Basin, (2017) 1-15.

[22] W.H. Glaze, J.-W. Kang, D.H. Chapin, The Chemistry of Water Treatment Processes Involving Ozone, Hydrogen Peroxide and Ultraviolet Radiation, Ozone Sci. Eng. 9 (1987) 335-352. doi:10.1080/01919518708552148.

[23] R. Andreozzi, V. Caprio, A. Insola, R. Marotta, Advanced oxidation processes ( AOP ) for water purification and recovery, Catal. Today. 53 (1999) 51-59.

[24] P. Fernandez-Castro, M. Vallejo, M.F. San Roman, I. Ortiz, Insight on the fundamentals of advanced oxidation processes: Role and review of the determination methods of reactive oxygen species, J. Chem. Technol. Biotechnol. 90 (2015) 796-820. doi:10.1002/jctb.4634.

[25] A. Hong, M.E. Zappi, C.H. Kuo, D. Hill, Modeling Kinetics of Illuminated and Dark Advanced Oxidation Processes, J. Environ. Eng. 122 (1996) 58-62. doi:10.1061/(ASCE)0733-9372(1996)122:1(58). 
[26] L.M. Dorfman, G.E. Adams, Reactivity of the hydroxyl radical in aqueous solutions, Natl. Bur. Stand. (1973) 38-39. doi:10.6028/NBS.NSRDS.46.

[27] M.A. Tarr, Fenton and Modified Fenton Methods for Pollutant Degradation, in: Chem. Degrad. Methods Wastes Pollut., 2003.

[28] S. Gligorovski, R. Strekowski, S. Barbati, D. Vione, Environmental Implications of Hydroxyl Radicals ( $\mathrm{OH}), \quad$ Chem. Rev. $115 \quad$ (2015) 13051-13092. doi:10.1021/cr500310b.

[29] R. Hernandez, M. Zappi, J. Colucci, R. Jones, Comparing the performance of various advanced oxidation processes for treatment of acetone contaminated water, J. Hazard. Mater. 92 (2002) 33-50. doi:10.1016/S0304-3894(01)00371-5.

[30] M.R. Hoffmann, S.T. Martin, W. Choi, D.W. Bahnemann, Environmental Applications of Semiconductor Photocatalysis, Chem. Rev. 95 (1995) 69-96. doi:10.1021/cr00033a004.

[31] K. Hashimoto, H. Irie, A. Fujishima, TiO2 Photocatalysis: A Historical Overview and Future Prospects, Jpn. J. Appl. Phys. 44 (2005) 8269-8285. doi:10.1143/JJAP.44.8269.

[32] D. Chatterjee, S. Dasgupta, Visible light induced photocatalytic degradation of organic pollutants, J. Photochem. Photobiol. C Photochem. Rev. 6 (2005) 186-205. doi:10.1016/j.jphotochemrev.2005.09.001.

[33] C.S. Turchi, D.F. Ollis, Photocatalytic degradation of organic water contaminants: Mechanisms involving hydroxyl radical attack, J.Calatysis. 122 (1990) 178-192. doi:10.1016/0021-9517(90)90269-P.

[34] S.G. Kumar, L.G. Devi, Review on modified TiO2 photocatalysis under UV/visible light: Selected results and related mechanisms on interfacial charge carrier transfer dynamics, J. Phys. Chem. A. 115 (2011) 13211-13241. doi:10.1021/jp204364a.

[35] A. Fujishima, T.N. Rao, D.A. Tryk, Titanium dioxide photocatalysis, J. Photochem. Photobiol. C Photochem. Rev. 1 (2000) 1-21. doi:10.1016/S1389-5567(00)000022.

[36] M.A. Oturan, J.-J. Aaron, Advanced Oxidation Processes in Water/Wastewater Treatment: Principles and Applications. A Review, Crit. Rev. Environ. Sci. Technol. 44 (2014) 2577-2641. doi:10.1080/10643389.2013.829765.

[37] J. Kopoldová, Š. Hrnčís, Gamma-Radiolysis of Aqueous Solution of Histidine, Zeitschrift Fur Naturforsch. - Sect. C J. Biosci. 32 (1977) 482-487. doi:10.1515/znc1977-7-802.

[38] J.P. Guin, Y.K. Bhardwaj, L. Varshney, Efficient degradation of butylparaben by gamma radiolysis, Appl. Radiat. Isot. 122 (2017) 21-27. doi:10.1016/j.apradiso.2016.12.025. 
[39] Nikola Getoff, Radiation-induced degradation of water pollutants-state of the art, Radiat. Phys. Chem. 47 (1996) 581-593.

[40] J.M. Anna Bojanowska-Czajka, Krzysztof Kulisa, Monika Łyczko, Gabriel Kciuk, M. Trojanowicz, P66-Application of ionizing radiation for decomposition of perfluorinated surfactants, Lab. Nucl. Anal. Methods. (2014). http://www.inspectieszw.nl/Images/Annual-Report-2014_tcm335-365558.pdf.

[41] K.E.O. Weihua Song, Tielian Xu, William J. Cooper, Dionysios D. Dionysiou, Armah A. de la Cruz, Radiolysis studies on the destruction of Microcystin-LR in aqueous solution by hydroxyl radicals, Env. Sci Technol. 43 (2009) 1487-1492. doi:10.1111/j.1743-6109.2008.01122.x.Endothelial.

[42] M. Sillanpää, Ultrasound Technology in Green Chemistry, SpringerBriefs Green Chem. Sustain. (2011) 1-21. doi:10.1007/978-94-007-2409-9.

[43] N. Serpone, R. Terzian, Ultrasonic Induced Dehalogenation and Oxidation of 2-, 3-, and 4-Chlorophenol in Air-Equilibrated Aqueous Media. Similarities with Irradiated Semiconductor Particulates, J. Phys. Chem. 98 (1994) 2634-2640.

[44] K.E. O'Shea, D.D. Dionysiou, Advanced Oxidation Processes for Water Treatment, J. Phys. Chem. Lett. 3 (2012) 2112-2113. doi:10.1021/jz300929x.

[45] K.S. Suslick, Sonoluminescence and sonochemistry, Encycl. Phys. Sci. Technol. 3rd Ed. 1 (2001) 1-22. doi:10.1109/ULTSYM.1997.663076.

[46] T. Leong, M. Ashokkumar, S. Kentish, The Fundamentals of Power Ultrasound- A Review, Acoust. Aust. 39 (2011) 54-63.

[47] K.S. Suslick, S.J. Doktycz, E.B. Flint, On the origin of sonoluminescence and sonochemistry, Ultrasonics. 28 (1990) 280-290. doi:10.1016/0041624X(90)90033-K.

[48] T.Y. Wu, N. Guo, C.Y. Teh, J.X.W. Hay, Advances in Ultrasound Technology for Environmental Remediation, Adv. Ultrasound Technol. Environ. Remediat. (2013) 5-12. doi:10.1007/978-94-007-5533-8.

[49] T.S. Hot, The Sonochemical Hot Spot, Am. Chem. Soc. 108 (1986) 5641-5642. doi:10.1121/1.2029381.

[50] J.M. Chalovich, E. Eisenberg, NIH Public Access, Biophys. Chem. 257 (2005) 2432-2437. doi:10.1016/j.immuni.2010.12.017.Two-stage.

[51] R. Xiao, Z. Wei, D. Chen, L.K. Weavers, Kinetics and Mechanism of Sonochemical Degradation of Pharmaceuticals in Municipal Wastewater, Environ. Sci. Technol. 48 (2014) 9675-9683.

[52] D.K. Kim, K.E. O'Shea, W.J. Cooper, Mechanistic considerations for the degradation of methyl tert-butyl ether (MTBE) by sonolysis: Effect of argon vs. oxygen saturated solutions, Ultrason. Sonochem. 19 (2012) 959-968. doi:10.1016/j.ultsonch.2011.12.003. 
[53] A. Hudder, W. Song, K.E. O'Shea, P.J. Walsh, Toxicogenomic evaluation of microcystin-LR treated with ultrasonic irradiation, Toxicol. Appl. Pharmacol. 220 (2007) 357-364. doi:10.1016/j.taap.2007.02.004.

[54] W.E. Luttrell, 4-Methylcyclohexane methanol (MCHM), J. Chem. Heal. Saf. 22 (2015) 39-41. doi:10.1016/j.jchas.2014.12.008.

[55] A.E. Sain, A.M. Dietrich, E. Smiley, D.L. Gallagher, Assessing human exposure and odor detection during showering with crude 4-(methylcyclohexyl)methanol (MCHM) contaminated drinking water, Sci. Total Environ. 538 (2015) 298-305. doi:10.1016/j.scitotenv.2015.08.050.

[56] K.S. Casteloes, R.H. Brazeau, A.J. Whelton, Decontaminating chemically contaminated residential premise plumbing systems by flushing, Environ. Sci. Water Res. Technol. 1 (2015) 787-799. doi:10.1039/C5EW00118H.

[57] E.R. Spill, Lessons from the Elk River Spill Inspectors, Environ. Health Perspect. 122 (2014) A215-A219.

[58] A.M. Dietrich, A. Thomas, Y. Zhao, E. Smiley, N. Shanaiah, M. Ahart, K.A. Charbonnet, N.J. Deyonker, W.A. Alexander, D.L. Gallagher, Partitioning, aqueous solubility, and dipole moment data for cis- and trans-(4-methylcyclohexyl)methanol, principal contaminants of the West Virginia chemical spill, Environ. Sci. Technol. Lett. 2 (2015) 123-127. doi:10.1021/acs.estlett.5b00061.

[59] L. Yuan, W. Zhi, Y. Liu, E. Smiley, D. Gallagher, X. Chen, A.M. Dietrich, H. Zhang, Degradation of cis - and trans - ( 4-methylcyclohexyl ) methanol in activated sludge, J. Hazard. Mater. 306 (2016) 247-256.

[60] Yusuf G. Adewuyi, Sonochemistry: Environmental Science and Engineering Applications, Ind. Eng. Chem. Res. (2001) 4681-4715. doi:10.1021/ie0100961.

[61] M.R. Hoffmann, I. Hua, R. Hchemer, Application of ultrasonic irradiation for the degradation of chemical contaminants in water, Ultrason. Sonochem. 3 (1996) S 163-S 172.

[62] I. Hua, R.H. Hoechemer, M.R. Hoffmann, Sonolytic Hydrolysis of p-Nitrophenyl Acetate: The Role of Supercritical Water, J. Phys. Chem. 99 (1995) 2335-2342. doi:10.1021/j100008a015.

[63] W. Shao, W. Chen, Effect of supercritical water shell on cavitation bubble dynamics, Chinese Phys. B. 24 (2015) 54701. doi:10.1088/1674-1056/24/5/054701.

[64] Christopher J. Cramer and Donald G. Truhlar, An SCF Solvation Model for the Hydrophobic Effect and Absolute Free Energies of Aqueous Solvation, Science (80-. ). 256 (1992) 213-217.

[65] K. Makino, M. Mossoba, P. Riesz, Chemical effects of ultrasound on aqueous solutions. Formation of hydroxyl radicals and hydrogen atoms, J. Phys. Chem. (1983) 1369-1377. doi:10.1021/j100231a020. 
[66] W.T. Foreman, D.L. Rose, D.B. Chambers, A.S. Crain, L.K. Murtagh, H. Thakellapalli, K.K. Wang, Determination of (4-methylcyclohexyl)methanol isomers by heated purge-and-trap GC/MS in water samples from the 2014 Elk River, West Virginia, chemical spill, Chemosphere. 131 (2015) 217-224. doi:10.1016/j.chemosphere.2014.11.006.

[67] Y. Jiang, C. Pétrier, T. David Waite, Kinetics and mechanisms of ultrasonic degradation of volatile chlorinated aromatics in aqueous solutions, Ultrason. Sonochem. 9 (2002) 317-323. doi:10.1016/S1350-4177(02)00085-8.

[68] E. Nie, M. Yang, D. Wang, X. Yang, X. Luo, Z. Zheng, Degradation of diclofenac by ultrasonic irradiation: Kinetic studies and degradation pathways, Chemosphere. 113 (2014) 165-170. doi:10.1016/j.chemosphere.2014.05.031.

[69] W. Song, A.A. De La Cruz, K. Rein, K.E. O'Shea, Ultrasonically induced degradation of microcystin-LR and -RR: Identification of products, effect of $\mathrm{pH}$, formation and destruction of peroxides, Environ. Sci. Technol. 40 (2006) 39413946. doi:10.1021/es0521730.

[70] a De Visscher, H. Van Langenhove, Sonochemistry of organic compounds in homogeneous aqueous oxidising systems., Ultrason. Sonochem. 5 (1998) 87-92. doi:10.1016/S1350-4177(98)00018-2.

[71] D. Kobayashi, C. Honma, H. Matsumoto, T. Takahashi, C. Kuroda, K. Otake, A. Shono, Kinetics analysis for development of a rate constant estimation model for ultrasonic degradation reaction of methylene blue, Ultrason. Sonochem. 21 (2014) 1489-1495. doi:10.1016/j.ultsonch.2013.12.022.

[72] P.E. Savage, Organic Chemical Reactions in Supercritical Water., Chem. Rev. 99 (1999) 603-622. doi:10.1021/cr9700989.

[73] C. Pétrier, E. Combet, T. Mason, Oxygen-induced concurrent ultrasonic degradation of volatile and non-volatile aromatic compounds, Ultrason. Sonochem. 14 (2007) 117-121. doi:10.1016/j.ultsonch.2006.04.007.

[74] J. Slcopp, Derivation of the freundlich adsorption isotherm from kinetics, J. Chem. Educ. 86 (2009) 1341-1343. doi:10.1021/ed086p1341.

[75] M.D. LeVan, T. Vermeulen, Binary Langmuir and Freundlich isotherms for ideal adsorbed solutions, J. Phys. Chem. 85 (1981) 3247-3250. doi:10.1021/j150622a009.

[76] I. Quiñones, G. Guiochon, Extension of a Jovanovic-Freundlich isotherm model to multicomponent adsorption on heterogeneous surfaces, J. Chromatogr. A. 796 (1998) 15-40. doi:10.1016/S0021-9673(97)01096-0.

[77] K. Okitsu, K. Iwasaki, Y. Yobiko, H. Bandow, R. Nishimura, Y. Maeda, Sonochemical degradation of azo dyes in aqueous solution: A new heterogeneous kinetics model taking into account the local concentration of $\mathrm{OH}$ radicals and azo dyes, Ultrason. Sonochem. 12 (2005) 255-262. doi:10.1016/j.ultsonch.2004.01.038. 
[78] B. Nanzai, K. Okitsu, N. Takenaka, H. Bandow, Sonochemical Degradation of Alkylbenzene Sulfonates and Kinetics Analysis with a Langmuir Type Mechanism, J. Phys. Chem. C. 113 (2009) 3735-3739.

[79] M. Chiha, S. Merouani, O. Hamdaoui, S. Baup, N. Gondrexon, C. Pétrier, Modeling of ultrasonic degradation of non-volatile organic compounds by Langmuir-type kinetics, Ultrason. Sonochem. $17 \quad$ (2010) 773-782. doi:10.1016/j.ultsonch.2010.03.007.

[80] H. Ferkous, O. Hamdaoui, S. Merouani, Sonochemical degradation of naphthol blue black in water: Effect of operating parameters, Ultrason. Sonochem. 26 (2015) 4047. doi:10.1016/j.ultsonch.2015.03.013.

[81] K.V. Kumar, Langmuir - Hinshelwood kinetics - A theoretical study, Catal. Commun. 9 (2008) 82-84. doi:10.1016/j.catcom.2007.05.019.

[82] C. Zhao, M. Pelaez, D.D. Dionysiou, S.C. Pillai, J.A. Byrne, K.E. O'Shea, UV and visible light activated $\mathrm{TiO} 2$ photocatalysis of 6-hydroxymethyl uracil, a model compound for the potent cyanotoxin cylindrospermopsin, Catal. Today. 224 (2014) 70-76. doi:10.1016/j.cattod.2013.09.042.

[83] B.H.H. K.Y.Foo, Review: Insights into the modeling of adsorption isotherm systems, Chem. Eng. J. 156 (2010) 2-10. doi:10.1016/j.cej.2009.09.013.

[84] A. Brotchie, F. Grieser, M. Ashokkumar, Effect of power and frequency on bubblesize distributions in acoustic cavitation, Phys. Rev. Lett. 102 (2009) 1-4. doi:10.1103/PhysRevLett.102.084302.

[85] C. Barckholtz, T. a. Barckholtz, C.M. Hadad, A Mechanistic Study of the Reactions of $\mathrm{H}, \mathrm{O}$ ( $3 \mathrm{P}$ ), and $\mathrm{OH}$ with Monocyclic Aromatic Hydrocarbons by Density Functional Theory, J. Phys. Chem. A. 105 (2001) 140-152. doi:10.1021/jp001884b.

[86] B.J. Lynch, D.G. Truhlar, How Well Can Hybrid Density Functional Methods Predict Transition State Geometries and Barrier Heights?, J. Phys. Chem. A. 105 (2001) 2936-2941. doi:10.1021/jp004262z.

[87] A.D. Becke, Density-functional thermochemistry. III. The role of exact exchange, J. Chem. Phys. 98 (1993) 5648. doi:10.1063/1.464913.

[88] M.P. Andersson, P. Uvdal, New scale factors for harmonic vibrational frequencies using the B3LYP density functional method with the triple-zeta basis set 6311+G(d,p)., J. Phys. Chem. A. 109 (2005) 2937-41. doi:10.1021/jp045733a.

[89] J. Atkins, Peter and De Paula, Elements of physical chemistry, Oxford University Press, USA, 2013.

[90] A. Ratkiewicz, T.N. Truong, Kinetics of the C-C bond beta scission reactions in alkyl radical reaction class, J. Phys. Chem. A. 116 (2012) 6643-6654. doi:10.1021/jp3018265. 
[91] S.D.Z. Paul E.Stackelber, Edward T.Furlong, Michael T.Meyer, D.B.R. Alden K.Henderson, Persistence of pharmaceutical compounds and other organic wastewater contaminants in a conventional drinking-water-treatment plant, Sci. Total Environ. 329 (2004) 99-113. http://www.neiwpcc.org/ppcpconference/ppcpdocs/PaulStackelberg/STOTEN_Stackelberg_etal.pdf.

[92] Z. Li, P.H. Chang, W.T. Jiang, J.S. Jean, H. Hong, L. Liao, Removal of diphenhydramine from water by swelling clay minerals, J. Colloid Interface Sci. 360 (2011) 227-232. doi:10.1016/j.jcis.2011.04.030.

[93] C.A. Kinney, E.T. Furlong, S.L. Werner, J.D. Cahill, Presence and distribution of wastewater-derived pharmaceuticals in soil irrigated with reclaimed water, Environ. Toxicol. Chem. 25 (2006) 317-326. doi:10.1897/05-187R.1.

[94] E. Topp, M.W. Sumarah, L. Sabourin, The antihistamine diphenhydramine is extremely persistent in agricultural soil, Sci. Total Environ. 439 (2012) 136-140. doi:10.1016/j.scitotenv.2012.09.033.

[95] B. Huerta, S. Rodríguez-Mozaz, D. Barceló, Pharmaceuticals in biota in the aquatic environment: Analytical methods and environmental implications, Anal. Bioanal. Chem. 404 (2012) 2611-2624. doi:10.1007/s00216-012-6144-y.

[96] E.W. Goolsby, C.M. Mason, J.T. Wojcik, A.M. Jordan, M.C. Black, Acute and chronic effects of diphenhydramine and sertraline mixtures in Ceriodaphnia dubia, Environ. Toxicol. Chem. 32 (2013) 2866-2869. doi:10.1002/etc.2378.

[97] F. Yuan, C. Hu, X. Hu, J. Qu, M. Yang, Degradation of selected pharmaceuticals in aqueous solution with UV and UV/H2O2, Water Res. 43 (2009) 1766-1774. doi:10.1016/j.watres.2009.01.008.

[98] L.M. Pastrana-Martínez, J.L. Faria, J.M. Doña-Rodríguez, C. Fernández-Rodríguez, A.M.T. Silva, Degradation of diphenhydramine pharmaceutical in aqueous solutions by using two highly active $\mathrm{TiO} 2$ photocatalysts: Operating parameters and photocatalytic mechanism, Appl. Catal. B Environ. 113-114 (2012) 221-227. doi:10.1016/j.apcatb.2011.11.041.

[99] M. Klavarioti, D. Mantzavinos, D. Kassinos, Removal of residual pharmaceuticals from aqueous systems by advanced oxidation processes, Environ. Int. 35 (2009) 402-417. doi:10.1016/j.envint.2008.07.009.

[100] I. Oller, S. Malato, J.A. Sánchez-Pérez, Combination of Advanced Oxidation Processes and biological treatments for wastewater decontamination-A review, Sci. Total Environ. 409 (2011) 4141-4166. doi:10.1016/j.scitotenv.2010.08.061.

[101] T.J. Mason, A. Tiehm, Ultrasound in Environmental Protection, Elsevier Science, 2001.

[102] K.S. Suslick, Y. Didenko, M.M. Fang, T. Hyeon, J. Kenneth, W.B.M. Iii, M.M. Mdleleni, M. Wong, A. Cavitation, S. Feb, B.K.S. Suslick, Y. Didenko, M.M. Fang, Acoustic cavitation and its chemical consequences, Phil. Trans. R. Soc. Lond. A. 357 (1999) 335-353. 
[103] A.J. Colussi, L.K. Weavers, M.R. Hoffmann, Chemical bubble dynamics and quantitative sonochemistry, J. Phys. Chem. A. 102 (1998) 6927-6934. doi:10.1021/jp980930t.

[104] J. Peller, O. Wiest, P. V Kamat, Sonolysis of 2,4-Dichlorophenoxyacetic Acid in Aqueous Solutions. Evidence for .OH-Radical-Mediated Degradation, J. Phys. Chem. A. 105 (2001) 3176-3181. doi:10.1021/jp003478y.

[105] W. Song, T. Teshiba, K. Rein, K.E. O'Shea, Ultrasonically induced degradation and detoxification of microcystin-LR (Cyanobacterial Toxin), Environ. Sci. Technol. 39 (2005) 6300-6305. doi:10.1021/es048350z.

[106] D.K. Kim, Y. He, J. Jeon, K.E. O'Shea, Irradiation of ultrasound to 5methylbenzotriazole in aqueous phase: Degradation kinetics and mechanisms, Ultrason. Sonochem. 31 (2016) 227-236. doi:10.1016/j.ultsonch.2016.01.006.

[107] J.D. Seymour, H.C. Wallace, R.B. Gupta, Sonochemical reactions at $640 \mathrm{kHz}$ using an efficient reactor. Oxidation of potassium iodide, Ultrason. Sonochem. 4 (1997) 289-293. doi:10.1016/S1350-4177(97)00039-4.

[108] P. Taylor, O. Aguilar, C. Ángeles, C.O. Castillo, C. Martínez, R. Rodríguez, R.S. Ruiz, M.G. Vizcarra, On the ultrasonic degradation of Rhodamine B in water: kinetics and operational conditions effect, Environ. Technol. 35 (2014) 1183-1189. doi:10.1080/09593330.2013.864711.

[109] D. Cui, A.M. Mebel, L.E. Arroyo-Mora, H. Holness, K.G. Furton, K. O'Shea, Kinetic, product, and computational studies of the ultrasonic induced degradation of 4-methylcyclohexanemethanol (MCHM), Water Res. 126 (2017) 164-171. doi:10.1016/j.watres.2017.09.005.

[110] W. Song, W.J. Cooper, B.M. Peake, S.P. Mezyk, M.G. Nickelsen, K.E. O'Shea, Free-radical-induced oxidative and reductive degradation of $\mathrm{N}^{\mathrm{N}} \mathrm{N}^{6}$-diethyl-mtoluamide (DEET): Kinetic studies and degradation pathway, Water Res. 43 (2009) 635-642. doi:10.1016/j.watres.2008.11.018.

[111] G.T. Güyer, N.H. Ince, Degradation of diclofenac in water by homogeneous and heterogeneous sonolysis, Ultrason. Sonochem. 18 (2011) 114-119. doi:10.1016/j.ultsonch.2010.03.008.

[112] Y. Jiang, C. Pétrier, T.D. Waite, Effect of $\mathrm{pH}$ on the ultrasonic degradation of ionic aromatic compounds in aqueous solution, Ultrason. Sonochem. 9 (2002) 163-168. doi:10.1016/S1350-4177(01)00114-6.

[113] C. Sicard-Roselli, E. Brun, M. Gilles, G. Baldacchino, C. Kelsey, H. Mcquaid, C. Polin, N. Wardlow, F. Currell, A New Mechanism for Hydroxyl Radical Production in Irradiated Nanoparticle Solutions, Nanoparticle Solut. 10 (2014) 3338-3346. doi:10.1002/smll.201400110.

[114] G.L. Newton, J.R. Milligan, Fluorescence detection of hydroxyl radicals, 75 (2006) 473-478. doi:10.1016/j.radphyschem.2005.10.011. 
[115] X. Feng, Z. Wang, Y. Chen, T. Tao, F. Wu, Y. Zuo, Effect of Fe(III)/citrate concentrations and ratio on the photoproduction of hydroxyl radicals: Application on the degradation of diphenhydramine, Ind. Eng. Chem. Res. 51 (2012) 7007-7012. doi:10.1021/ie300360p.

[116] G. Louit, S. Foley, J. Cabillic, A. Valleix, J.P. Renault, S. Pin, The reaction of coumarin with the $\mathrm{OH}$ radical revisited : hydroxylation product analysis determined by fluorescence and chromatography, Radiat. Phys. Chem. 72 (2005) 119-124. doi:10.1016/j.radphyschem.2004.09.007.

[117] S.P.M. Menachery, O. Laprévote, T.P. Nguyen, U.K. Aravind, P. Gopinathan, C.T. Aravindakumar, Identification of position isomers by energy-resolved mass spectrometry, J. Mass Spectrom. 50 (2015) 944-950. doi:10.1002/jms.3607.

[118] S.P.M. Menachery, S.R. Nair, P.G. Nair, U.K. Aravind, C.T. Aravindakumar, Transformation Reactions of Radicals from the Oxidation of Diphenhydramine: Pulse Radiolysis and Mass Spectrometric Studies, Electro,Physical Theor. Chem. 5 (2016) 924-933. doi:10.1002/slct.201600103.

[119] T. W. Graham Solomons, Organic Chemistry, 7th Editio, Wiley, 2001.

[120] W.J. Cooper, C.J. Cramer, N.H. Martin, S.P. Mezyk, K.E.O. Shea, Free Radical Mechanisms for the Treatment of Methyl tert -Butyl Ether ( MTBE ) via Advanced Oxidation / Reductive Processes in Aqueous Solutions, (2009) 1302-1345.

[121] S.D. Richardson, S.Y. Kimura, Water Analysis: Emerging Contaminants and $\begin{array}{llllll}\text { Current Issues, Anal. } & \text { Chem. } 81 & \text { (2009) 4645-4677. }\end{array}$ doi:10.1021/acs.analchem.5b04493.

[122] D.W. Kolpin, M.T. Meyer, Pharmaceuticals , Hormones , and Other Organic Wastewater Contaminants in U . S . Streams , 1999 - 2000: A National Reconnaissance, Environ. Sci. Technol. 36 (2002) 1202-1211. doi:10.1021/es011055j.

[123] K. Lee Barnes, Connie and McKenzie, Constance A and Webster, Kathy D and Poinsett-Holmes, Cetirizine: A New, Nonsedating Antihistamine, Ann. Pharmacother. 27 (1993) 464-470.

[124] C. Desager, Jean-Pierre and Dab, I and Horsmans, Yves and Harvengt, A pharmacokinetic evaluation of the second-generation H1-receptor antagonist cetirizine in very young children, Clin. Pharmacol. Ther. 53 (1993) 431--435.

[125] M. Aoshima, K. Fukasawa, K. Kaneko, Absorption, distribution, metabolism and excretion of $[14 \mathrm{C}]$ levocetirizine, the $\mathrm{R}$ enantiomer of cetirizine, in healthy volunteers, Eur. J. Clin. Pharmacol. 57 (2001) 571-582. doi:10.1007/s002280100364.

[126] D.G.J.L. JERKER FICK, HANNA SODERSTROM, RICHARD H. LINDBERG,CHAU PHAN,MATS TYSKLIND, Contamination of Surface, Groud, and Drinking Water from Pharmaceutical production, Environ. Toxicol. Chem. 28 (2009) 2522-2527. 
[127] I. Ferrer, E.M. Thurman, Analysis of 100 pharmaceuticals and their degradates in water samples by liquid chromatography/quadrupole time-of-flight mass spectrometry, J. Chromatogr. A. 1259 (2012) 148-157. doi:10.1016/j.chroma.2012.03.059.

[128] D.G.J.O.L. Arsson, Pharmaceuticals and Personal Care Products in the Environment: contamination of surface, ground, and drinking water from pharmaceutical production, 28 (2009) 2522-2527.

[129] J. Kosonen, L. Kronberg, The occurrence of antihistamines in sewage waters and in recipient rivers, Environ. Sci. Pollut. Res. 16 (2009) 555-564. doi:10.1007/s11356009-0144-2.

[130] H. Sanderson, Presence and risk assessment of pharmaceuticals in surface water and drinking water, Water Sci. Technol. 63 (2011) 2143-2148. doi:10.2166/wst.2011.341.

[131] A. Bahlmann, J.J. Carvalho, M.G. Weller, U. Panne, R.J. Schneider, Immunoassays as high-throughput tools: Monitoring spatial and temporal variations of carbamazepine, caffeine and cetirizine in surface and wastewaters, Chemosphere. 89 (2012) 1278-1286. doi:10.1016/j.chemosphere.2012.05.020.

[132] V. Calisto, C.I.A. Ferreira, J.A.B.P. Oliveira, M. Otero, V.I. Esteves, Adsorptive removal of pharmaceuticals from water by commercial and waste-based carbons, J. Environ. Manage. 152 (2015) 83-90. doi:10.1016/j.jenvman.2015.01.019.

[133] R.A.N.M. Ead, S.E.T.H.B. Arefoot, J.O.H.N.R.H. Elms, J.E.B.M. Organ, R.O.J.K. Ieber, Photodegradation of the Antihistamine Cetirizine in Natural Waters, Environ. Toxicol. Chem. 33 (2014) 2240-2245. doi:10.1002/etc.2691.

[134] R.S. Sutar, V.K. Rathod, Ultrasound assisted enzyme catalyzed degradation of Cetirizine dihydrochloride, Ultrason. Sonochem. 24 (2015) 80-86. doi:10.1016/j.ultsonch.2014.10.016.

[135] M. Hoffmann, Application of ultrasonic irradiation for the degradation of chemical contaminants in water, Ultrason. Sonochem. 3 (1996) S163-S172. doi:10.1016/S1350-4177(96)00022-3.

[136] H.E.R. Houghton, R.G.J. Scarth, Determination of Cetirizine in Human Plasma by Liquid Chromatography-Tandem Mass Spectrometry, Chromatogr. Suppl. 55 (2002) 145-149.

[137] G. Louit, S. Foley, J. Cabillic, H. Coffigny, F. Taran, A. Valleix, J.P. Renault, S. Pin, The reaction of coumarin with the $\mathrm{OH}$ radical revisited: Hydroxylation product analysis determined by fluorescence and chromatography, Radiat. Phys. Chem. 72 (2005) 119-124. doi:10.1016/j.radphyschem.2004.09.007. 
[138] D.M.B. and Y.Z. T.J. Mason, J.P. Lorimer, Dosimetry in sonochemistry: the use of aqueous terephthalate ion as a fluorescence monitor, Ultrason. Sonochem. 1 (1994) S91-S95.

[139] S. Nachiappan, K. Muthukumar, Treatment of pharmaceutical effluent by ultrasound coupled with dual oxidant system, Environ. Technol. 34 (2013) 209-217. doi:10.1080/09593330.2012.689367.

[140] S.E. Page, W. a Arnold, K. McNeill, Terephthalate as a probe for photochemically generated hydroxyl radical., J. Environ. Monit. 12 (2010) 1658-1665. doi:10.1039/c0em00160k.

[141] K. Hirano, T. Kobayashi, Coumarin fluorometry to quantitatively detectable $\mathrm{OH}$ radicals in ultrasound aqueous medium, Ultrason. Sonochem. 30 (2016) 18-27. doi:10.1016/j.ultsonch.2015.11.020.

[142] K.I. Ishibashi, A. Fujishima, T. Watanabe, K. Hashimoto, Detection of active oxidative species in $\mathrm{TiO} 2$ photocatalysis using the fluorescence technique, Electrochem. Commun. 2 (2000) 207-210. doi:10.1016/S1388-2481(00)00006-0.

[143] K.O. Badmus, J.O. Tijani, C.P. Eze, O.O. Fatoba, L.F. Petrik, Quantification of Radicals Generated in a Sonicator, Anal. Bioanal. Chem. Res. 3 (2016) 139-147.

[144] W. Song, K.E. O'Shea, Ultrasonically induced degradation of 2-methylisoborneol and geosmin, Water Res. 41 (2007) 2672-2678. doi:10.1016/j.watres.2007.02.041.

[145] N. Masuda, A. Maruyama, T. Eguchi, T. Hirakawa, Y. Murakami, Influence of Microbubbles on Free Radical Generation by Ultrasound in Aqueous Solution: Dependence of Ultrasound Frequency, J. Phys. Chem. B. 119 (2015) 12887-12893. doi:10.1021/acs.jpcb.5b05707.

[146] X. Fang, G. Mark, C. Von Sonntag, OH radical formation by ultrasound in aqueous solutions: Part I: The chemistry underlying the terephthalate dosimeter, Ultrason. Sonochem. 3 (1996) 57-63. doi:10.1016/1350-4177(95)00032-1.

[147] J. Rooze, E. V. Rebrov, J.C. Schouten, J.T.F. Keurentjes, Dissolved gas and ultrasonic cavitation - A review, Ultrason. Sonochem. 20 (2013) 1-11. doi:10.1016/j.ultsonch.2012.04.013.

[148] S.D. Lubetkin, Why is it much easier to nucleate gas bubbles than theory predicts?, Langmuir. 19 (2003) 2575-2587. doi:10.1021/la0266381.

[149] T. Frömel, T.P. Knepper, Biodegradation of fluorinated alkyl substances, Rev. Environ. Contam. Toxicol. 208 (2010) 161-177. doi:10.1007/978-1-4419-6880-7_3.

[150] W. D’Hollander, P. De Voogt, W. De Coen, L. Bervoets, Perfluorinated substances in human food and other sources of human exposure, 2010. doi:10.1007/978-14419-6880-7_4.

[151] X.C. Hu, D.Q. Andrews, A.B. Lindstrom, T.A. Bruton, L.A. Schaider, P. Grandjean, R. Lohmann, C.C. Carignan, A. Blum, S.A. Balan, C.P. Higgins, E.M. Sunderland, Detection of Poly- and Perfluoroalkyl Substances (PFASs) in U.S. Drinking Water 
Linked to Industrial Sites, Military Fire Training Areas, and Wastewater Treatment Plants, Environ. Sci. Technol. Lett. 3 (2016) 344-350. doi:10.1021/acs.estlett.6b00260.

[152] J.R. Baran, Fluorinated Surfactants and Repellents: Second Edition, Revised and Expanded Surfactant Science Series. Volume 97. By Erik Kissa (Consultant, Wilmington, DE). Marcel Dekker: New York. 2001., J. Am. Chem. Soc. 123 (2001) 8882-8882. doi:10.1021/ja015260a.

[153] USEPA, Drinking Water Health Advisory for perfluorooctane sulfonate (PFOS), (2016) 1-103.

[154] United States Environmental Protection Agency, Drinking Water Health Advisory for Perfluorooctanoic Acid ( PFOA ), (2016) 1-103.

[155] M. Sun, E. Arevalo, M. Strynar, A. Lindstrom, M. Richardson, B. Kearns, A. Pickett, C. Smith, D.R.U. Knappe, Legacy and Emerging Perfluoroalkyl Substances Are Important Drinking Water Contaminants in the Cape Fear River Watershed of North Carolina, Environ. Sci. Technol. Lett. (2016) acs.estlett.6b00398. doi:10.1021/acs.estlett.6b00398.

[156] M.J. Weiss-Errico, I. Ghiviriga, K.E. O'Shea, 19F NMR Characterization of the Encapsulation of Emerging Perfluoroethercarboxylic Acids by Cyclodextrins, J. Phys. Chem. B. 121 (2017) 8359-8366. doi:10.1021/acs.jpcb.7b05901.

[157] Z. Du, S. Deng, Y. Bei, Q. Huang, B. Wang, J. Huang, G. Yu, Adsorption behavior and mechanism of perfluorinated compounds on various adsorbents-A review, $\mathrm{J}$. Hazard. Mater. 274 (2014) 443-454. doi:10.1016/j.jhazmat.2014.04.038.

[158] I. Ross, J. McDonough, J. Miles, P. Storch, P. Thelakkat Kochunarayanan, E. Kalve, J. Hurst, S. S. Dasgupta, J. Burdick, A review of emerging technologies for remediation of PFASs, Remediation. 28 (2018) 101-126. doi:10.1002/rem.21553.

[159] S.P. Mezyk, T.J. Neubauer, W.J. Cooper, J.R. Peller, Free-radical-induced oxidative and reductive degradation of sulfa drugs in water: Absolute kinetics and efficiencies of hydroxyl radical and hydrated electron reactions, J. Phys. Chem. A. 111 (2007) 9019-9024. doi:10.1021/jp073990k.

[160] Y. Wang, P. Zhang, Photocatalytic decomposition of perfluorooctanoic acid (PFOA) by TiO 2 in the presence of oxalic acid, J. Hazard. Mater. 192 (2011) 1869-1875. doi:10.1016/j.jhazmat.2011.07.026.

[161] W. Song, A.A. De La Cruzm, K. Rein, E.K. O'Shea, Ultrasonically Induced Degradation of Microcystin-LR and -RR: Identification of Products, Effect of $\mathrm{pH}$, Formation and Destruction of Peroxides, Env. Sci Technol. 40 (n.d.) 3941-3946. doi:10.1111/j.1743-6109.2008.01122.x.Endothelial.

[162] J.I.E. Cheng, C.D. Vecitis, H. Park, B.T. Mader, Sonochemical Degradation of Perfluorooctane Sulfonate ( PFOS ) and Perfluorooctanoate ( PFOA ) in Landfill Groundwater : Environmental Matrix Effects, 42 (2008) 8057-8063. 
[163] S.H. Ma, M.H. Wu, L. Tang, R. Sun, C. Zang, J.J. Xiang, X.X. Yang, X. Li, G. Xu, EB degradation of perfluorooctanoic acid and perfluorooctane sulfonate in aqueous solution, Nucl. Sci. Tech. 28 (2017). doi:10.1007/s41365-017-0278-8.

[164] H. Park, C.D. Vecitis, J. Cheng, N.F. Dalleska, B.T. Mader, M.R. Hoffmann, Reductive degradation of perfluoroalkyl compounds with aquated electrons generated from iodide photolysis at $254 \mathrm{~nm}$, Photochem. Photobiol. Sci. 10 (2011) 1945-1953. doi:10.1039/c1pp05270e.

[165] K. Whitham, S. Lyons, R. Miller, D. Nett, P. Treas, A. Zante, T. Beta, R.W. Fessenden, M.D. Thomas, Y. Wang, Linear Accelerator for Radiation Chemistry Research at Notre Dame, 1996 IEEE. (n.d.) 131-133.

[166] S.P. Mezyk, D.B. Ewing, J.J. Kiddle, K.P. Madden, Kinetics and mechanisms of the reactions of hydroxyl radicals and hydrated electrons with nitrosamines and nitramines in water, J. Phys. Chem. A. 110 (2006) 4732-4737. doi:10.1021/jp056017r.

[167] M.I. Gomis, Z. Wang, M. Scheringer, I.T. Cousins, A modeling assessment of the physicochemical properties and environmental fate of emerging and novel per- and polyfluoroalkyl substances, Sci. Total Environ. 505 (2015) 981-991. doi:10.1016/j.scitotenv.2014.10.062.

[168] E.L. Evans, T.C., Gavrilovich, E., Mihai, R.C. and Isbasescu, I., Abatement of Fluoroether Caroboxylic Acids or Salts Employed in Fluoroopolymer Resin Manufactor, 2015. doi:10.1037/t24245-000. 
VITA

DANNI CUI

Born, Shenyang, Liaoning, China

\section{EDUCATION BACKGROUND}

Florida International University (2013-present)

PhD Candidate; Advisor- Professor Kevin E. O’Shea;

Liaoning University, China (2007- 2011)

B.S. in Applied Chemistry (Product Quality Inspection)

\section{PUBLICATIONS \& PRESENTATIONS}

Danni Cui, Alexander M. Mebel, Luis E. Arroyo-Mora, Howard Holness, Kenneth G. Furton, Kevin O'Shea, Kinetic, product, and computational studies of the ultrasonic induced degradation of 4-methylcyclohexanemethanol (MCHM). Water Research, 126, 164-171.

D. Cui, A.M. Mebel, L.E. Arroyo-Mora, C. Zhao, A. De Caprio, K. O'Shea, Fundamental study of the ultrasonic induced degradation of the popular antihistamine, diphenhydramine (DPH), Water Res. 144 (2018) 265-273. doi:10.1016/j.watres.2018.07.032.

$\underline{\text { ACS256 }}{ }^{\text {th }}$ National Meeting (Boston,MA, Aug.2018)

Ultrasonic degradation of an emerging perfluoro ether, "GenX"

Authors: Danni Cui, Alexander Mebel, Kevin O’Shea

$\underline{\text { ACS } 255^{\text {th }} \text { National Meeting (New Orleans, LA, Mar.2018) }}$

Fundamental studies of ultrasound induced degradation of a popular antihistamine, Cetirizine

Authors: Danni Cui, Anamary Tarifa, Anthony De Caprio, Kevin O’Shea

The $23^{\text {rd }}$ International Conference on Advanced Oxidation Technologies for Treatment of Water, Air and Soil (Clearwater Beach, FL, Nov.2017)

1. Kinetic, Product, and Computational Studies of the Ultrasonic Induced Degradation of 4-Methylcyclohexanemethanol (MCHM) 
Authors: Danni Cui, Alexander M. Mebel, Luis E. Arroyo-Mora, Howard Holness, Kenneth G. Furton, Kevin O’Shea

2. Detailed study of the ultrasound induced degradation of the popular antihistamine, diphenhydramine

Authors: Danni Cui, Alexander M. Mebel, Luis E. Arroyo-Mora, Cen Zhao, Anthony De Caprio, Kevin O'Shea

$\underline{\text { ACS } 253^{\text {rd }} \text { National Meeting (San Francisco, Apr.2017) }}$

Kinetic, product, and computational studies of the ultrasonically induced degradation of 4methylcyclohexanemethanol (MCHM)

Authors: Danni Cui, Alexander M. Mebel, Luis E. Arroyo-Mora, Howard Holness, Kenneth G. Furton, Kevin O'Shea

$\underline{\text { ACS } 251^{\text {st }} \text { National Meeting (San Diego, Mar. 2016) }}$

Detailed product and kinetic studies of the ultrasonically induced degradation of the popular antihistamine, diphenhydramine

Authors: Danni Cui, Kevin O’Shea, Cen Zhao, Luis Arroyo 